Illinois State University

ISU ReD: Research and eData

Theses and Dissertations

$3-9-2021$

\title{
Accounting for Trauma and Mindset in Elementary School \\ Classrooms: A Study of Check-in/Check-Out as Trauma Intervention
}

Jenifer Lynne McGowan

Illinois State University, mcgowanj@district87.org

Follow this and additional works at: https://ir.library.illinoisstate.edu/etd

\section{Recommended Citation}

McGowan, Jenifer Lynne, "Accounting for Trauma and Mindset in Elementary School Classrooms: A Study of Check-in/Check-Out as Trauma Intervention" (2021). Theses and Dissertations. 1497.

https://ir.library.illinoisstate.edu/etd/1497

This Dissertation is brought to you for free and open access by ISU ReD: Research and eData. It has been accepted for inclusion in Theses and Dissertations by an authorized administrator of ISU ReD: Research and eData. For more information, please contact ISUReD@ilstu.edu. 


\title{
ACCOUNTING FOR TRAUMA AND MINDSET IN ELEMENTARY SCHOOL
}

\section{CLASSROOMS: A STUDY OF CHECK-IN/CHECK-OUT AS TRAUMA}

\author{
INTERVENTION
}

\section{JENIFER LYNNE MCGOWAN}

\section{3 pages}

This mixed methods study examines trauma in elementary school children and the need for a relationship to maximize their learning opportunities. Check-in/Check-out is a Tier Two intervention that was used to prioritize behavioral goals, maximize the relationship based on a less-than five minute meeting between the student and the Check-in/Check-out mentor at different points in the day, and provide daily feedback to parents. Within the meeting, the teacher and the student reflect on how the day is going, how the student has met their goal or what needed to be done to meet their goal, all based on positive comments. Check-in/Check-out gave students an opportunity to have a caring adult, who was not their teacher, interact with them and assist with communication to families. The result is often improved behavior in the class. With students understanding their goals and how to achieve them, which often leads to improved academics, there are advances within the classroom with behavior and academics. The purpose of the study is to gain a better understanding of trauma, given its prevalence within our schools, understand how an intervention such as Check-in/Check-out can assist both students and teachers, and understand how teachers view professional development, as supported through a book study. Centering on Check-in/Check-Out, a Tier II intervention, in conjunction with professional development through a book study, Help for Billy, teachers and staff will 
understand why making relationships the center of learning are important with students who have experienced trauma. Relationships and understanding are at the forefront in supporting all. Professional development regarding trauma and trauma-informed strategies were something that teachers continue to explore through weekly professional development and the Multi-Tiered Systems of Support (MTSS) structure provided. Implementing a book study, Help for Billy, offered staff an opportunity to understand trauma through a different mindset, reflect on individual students, and make plans for future classes all while participating in collaborative presentations during a pandemic. The findings of this study has implications on how CheckIn/Check-Out is utilized within buildings, how relationships are enhanced, and perceived perceptions of professional development.

KEYWORDS: trauma, mindset, CICO, professional development, relationships, elementary 
ACCOUNTING FOR TRAUMA AND MINDSET IN ELEMENTARY SCHOOL

CLASSROOMS: A STUDY OF CHECK-IN/CHECK-OUT AS TRAUMA INTERVENTION

JENIFER LYNNE MCGOWAN

A Dissertation Submitted in Partial Fulfillment of the Requirements for the Degree of DOCTOR OF EDUCATION

Department of Educational Administration and Foundations

ILLINOIS STATE UNIVERSITY 
(C) 2021 Jenifer Lynne McGowan 
ACCOUNTING FOR TRAUMA AND MINDSET IN ELEMENTARY SCHOOL

CLASSROOMS: A STUDY OF CHECK-IN/CHECK-OUT AS TRAUMA INTERVENTION

JENIFER LYNNE MCGOWAN

COMMITTEE MEMBERS:

Dianne Renn, Chair

Lydia Kyei-Blankson

Guy Banicki

Diane Wolf 


\section{ACKNOWLEDGMENTS}

In writing this dissertation, and frankly everything I have done, there are people in my life who support me, encourage my talents, and inspire me to learn and grow daily. In my journey, there were many who have helped me complete this doctorate. I want to begin by thanking the staff and students at Shandy Elementary. I am lucky enough to work with many caring, hardworking, dedicated, and determined adults who give their all each day. I love that we learn and grow together, with our students. Thank you to Erin Knuth and Meg Johnson for being the best friends anyone could ask for and the unconditional support and encouragement you give each time we talk. Also, thank you to Cheryl Fogler, Christy West, and Tammy Galliday for your constant coaching, listening, and confidence in what I was doing.

To Dr. Dianne Renn, my committee chair for this study, I owe much to you. Without your guidance, persistence, restructuring due to COVID-19, and your help, I am unsure of where I would be. You have provided so much in the forms of resources and guidance. I have been lucky to be in several classes with you, Dr. Renn throughout my doctoral program and have greatly benefited from your expertise.

I would also like to thank the members of my committee: Dr. Guy Banicki, Dr. Lydia Kyei-Blankson, and Dr. Diane Wolf. Without their guidance, honest feedback, and support, I would not have completed my dissertation. I have had the privilege of being in multiple classes

taught by both Dr. Kyei-Blankson and Dr. Banicki. Thank you for all your support and guidance throughout this process. I greatly appreciate it! Dr. Wolf, thank you for believing in this study and in me. District 87 has always been my professional home. I have greatly benefited from working with phenomenal administration that believes in me, pushes me, and continues to inspire me to do what is best for students. 
To my friends, my parents, and my siblings: you put up with me being distracted and missing many events. I am forever grateful for your patience and understanding. I hope to have time now to reconnect with each of you. Nikki Maurer, I cannot thank you enough for your support.

To my parents, Paul and Lynne Kendall, you never stopped believing in me or supporting my endeavors and I am forever grateful to you both. Education was always a priority in our family, and you continue to model this. You have raised three servant leaders, supported and listened when we felt like we could not continue, and assisted in so many ways.

Finally, to my husband, Matt, and our children, Zach and Kate, your love and understanding helped me through all of this. Without you believing in me, I never would have made it. Matt continued to get our children where they needed to be, make dinner, help with homework, and take care of whatever was happening at home. It is because of you and our kids that I was able to complete this! Thank you for your support, encouragement, and love throughout this time. It is time to celebrate; you earned this degree right along with me. 


\section{CONTENTS}

Page

ACKNOWLEDGMENTS

TABLES Niii

FIGURES - ix

CHAPTER I: INTRODUCTION TO THE STUDY 1

Trauma Impact $\quad 2$

Trauma in School and Society 3

$\begin{array}{ll}\text { CICO Intervention Cycle } & 6\end{array}$

Multi-Tiered Systems of Support (MTSS)

The CICO Intervention Cycle $\quad 8$

Study of the School Context $\quad 9$

Problem of Practice 11

Purpose of the Study 13

Book Study: Help for Billy 15

Research Questions 16

$\begin{array}{ll}\text { Theoretical Framework } & 16\end{array}$

Overview of Research Design 19

$\begin{array}{ll}\text { Summary } & 20\end{array}$

CHAPTER II: LITERATURE REVIEW 23

$\begin{array}{ll}\text { Theoretical Framework } & 26\end{array}$

CICO and Theoretical Framework $\quad 31$

$\begin{array}{ll}\mathrm{CICO} & 34\end{array}$ 
Relationships Matter

Supports for Social/Emotional Learning 36

Why CICO? 39

Social Importance $\quad 39$

Limitations of CICO 40

Teachers and Parents: Support and Involvement 40

Teacher Response

Healthy Relationships $\quad 42$

Professional Development $\quad 43$

$\begin{array}{ll}\text { Equity } & 44\end{array}$

Critical Race Theory $\quad 45$

$\begin{array}{ll}\text { Ethical Consideration } & 46\end{array}$

Restorative Practices $\quad 47$

Relationship of Study to Theory and Research 49

$\begin{array}{ll}\text { Summary } & 51\end{array}$

CHAPTER III: RESEARCH DESIGN AND METHODS 52

$\begin{array}{ll}\text { Introduction } & 52\end{array}$

$\begin{array}{ll}\text { Purpose } & 52\end{array}$

Study of the School Context

Role of Researcher $\quad 54$

$\begin{array}{ll}\mathrm{CICO} & 55\end{array}$

$\begin{array}{ll}\text { COVID-19 } & 57\end{array}$

Research Questions $\quad 58$ 
CPED

Dissertation in Practice

Problem of Practice

Cycle of Inquiry

Laboratory of Practice

Research Paradigm and Design

Students and Staff

Data Collection Procedures

Fidelity

Maintenance

Ethical Consideration

Data Analysis Procedures

Book Study Data

CICO Data Analysis

Summary

Introduction

Participant Profiles

Student A

Student B

Student C

Student D

Student E 
$\begin{array}{lr}\text { Student F } & 83\end{array}$

$\begin{array}{ll}\text { Student G } & 84\end{array}$

$\begin{array}{ll}\text { Student H } & 85\end{array}$

$\begin{array}{ll}\text { Student I } & 86\end{array}$

$\begin{array}{ll}\text { Student J } & 87\end{array}$

$\begin{array}{lr}\text { Student K } & 88\end{array}$

$\begin{array}{lr}\text { Student L } & 89\end{array}$

$\begin{array}{ll}\text { Research Question } 1 & 90\end{array}$

$\begin{array}{ll}\text { Attendance Data } & 94\end{array}$

Research Question $2 \quad 96$

Themes from Open Ended Questions 99

$\begin{array}{ll}\text { Continue } & 100\end{array}$

$\begin{array}{ll}\text { Change } & 100\end{array}$

$\begin{array}{ll}\text { Supports Needed } & 101\end{array}$

$\begin{array}{ll}\text { Additional Themes } & 102\end{array}$

$\begin{array}{ll}\text { Research Question } 3 & 103\end{array}$

$\begin{array}{lr}\text { Conclusion } & 109\end{array}$

CHAPTER V: ANALYSIS, DISCUSSION, AND RECOMMENDATIONS 112

$\begin{array}{ll}\text { Introduction } & 112\end{array}$

Teacher Perceptions: The Rank Ordering Exercise 114

Answers to Research Questions 117

$\begin{array}{lr}\text { Limitations } & 120\end{array}$

$\begin{array}{ll}\text { Recommendations } & 121\end{array}$ 
$\begin{array}{ll}\text { Implications for Teachers } & 124\end{array}$

Recommendations for Future Research $\quad 125$

$\begin{array}{ll}\text { Conclusion } & 125\end{array}$

$\begin{array}{ll}\text { REFERENCES } & 127\end{array}$

APPENDIX A: FIDELITY CHECKLIST FOR CICO 140

APPENDIX B: BREAKOUT SESSION FORMS 141 


\section{TABLES}

Table

Page

1. Correlation Data 94

2. Rank Ordering Exercise Comments 97

3. Average Rank Ordering of Supports/Interventions 104 


\section{FIGURES}

Figure $\quad$ Page

1. Check-In Check-Out Intervention Cycle 6

2. Sample CICO Card 76

3. Student A Data $\quad 79$

4. Student B Data $\quad 80$

5. Student C Data $\quad 81$

6. Student D Data 82

7. Student E Data $\quad 83$

8. Student F Data $\quad 84$

9. Student G Data $\quad 85$

10. Student H Data 86

11. Student I Data $\quad 87$

12. Student J Data $\quad 88$

13. Student K Data $\quad 89$

14. Student L Data $\quad 90$ 


\section{CHAPTER I: INTRODUCTION TO THE STUDY}

Imagine, if you would, being a boy in second grade with a speech impairment. You already talk funny, and you know it. On top of it, you have been diagnosed with the following: Attention Deficit Disorder, Oppositional Defiant Disorder, depression, and anxiety. Plus, the word bipolar has been iterated. Even though doctors really do not diagnose until children are at least in their teens, there is a long family history of relatives diagnosed with bipolar disease. You witnessed physical abuse when your mom beat up her boyfriend in front of you and was then arrested. Mom has been in and out of jail more times than you can count. What you can count on is that you are going to be with either grandma or grandpa who struggle to get along with each other. The Screening Assessment and Support Services program has evaluated you twice within the last two weeks, with the recommendation of admittance, however, grandma refused. The psychiatrist you are waiting to see cannot squeeze you in until June. When you get frustrated in school, you begin shredding paper, pushing over furniture, yelling, and leaving your classroom without permission. You begin pushing chairs down the hallway forcefully, leaving marks the custodian cannot get out. Tiles in the classroom are broken from the force of your aggressions. Destroying classrooms by throwing manipulatives, pushing over desks and chairs, and flinging books and resources on the floor has become a likely event. Classmates leave hurriedly to get out of your path at least three to four times within a given week. You already have a police report record due to the incident when you spit on every adult helping you through your meltdown in the heart of flu season. Tirelessly, many adults come to your rescue and try to switch the channel in your brain so you can remember "good" things like how talented you are at crafts, your love of babies and puppies, and playing games. Remember that time you beat me at tic tac toe during your sensory break? Your teacher has been to the problem-solving team, the 
crisis team intervenes multiple times within a week, and multiple plans have been put into place. Yet, you refuse to even walk into your classroom on most days.

\section{Trauma Impact}

On a daily basis, sometimes multiple times within a given day, I observe students who become exceedingly frustrated with routine tasks, daily work, obstacles, and unsuccessful attempts at grade level academic work. These students have a variety of responses when they are successful or unsuccessful and they handle these tasks in a variety of ways. Behavior is a form of communication and often interrupts teachers while they are working with other students, especially if it is a negative response due to frustration. Teachers are forced to make many choices throughout the day, especially with behavior. The ultimate goal is to assist and support the student in order to help them learn and grow, but also to support the teachers to build the kinds of relationships with students that prevent behavior outbreaks and provide tools for handling them when they do. Sometimes this is uncomfortable, and students are not sure how to move forward, then their behavior is escalated due to the teacher's response. Given these constant issues, teachers need continued support and professional development to engage without escalating the behavior of the student. Check-In/Check-Out (CICO) is a promising intervention that gives teachers the relational tools to prevent escalation and to form the kinds of bonds with their kids that prevent acting out behavior over time. According to Horner et al. (2005), three components are crucial to Tier 2 interventions being effective: system planning, interventions that are available to staff, and use of data to drive decisions.

Within classrooms in every school, students have life experiences that affect their daily lives. For some, it could be not eating breakfast, not having a pencil, or not getting homework completed. For others, it could be witnessing domestic violence or enduring physical and/or 
emotional abuse. For some children, school is the only place in their lives where they know they are safe and can form trusted and long-term relationships. Therefore, it is a cruel realization that many students who are affected by trauma also have trouble being engaged at school. Data from the National Child Traumatic Stress Network notes that close to 40 percent of students have been exposed to some type of traumatic event in their lives. They may attend school with the best of intentions, hoping to form friendships, feel connected to their teachers, peers, and others, and succeed at the tasks they are given throughout the day. However, they can find themselves unfocused and struggling to make sense of it all, unable to learn and confused about why they do not relate or form positive relationships with others.

It is imperative for teachers to understand trauma and how to prevent re-traumatizing students by not escalating situations in which students are frustrated. Often times, school is the place where students feel as though they are safe (Waters \& Brunzell, 2018). This requires a shift in mindset away from their previous views on student discipline to an updated perspective that students act out due to previous traumatic incidents which have reshaped their brains. This is the key to having a positive relationship and open communication skills. CICO can help.

\section{Trauma in School and Society}

Creating and sustaining trauma-informed child-serving systems requires a mindset centered on positive relationships, committed organizations, and skilled teachers and staff. Traumatic stress is associated with increased use of health and mental health services, as well as elevated involvement with other child-serving systems, such as the child welfare and juvenile justice systems (Chapman, Ford, Albert, \& Hawke, 2001). Schools too are on the line to address the needs of trauma-impacted students. Reviews of studies of children's access to mental health services note that schools are often the first opportunities for entry (Cole et al., 2005). For 
example, children are more likely to access mental health services through primary care and schools than through specialty mental health clinics. Seventy-five percent of children under age 12 see a pediatrician at least once per year, whereas $4 \%$ see a mental health professional (Costello, \& Angold, 2006). Schools, doctors, and health systems approach trauma differently, due to various levels of awareness, knowledge, and skill about trauma, as well as diverse perceptions of the utility of gathering information about trauma. Also, a longitudinal study of children in the community found that services were most often provided by the education system (Farmer, Burns, Phillips, Angold, \& Costello, 2003). Schools also differ in their perceived responsibilities for meeting children's needs. However, the goal for all systems is to improve outcomes for children. Addressing the impact of trauma on children and families therefore is a crucial—although often overlooked—priority for all systems.

Along with classroom interventions is the question of whether teachers feel they have the required skill set to handle trauma and all that it brings into the classroom. Reinke, Stormont, Herman, Puri, and Goel (2011) reviewed teachers' perceptions of the issues regarding mental health support in schools. Approximately $28 \%$ of teachers feel as though they have enough knowledge to assist with the mental needs of their students and approximately one third of teachers note they have the required skills. Results of the Reinke et al. (2011) study notes a need for recognizing and understanding mental health issues in children, adopting strategies for working with children, and externalizing behavioral issues. Hence, a plan is needed to support all involved through a relational lens.

My theory of action supports the need for understanding escalation and de-escalation in situations that arise with our students where relationships are not as strong as they might be. MTSS, Multi-Tiered Systems of Support, provides a way to identify any student who has any 
academic or behavioral needs. Tier 1 focuses on the entire school. Tier 2 is a more individualized student intervention. Check In/Check out (CICO) as one relationship-oriented intervention is one way to assist students who have high numbers of behavioral marks, referrals, and Office Discipline Referrals (ODRs). CICO is a Tier 2 intervention which encompasses students who have behavioral issues that are not responding to Tier 1 practices and systems, do not require more individualized interventions, and are noted across multiple settings or contexts (Crone, Hawken, \& Horner, 2010). CICO has the opportunity to be a de-escalation strategy due to: 1) identifying clear behavioral goals and targets; 2) keeping teachers hyper-focused on these goals; 3) forming relationships outside of the classroom to check-in; and 4) making an alternative place or relationship available when a student is escalated. Knowing that all teachers are not mental health professionals, trauma-informed learning or relationship approaches can be integrated into classrooms to assist teachers and students (Waters \& Brunzell, 2018). CICO consists of student daily check-ins in with an adult (mentor) at the start of the day to review their pre-determined goal sheet, have a conversation with a caring adult and be encouraged to meet their daily goals (See Figure 1). All teachers throughout this student's day then provide helpful, positive feedback on the point sheet multiple times throughout the day. The student then checks out at the end of the day with a caring adult (mentor) who reviews the day with them and adds up the points earned. Then the student takes the sheet home to be signed by their caring adult, and returns it the following morning to their mentor at check in. CICO is an important intervention due to the relationship aspect in addressing trauma in schools. 
Figure 1: Check-In Check-Out Intervention Cycle

Problem Solving Team Meeting on Individual Student

Recommendation for CICO

1-Morning Check-in w/CICO Mentor (Reminder of goals and how to achieve)

2-Teacher feedback on form for each class/hour

3-Afternoon Check-out w/CICO Mentor (Review results of day)

4-Parent Signature

CICO Mentor Summarizes data for continued decision making Bi-Weekly CICO Meeting to Review Data on Individual Students

Either Revise/Individualize CICO

Or Exit CICO if continued success

\section{CICO Intervention Cycle}

Professional development for teachers and staff is a necessary component of the whole puzzle, especially with understanding trauma and the resources necessary to support. CICO is just one strategy among many that, when coupled with the Multi-tiered Systems of Support framework and associated practices, can serve as a powerful intervention, relying as it does on a key component of education, human relationships. CICO raises the possibility of helping teachers prevent classroom triggering incidents from escalating, resulting in the need for more involved approaches that are responsive interventions. By utilizing CICO, the goal is to have students receive the relational supports needed within the school setting and consequently have fewer office referrals and behavioral marks throughout their time at school. CICO furthermore 
allows for daily home-school communication using a monitored form to allow caring adults to see how their student performed in a variety of settings.

\section{Multi-Tiered Systems of Support (MTSS)}

Multi-Tiered Systems of Support or MTSS is a framework that assists educators with academic and behavioral interventions for students with a variety of needs and are often used for the prevention of academic and behavioral issues within schools (Crone, Hawken, \& Horner, 2010). MTSS is an important framework that encumbers a system of supports, focuses on relationships and educator collaboration, is research-based, and is widely used. Relationships are a critical component within MTSS. CICO, a Tier 2 intervention, is an additional instructional resource or support, beyond the instruction all students have in place that is aligned to a student's individual needs (Adelman \& Taylor, 2008). MTSS supports the systematic approach of identifying an individual student in regard to their academic, behavioral, or social emotional areas of need (Campbell \& Anderson, 2008).

MTSS provides a proactive approach in the identification of students with academic or behavioral needs. MTSS begins with a universal screening of all students at the beginning of the school year. One set of responses regarding trauma, CICO, can inform instruction comes from MTSS with Problem-Solving Meetings involving teams of staff members (Blodgett, Turner, \& Harrington, 2010). A multi-tier approach, within the MTSS framework, is utilized to differentiate instruction for all students. MTSS tiers help schools organize the three levels of support based on intensity so that students receive necessary instruction, support, and interventions based on their individual needs. Tier 2 interventions include targeted strategies, impacting approximately 15$20 \%$ of students, noting that Tier One interventions have not been effective. The remaining 
students require tertiary (Tier 3) support which includes individualized interventions due to severe behaviors or academic deficits (Crone, Hawken, \& Horner, 2010).

Schools using MTSS look for successful educational and behavioral outcomes for all students, regardless of challenges. This may involve significant interventions for a small part of the student population, with the goal of moving these students into reduced interventions as they continue to make progress and grow. Tier 1 interventions are universal, meaning approximately $80 \%$ of students typically respond to them. Also, this is where the bulk of work for the school should take place with the overall idea of improving instruction as a means to prevent the need for deeper and more challenging interventions for the future.

According to Horner, Sugai, Todd, and Lewis-Palmer (2005), there are three elements that have been noted as being critical to the effectiveness of Tier 2 interventions: 1) a team-based system of planning; 2) intervention practices that are available and implemented by staff; 3) and utilizing data to make program or system changes. This supports the current MTSS framework that is in place to assist teachers and staff, students, and families. Much of the trauma-informed instruction, especially with being relational, can be utilized within Tier II interventions. Ultimately, there is a need for all three tiers, however, much of what needs to be done with relationships can be connected within Tier II, which much of this dissertation will focus on, recognizing that relationships are primary and improving them is crucial in Tiers I and III.

\section{The CICO Intervention Cycle}

As a result of the different tiers in MTSS, Trauma-informed students often leave the general education setting for different amounts of time almost every day to receive the support of tiered interventions like CICO. While MTSS supports trauma-informed students, the pulling students out of classrooms for separate interventions widens an already existing academic gap 
and does not allow for educational services to continue in the classroom environment.

Nonetheless, interventions like CICO are nestled into a student's day with very little time out of the classroom. Research indicates that CICO is an effective Tier 2 intervention for students who are seeking adult attention rather than peer attention or task avoidance (Campbell \& Anderson, 2008; Fairbanks, Sugai, Guardino, \& Lathrop, 2007). Often, interventions require the student to be pulled out of class, keeping them away from core instruction, however, CICO requires a small amount of time outside of the regular classroom. By having another caring adult in the life of the student, it allows for further connection and support given that the students' behavior problems were not responsive to Tier 1 practices and systems (Crone, Hawken, and Horner, 2010).

The Check- In Check -Out (CICO) Intervention cycle, as shown in figure 1, is a systematic way to support students in need of additional supports when the Universal Tier 1 Supports are no longer meeting their needs. CICO is a Tier 2 targeted Intervention that is included in a menu of interventions that school sites create for students who are at risk for academic and/or behavior challenges.

\section{Study of the School Context}

Shandy Elementary School is a Kindergarten through fifth grade building located in Bloomington, Illinois. There are approximately 364 students currently enrolled. Currently, $8 \%$ of our school population is considered homeless and the mobility rate stands at $14 \%$. Currently, the student body is comprised of mainly minoritized students with only $29.4 \%$ being white. Additionally, over $80 \%$ of students come from low-income households. Due to these demographics, my theory of action supports the need for understanding de-escalation techniques, including building solid relationships with our students, especially those who have trauma in their lives. The need for relationship-based interventions, such as CICO, paralleled with 
professional development for staff regarding trauma, brain, and relationships is a necessity as students who are impacted by trauma, even minor events, continue to enroll in our schools. With COVID 19, trauma could be even more prevalent as students have been away from school since mid-March and have not been in a classroom setting with structure for quite some time. Trauma, as noted in earlier chapters, can be present in many different forms.

Being the principal of Shandy Elementary, I see how time is an important factor considering how much actual time behavior takes out of daily schedules, routines, academics, and structures. Thus, having a positive relationship matter from the start, especially those supported with CICO. CICO can include multiple layers of relationships and staff to utilize within a school setting. CICO becomes a tool that is used school-wide, not just a singular trick a teacher has in their tool basket. Teaching practices must be reviewed and considered, especially de-escalation techniques in order to build capacity to handle childhood trauma in schools. There are older practices, such as administering punitive consequences, yelling at a student, and sending a student out of the classroom for the remainder of the day, which are embedded in the culture of the school and can elicit more trauma due to the non-relational nature of the techniques. There are instances every day in which our students need more than we are giving them. For example, when a student runs around the classroom and throws an item in frustration, the goal is to seek a calm state rather than pushing the student out of the classroom and shutting the door. The main objective is to increase positive relationships and academic achievement, focusing on these win-wins and preventing trauma-induced behaviors from nullifying our efforts to support all the students. 


\section{Problem of Practice}

Trauma is a prevalent issue in schools today with approximately 50\% of all children having experienced one form or another (Measurement Initiative, 2013). With students carrying their own personal trauma histories into the classroom, instruction with trauma in mind, along with professional development, needs to utilize key strategies, including CICO to make both behavioral and academic gains with students. Trauma is a harmful and costly public health issue that affects many in a variety of ways. Trauma occurs as a result of numerous different experiences: violence, abuse, neglect, loss, natural disaster, war, and other serious situations in which children have little or no power (Child and Adolescent Health Measurement Initiative, 2013). Trauma sees no boundaries with regard to age, gender, socioeconomic status, race, ethnicity, location, or sexual orientation (Child and Adolescent Health Measurement Initiative, 2013). At Shandy Elementary, we have several staff members who know and understand how to de-escalate situations with more of a relational approach versus a traditional approach of consequences, especially punitive. The need to address trauma is often viewed as an important component of any educational experience, especially when students are struggling either academically, behaviorally, or both. With services that are in place, such as Multi-Tiered Systems of Support (MTSS), daily practices within the school often prompt teams to find the root of the issue at hand, often leading to trauma or traumatic incidents that have now shaped these students lives. Hence, trauma is very often noted in Problem-Solving Meetings, especially as we continue to learn more. Prevention, awareness, and early identification are essential in maximizing efforts to make schools effective with whom they serve. It is important to accept a key idea that schools today continue to deal with societal issues that are challenging to the 
extreme, hence there is a need to obtain the best and most efficient tools for staff to support students, teachers, and the community as a whole.

It is extremely important that teachers have the knowledge, confidence, and ability to assist with students who have been negatively impacted by traumatic events. Previous research findings noted that teachers feel unprepared to address the students' traumatic events (Alisic, 2012) hence the need for professional development. Teachers have a variety of standards to teach, however, there are not many curricula currently which explicitly focus on social and emotional learning, despite a growing interest in the topic. Teachers have many roles they play in the lives of their students and each are impactful on the students' days and their responses. Students who display negative behavior due to traumatic events have opportunities within the school setting for intervention with mental health concerns (Weist et al., 2003). Social workers, counselors, and psychologists are often the first considered to assist with mental health issues, however, more responsibility is being placed on teachers to implement classroom interventions, providing approximately $41 \%$ of mental health interventions (Franklin, Kim, Ryan, Kelly, \& Montgomery, 2012). School responses and being trauma-informed motivates staff to review their current protocols through a trauma-informed lens based on the impact of the entire learning community.

I have been involved with staff and parent conflicts in which they have struggled to understand each other's sides of the situation. There is a divide and a need for understanding, hence the book study to help staff understand trauma and use tools like CICO to build the kinds of relationships with students that prevent or lessen trauma-informed behaviors. When students are enraged or acting out, it takes a toll on the staff members who continuously work and deal with those outbursts. Most often, the outbursts are a response by the student to not getting what 
they feel they want at the time, hence the reaction. Keeping students on track while another student completely loses their self-control is a tough balancing act. When this happens day after day and includes screaming, hitting, kicking, throwing items at teachers or other students, it can take a heavy toll on everyone. Teachers and staff continue to struggle with these responses daily and thus experience their own form of trauma. Ultimately, relationships do assist with these students and are a positive approach to dealing with their issue or trauma.

Given the current situation of the number of students who had experienced trauma within Shandy, more professional development was needed as expressed by staff. A book study, Help for Billy, provided an opportunity for staff to better understand how trauma shaped the brain and how to support students and families given traumatic experiences. CICO was an opportunity for students to receive support, and the book study was an opportunity for staff to receive additional support and gain understanding through a different lens other than a presenter giving information about trauma and how to support students.

Unfortunately, there is not one-hundred percent buy-in among the Shandy staff, and teachers resort back to old practices that seem to be ineffective and in fact, exacerbate the trauma at hand. In essence, I want to describe CICO as one de-escalation and relationship-based practice that enhances relational work with the potential to, make a positive impact on our students, particularly those with a history of trauma.

\section{Purpose of the Study}

The purpose of this study is to examine how the use of CICO by teachers coupled with the book study helped improve practice and student behavior at Shandy Elementary School. Quite often, CICO is a Tier Two intervention that is often recommended when issues arise in the classroom. The goal of the research is to consider Check In/Check Out (CICO) as an 
intervention for students impacted by trauma and explore the effectiveness of book study as professional development in support of implementing CICO and plan for teachers and staff to effectively meet the needs of all with whom they work. The problem is large, impacting students, families, and staff. The need to connect is real along with an overall sense of belonging. Checkin/Check-out (CICO), an effective classroom intervention that provides a sense of connection to the student with the check-in process and goal conferencing that occurs on a regular basis. In utilizing $\mathrm{CICO}$, the goal is to form positive relationships to benefit the student in understanding what needs to be done to meet their daily goal and support both academic and behavioral needs.

Having a safe and stable school culture is key to the healing process for children of trauma (Brunzell, Waters, \& Stokes, 2015). Along with larger scale interventions within the school, such as Multi-tiered Systems of Support (MTSS), CICO is one tool to support traumaaffected students within a framework of supports. First and foremost, schools must be safe places where supportive relationships can thrive regardless of trauma or experiences had outside of the school setting. In order to support the whole child, a system of support is needed for a variety of levels.

As the leader of Shandy or of any school, I want to better understand what teachers need in order to support any and all students, and in the case of this study, to understand if and how CICO affected teachers' ability to build relationships that prevented escalation and ultimately, office referrals. It is important to remember the reasons why many went into education: to make a positive difference in the lives of others. Teachers or staff members in a building with low income and high mobility, or frankly any school building, need to make a positive impact. As a leader, I wanted to tackle this issue because our students did not ask to experience negative events that essentially shaped their being; however, we are there to foster their continued 
academic and social/emotional learning in order to increase academic excellence. Ultimately, we work with the whole child, which is complex.

Due to COVID 19 and the use of retrospective data, CICO was researched as one form of de-escalation with students for which data were available from the time prior to the March shutdown of district schools. Initially, the interest was in de-escalation techniques used along with the collaborative professional development on strategies related to de-escalation, including CICO, which is an easy intervention to utilize when paired with a relational approach and other approaches to building teacher-student relationships. CICO was studied as a means to de-escalate students and build better relationships and communication with families. With pressures from every direction, teachers have expressed their need to teach the students. Yet, for real learning to occur, behavior management must be solid, practices have to be implemented with integrity, communication between home and school must be occurring, and students have to feel safe within their environment. De-escalation practices reflect respect for the whole child in preserving their dignity, which CICO supports and utilizes through goal setting, progress, and check-ins emphasizing communication. In addition, a book study, Help for Billy, was completed to add perspective of supports in place and to further understanding of trauma and how to deal with the effects within the school and classroom.

\section{Book Study: Help for Billy}

To address the growing need to engage students who have been traumatized and are easily triggered in a classroom, the staff at Shandy Elementary participated in a book study, Help for Billy, to better understand trauma, the brain, and the daily affects it has on students in order to better support them within classrooms. Together, teams of teachers read and reviewed chapters and later participated in sharing these chapters with the staff in their own way. The intended goal 
was to better understand trauma, utilize a growth mindset when learning about students who have experienced trauma, and provide support within grade levels to make better academic and behavioral gains. Culture and diversity are both considered important among the Shandy staff;

however, there is still much progress needed in this area. Keller, 2008, wrote that "The pairing of books and teachers might seem natural, but it has taken the convergence of at least two trends to move book study far up the list of the ways teachers spend their professional development time." Shandy teachers did exactly this which was to work on their own practice, utilize their colleagues, and integrate their own experiences within their day-to-day lives.

\section{Research Questions}

The research questions for this study are as follows:

1. To what extent did the implementation of one trauma-influenced practice, Check In/Check Out (CICO), help change behaviors within the classroom setting at Shandy Elementary School?

2. In what ways did the addition of a trauma-influenced book study on CICO inform teachers and staff to alter their professional practice to achieve better student behavioral outcomes at Shandy Elementary School?

3. What other forms of trauma-influenced practice supports do teachers at Shandy Elementary School say they need in order to better their practice in student behaviors and responses?

\section{Theoretical Framework}

Three theories were explored within this study: Bronfenbrenner's relationship theory (1993), Brown's (2012) connections with empathy and shame, and Ko et al.'s (2008) traumainformed care. Taken together, these three theories can provide ways to consider how student 
function in relational ways that affect how well they can manage their trauma in a school setting. Bronfenbrenner's theory, the first of the three regarding relationships, directly impacts our staff and how they handle students on a daily or minute by minute basis. A comprehensive systems approach which allows the development of responses at a variety of levels relates to Bronfenbrenner's (1993) Ecosystemic model which accounted for the complexity of trauma and its impact. This model allows for an understanding of the effects, the fall-out, prevention, and the research behind the trauma. Bronfenbrenner's (1993) theory also developed a pathway into additional services, such as counseling or psychology, and for a framework on unique skills or perspectives. This study explored Bronfenbrenner's theory due to its relationship aspect and how important it is for teachers to have positive connections with their students. This theory also supports that behavior is complex and is a form of communication and it suggests that the value of relationships in an ecosystem is likely to impact how well one does in any setting they are in.

Dr. Brené Brown, a researcher at the University of Houston, has spent much time studying courage, vulnerability, shame, and empathy, in addition to focusing on how vulnerability impacts various aspects of people's lives. Brown has completed many TED Talks and written numerous books, with many being geared for teachers and leaders. Brown (2012) notes the importance of teachers in their role of waking up each day and being brave with students by being vulnerable which opens the connection with students. Having vulnerability within the classroom allows for students to be out of their comfort zone and learn in a more intentional way (Brown, 2012). One can connect Brown's relational approach to her work as a teacher in a classroom who has the opportunity to be vulnerable, empathetic, courageous, and have trust. With these characteristics, learning is optimized and the risk is in the student's court (Brown, 2012). Also, shame is an aspect that Brown references quite frequently within school 
settings. Brown (2012) notes that approximately $85 \%$ of the people she has interviewed remembered an incident in which they were shamed at school and approximately $90 \%$ of those interviewed remembered a person, administrator, teacher, or coach who made a positive difference in their lives. Brown (2012) reiterates the importance that parents, teachers, clergy and peers, in that order, have on a student's life. Shame is the threat of being unlovable, which through fifth grade, is very impactful (Brown, 2012). Within an educational setting, one can conceptualize that Brown noted the importance of children's complex social networks and the effects they have on relationships. Well-nourished relationships can enhance the capacity for youth to develop better interpersonal connections, thus increasing academic achievement (Brown, 2012). It is a necessity for teachers and staff to have supportive relationships with their students so that when students feel that they have a meaningful personal connection, they may utilize these supports for further development and encouragement within the classroom (Brown, 2012). CICO supports positive relationships with the collaboration on set goals, reflecting on progress or growth, and meeting times throughout the day to continue conversations and/or support.

Traumatic experiences can result in significant disruptions in child or adolescent development, with profound long-term consequences (Pynoos, Steinberg, Schreiber, \& Brymer, 2006). Ko et al. (2008) notes that children can recover quickly after adversity, however, repeated exposure to traumatic events may change a child's development and increase the risk of low academic performance and difficulties in peer and family relationships. With schools being the beginning points for mental health services, many children are processed through frameworks, such as MTSS and trauma is recognized through conversations with both the student and the 
family. This then impacts on a student's ability to manage all demands they have throughout their school day and quite often, interventions are put into place, such as CICO.

With CICO, one of the biggest benefits is to have a mentor to check in and out with multiple times each day, hence supporting a relationship. One could conclude with Ko's theory that when teachers and staff are given support and training from people who specialize in trauma, students who have experienced trauma can be supported and hopefully diminish the long-term effects that are initially possible. Some recommendations could be: the promotion of traumafocused practices and frequent professional development, identify changes in practice in which schools and policy makers support the whole student, and provide an emphasis on relationshipbuilding between a variety of services: mental health practitioners, front line workers, administrators, and other staff. (Ko \& Sprague, 2007).

\section{Overview of Research Design}

This study involves action research with students and staff being the primary focus. The study centers on recognizing trauma and how it plays into education, as well as utilizing relationships to make a positive impact with CICO for both academic and behavioral gains. Due to COVID 19, the study was altered from strictly understanding de-escalation techniques within professional development to CICO, to make use of data collected prior to the COVID shutdown in Spring 2020. After the shutdown, the children were in remote learning and not in a classroom, hence no data could be collected after early March. The book study was a professional learning opportunity, and thus was completed with teachers between August, 2019 and May, 2020. Professional development, coupled with support for teachers and staff with the addition of a

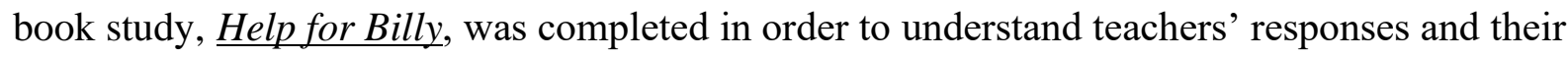
impact, especially with students who have experienced trauma. CICO data was analyzed, along 
with a survey for staff to better understand how they rank supports that are currently available within the school.

\section{Summary}

There are a significant number of children who come to school each day who have either witnessed or experienced a traumatic event. It is noted that trauma significantly affects a child in numerous ways, including social, emotional, and cognitive functions. In order to make academic gains, plus maximize the use of teaching time to the greatest extent possible, appropriate methods to address trauma and the best teaching methodologies need to be established. By enlisting the theories of Bronfenbrenner (1993), Brown (2012), and Ko et al. (2008), this study acknowledges that positive relationships are vital, shame should not occur, and systems need to be in place to assist. I am currently focused on CICO to support the whole child, teachers, and staff.

Also, this research benefits Shandy Elementary and District 87 by improving the quality of CICO and assisting teachers with understanding trauma and the effects. The goal is to enhance support, teaching methodologies, and techniques that enrich the lives of our students, staff, and families, essentially providing a wrap-around for all. Understanding trauma and its effects is essential but so is how educators teach. Teachers are the key in understanding that changes in practice and methods are essential. Professional development regarding trauma, in this case, based on a book study, will continue to provide enrichment for all. Working with their grade level team supports collaboration, support in response to ideas, and a way to better utilize strategies across teams rather than working independently. Learning from each other, during a pandemic, supports trauma and the need for relationships and others in order to best serve others. Along with trauma lies the issue of equity, since significant behaviors can be a direct or indirect 
result of trauma and can impede the student from participating in the classroom. These students then struggle even more with relationships, especially with the classroom teacher due to frustration and the stress of teaching the rest of the children within that class. Within public education, school officials do not choose who comes to their buildings, but they are expected to support every person who enters. I have many teachers at Shandy who know how to de-escalate students; however, those who do not know, or do not care, are negatively impacting the whole building and many other educators' time. Punitive approaches have not been found to be effective and can harm the school culture. MTSS within Tier 2 includes CICO and was studied with teachers and staff as a powerful, relational tool without the negative effects of other interventions that pull students out of class for longer periods of time and interrupt the learning.

Chapter Two focuses on understanding the research behind trauma, CICO as a main intervention with relationships at the center. Chapter Two includes on CICO as an opportunity for students along with a book study for staff to support teachers and staff members in working effectively with all students, but especially with those who exhibit extreme behaviors stemming from a traumatic past. Additionally, the Chapter Two literature review covers trauma, Check-in and Check-out, an overview of key theories synthesized to create a conceptual framework for considering $\mathrm{CICO}$, and the impact on schools today to further explain what can be done in relation to trauma in schools. Chapter Three will concentrate on the methodology for this research. Check-in and Check-out will be further explained along with professional development while an intervention for students is taking place. Chapter Four focuses on the data and results of the CICO process for individual students. Chapter Four also includes information from the teacher and staff rank ordering exercise which includes supports and interventions 
which were rank ordered in their view of effectiveness. Chapter Five is an analysis of the research findings and the implications for practice. 


\section{CHAPTER II: LITERATURE REVIEW}

Teachers and staff members spend many hours with their students each week and form relationships. Hence, these adults can be a supportive member in their students' lives. Teachers, from their daily exposure with students, are usually the first to identify behavioral concerns and indications of trauma (Alisic et al., 2012). With the intent to understand trauma and the impact it has on schools, particularly elementary schools, an extensive review of literature on the topic of trauma, relationships, and supports has taken place. Teachers and staff members play an important role supporting their students who are recovering from trauma or utilizing strategies when they are upset. However, research shows that elementary school teachers and staff members are uncertain about their role and how they can help their students in a positive manner following traumatic experiences (Alisic et al., 2012). Below, trauma is defined along with the necessity of professional development to assist with supporting these students. The introduction also notes that this qualitative study examines the role of administration in supporting staff members to create a trauma-informed learning environment by providing professional development in the form of a book study.

Today, most schools utilize a three-tiered systems approach for behavior. Tier 1 represents any universal approach or core program in which all students participate. Within Tier 1, behaviors are traditionally managed by creating school-wide expectations that promote appropriate behavior observed from approximately $80 \%$ of the students in the school setting. Tier 2 encompasses targeted interventions for students, approximately $15 \%$ of the student population, for whom Tier 1 does not produce expected results. Tier 2 interventions usually include social support, peer mentors, and CICO. Filter et al. (2007) explained that CICO has many benefits, such as identifying targets for individual students, increasing the amount of 
prompts used for goals, daily and weekly feedback from caring adults, structured daily schedules, and providing positive feedback to families given behavioral goals that are identified. According to Horner et al. (2005), there are three components that have been noted to be crucial for effective Tier 2 interventions: team-based systems of planning, interventions that have been taught to the staff, and utilizing data to make decisions regarding the student(s) involved. Lastly, Tier 3 involves approximately 5\% of students who exhibit more severe behavioral issues (Crone et al., 2010). Tier 3 consists of supports such as Behavioral Intervention Plans, collaboration with the student's pediatrician and/or mental health provider, a counselor referral, among others. Within classrooms everywhere, students arrive with baggage from past events that have affected them. Initially, it could be not eating breakfast, not having a pencil, or not getting homework completed. Others could have experienced or witnessed domestic violence. SAMHSA (2014a) noted that trauma "results from an event, series of events, or set of circumstances that is experienced by an individual as physically or emotionally harmful or threatening and that has lasting adverse effects on the individual's functioning and physical, social, emotional, or spiritual well-being" (p.7). Another study revealed that almost half of all children experience at least one of these difficulties as a childhood incident (Child and Adolescent Health Measurement Initiative, 2013), and each educational employee's path to address trauma in the classroom is therefore crucial. Having said that, professional development is necessary for educators to increase their knowledge and confidence to be able to assist students who have experienced critical events (Child and Adolescent Health Measurement Initiative, 2013).

In order to address concerns related to trauma and professional development, there is a need to also identify the effects it has on staff and students. Students who display negative 
behavior due to traumatic events have opportunities within the school setting for intervention with mental health concerns (Weist et al., 2003). Many believe that within our schools, social workers, counselors, and psychologists are often the first staff members to assist with mental health issues; however, current research proves that teachers are actually the first in line implementing classroom interventions as they provide approximately $41 \%$ of mental health interventions (Franklin et al., 2012).

Complex trauma is then analyzed, and data is provided examining the effects. School responsiveness and being trauma-informed motivates staff to review their current protocols through a new lens based on the impact on the entire learning community. Professional development from one school is considered and reviewed, along with their mission statement. The review also highlights staff members who were resistant which added a challenge to the staff. The statement of the problem was reviewed noting that trauma is a large factor in schools today. Students in schools today require educators to use different strategies and skills than they did previously to meet the needs of the ever-changing population of students who are served (Cole et al., 2005).

Trauma-informed care incorporates a model of service that takes knowledge and understanding of trauma and its effects in order to provide services to students in supportive environments to avoid re-traumatization for children who have experienced trauma (Harris \& Fallot, Eds., 2001). In connection with education, trauma-informed schools utilize information regarding trauma to design programs and classrooms that will provide a sense of safety, routine, support, and success for all students. 


\section{Theoretical Framework}

Within the social-ecological model of trauma, it is important to understand the theories regarding attachment, trauma, and development. In the book, Calmer Classrooms: A Guide to Working with Traumatized Children (2007), Downey notes:

School systems must understand these three theories that are foundational in addressing the issues of complex trauma in school aged children...Attachment Theory helps us understand human relationship development from pre-birth onwards throughout the life span. Trauma theory helps us to understand the neurobiological and psychological impact of abuse and neglect on the human individual. Child development theory helps us understand normal development and consequently development under adversity. (p.2 These theories promote the need for a relational approach to students, such as CICO. The desire for positive adult attention is a real one. With CICO, the focus begins with understanding the student needs, initiated by other caring adults.

In order to assist with mental health within the classroom, these are important theories to consider. Schools are set up to use intervention systems with teachers at the front to collaborate with others in order to find success for all students. With trauma at the forefront of school days, it is important to understand that it varies by each setting and circumstance as does each classroom and student. According to SAMHSA (2013), TIC includes the following key concepts: ...realizes the widespread impact of trauma and understands potential paths for recovery; recognizes the signs and symptoms of trauma in clients, families, staff, and others involved with the system; and responds by fully integrating knowledge about trauma into policies, procedures, and practices, and seeks to actively resist re-traumatization. (p. 9) 
As one part of applying these concepts from TIC, I am currently reviewing escalating and de-escalating practices that are in place at Shandy Elementary. De-escalation practices, such as use of sensory items, push-in support, restorative practices, calming centers, and paths for releasing energy, aim to keep students in the classrooms as long as they are safe. As highlighted by Rossin and Hull (2013), schools today should focus on acknowledging the issues surrounding trauma and work towards enhancing school cultures, protocols within the classroom, procedures, and routines to create a more "trauma informed or trauma sensitive" learning environment. In addition to classroom interventions, it is essential to consider whether teachers have the required skill set to handle trauma. Being trauma-sensitive involves creating a positive environment which notes the importance of safety, trust, choice, and collaboration (Evers, 2012). Therefore, having continuous professional development regarding trauma and responses is critical in assisting staff moving forward.

As identified earlier, the three theories explored in this study are Bronfenbrenner's relationship theory, Brown's connections with empathy and shame, and Ko's trauma informed care. Bronfenbrenner's (1993) theory aligns with the way staff build relationships with students to best handle issues during the school day. The comprehensive nature of Brofenbrenner's ecosystemic model calls for the development of various responses to address the intricacies of trauma and its impact on children. This model allows for an understanding of the effects, the fallout, and the research behind the trauma. The concepts presented by Bronfenbrenner (1993) also provide avenues for other services, such as counseling or psychology, to effectively assist students. According to Tishelman, Haney, O’Brien, and Blaustein (2010), having a traumasensitive approach acknowledge that trauma could significantly contribute to a student's behavior at school and the individual's response to trauma can vary. This justifies a proactive 
approach with relationships at the center for students, their learning, and behavioral interventions. Integrating available research on approaches to handling students with trauma, brain development, and the causes and solutions to emotional outbursts could lead to beneficial learning theories and academic opportunities for students (Zielger, 2011).

Bronfenbrenner's (1993) Ecological Systems Theory (EST) posed the theoretical framework that is captured within the review. EST noted that one's development is influenced by microsystems, mesosystems, exosystems, macrosystems, and chronosystems. Within ecological theory, Bronfenbrenner (1993) emphasized the importance of interpersonal interactions within the environmental systems. McLaren and Hawe (2005) highlighted the need for an individual to fit into their environment. However, traumatic experiences negatively impact the student and their ability to form positive relationships, regulate their response, and perform academically (Cook et al., 2005). Thus, relationships should also be a consideration, especially when they are included within interventions, such as Check-In Check-Out (CICO).

Brené Brown has spent much time studying courage, vulnerability, shame, and empathy. Within all of these aspects, relationships are one of the biggest to consider. One of Brown's most impactful works focused on being vulnerable and the impacts that can have on various aspects of one's life. Brown (2012) discussed vulnerability and the impact it has within innovation, creativity, and change. From a leader's standpoint, change is a positive aspect of learning and growing. This is an expectation given to students; however, it tends to be more difficult with some staff populations. Within an educational setting, Brown (2012) noted the importance of children's complex social networks and the impact on relationships. She contended that fostering relationships between students and staff can bolster interpersonal skills, and in turn improve academic achievement. It is essential that teachers and staff build supportive relationships with 
their students in order to support trauma, academics, and social interactions as a whole. Brown's work promotes the notion that when students develop personal connections with their teachers the tendency for behavior to interrupt class decreases and academic growth increases.

Brown (2012) further claimed that caring connections between staff and students are requirements for productive relationships. It takes courage and the ability to put oneself out there to build authentic connections with students, staff, parents, and other members of the school community. Once these relationships take shape, connections are formed, trust is earned, and growth can occur. Exercising empathy to understand what students, co-workers, and parents bring to the table each day, plus engaging in vulnerable conversations, are necessary steps for improvement to occur. Brown (2012) focused on the following aspects of fear: vulnerability, getting hurt, disconnection, criticism and failure, conflict, and not measuring up. There seems to be an emphasis of moving away from a belief in humanity, especially change and moving into blame or shame. This also may mean that a teacher needs to reframe their story and recognize that students are doing the best they can to build opportunities moving forward. Brown (2012) noted that the key to building a relationship is maintaining the belief in human connection. She stated that addressing this will take a lot of courage. From a behavioral aspect, staff must understand that the behavior of the student is impacted from many angles and is not necessarily aimed at the teacher.

As mentioned in the introduction, Brown (2012) focused on the characteristics of connection, integrity, and love in her work. Connections between teachers and students are extremely important with having a positive relationship, which supports Bronfenbrenner's (1993) interpersonal theory. By valuing courage over comfort, integrity leads to the implementation of new strategies for behavior management since punitive consequences have 
been typically ineffective. Loving relationships must be nurtured and grown with time and through joint experiences, and teachers have a unique opportunity to do this daily in order to gain trust. Bronfenbrenner and Brown's theories both address trauma and how to approach it from a relational standpoint. The notion of a positive relationship connects positive circumstances, and perhaps enhanced academic performance for all involved. True belonging is a practice that requires anyone to be vulnerable, uncomfortable, and know how to be present without sacrificing who you really are (Brown, 2012). The tough part for some comes in learning how to listen better, have difficult conversations, be more curious than defensive, while looking for that togetherness factor (Brown, 2012). Bronfenbrenner's (1993) ecological systems theory and Brown's (2012) model of interpersonal connections, along with equity and ethics, align with the scope and scale of this problem of practice. These issues can be overwhelming; thus, determination and commitment are needed in order to make a positive difference to alter the methods educators utilize with children.

Furthermore, Ko (2008) found that some children may recover quickly after adversity; however, child or adolescent development can be stunted by traumatic experiences, which can also result in profound long-term effects (Pynoos et al., 2006). This notion that repeated exposure to traumatic events may change a child's development in turn validates the theories of increased risk of low academic performance and difficulties in peer and family relationships for these children. Combined with a trauma-informed staff, Brown's (2012) power of vulnerability, and Bronfenbrenner's (1993) ecological theory supporting change, there is a greater chance of success for students when these concepts are appropriately implemented into school systems. This gives students a fighting chance within their classrooms to get the best opportunities possible and to change their trajectory despite any history of trauma. 
In connection with the social-ecological model, Ko et al. (2008) suggested the inclusion of trauma-informed care within the schools and an integration of services. Schools house a variety of students, regardless of academic talent, who all have different responses to trauma and traumatic events. Schools are an important component of each child's microsystems and mesosystems, noting the interactions and influences of teachers, and adding the importance of the classroom as the beginning for trauma-informed implementation of services (Bronfenbrenner, 1993). These theories connect in their support of students in a relational and positive sense since trauma care, classroom interventions, and relationships support the whole child. Conversely, Brown (2012) highlighted the importance of understanding that shame is one of the worst things an educator can do, especially repeatedly. When tied together, all three theories agree that positive relationships are key, classroom teachers are instrumental in handling trauma, and systems are developed based on responses. Therefore, it is vital to classroom success for teachers and staff to be well-educated in how they respond to trauma among their students.

\section{CICO and Theoretical Framework}

CICO along with three theories, Bronfenbrenner's relationship theory (1993), Brown's (2012) connections with empathy and shame, and Ko et al.'s (2008) trauma-informed care are connected with trauma and supports within schools. Mission statements support students in their educational experiences, however, students need to feel safe in order to learn (SAMHSA, 2014b). Within feeling safe to learn, teachers focus on positive relationships in order to promote a good school environment. Within the social-ecological model of trauma, the Substance Abuse and Mental Health Services Administration (SAMHSA) noted that trauma-informed care (TIC) is promoted across settings. SAMHSA (2014b) explained that TIC is an "intervention and organizational approach which focuses on how trauma may affect an individual's life and his or 
her response to behavioral health services from prevention through treatment" (p. 11). It is important to understand that TIC varies by each setting and circumstance.

For the purposes of this study, I reviewed escalating and de-escalating practices that are currently in place at Shandy which result in marks, Office Discipline Referrals, and other disciplinary procedures which later results in the use of CICO as a Tier II intervention. With analyzing data, next steps are then taken to assist students with their needs through the MTSS process. Quite often CICO is considered as an initial possibility. One of the first questions that comes up is in regards of who the student has a positive relationship with already that we can continue to utilize to benefit the student. De-escalation practices can focus on the relationships already established and understandings that are built with our students. We also utilize sensory items on a regular basis, push-in support for students who are struggling, restorative practices, calm-down centers or stations, a sensory path for releasing energy, CICO, and other unique opportunities within the classroom. The main goal is to be able to keep students in the classrooms as long as they are safe.

Bronfenbrenner's Ecological Systems Theory (EST) posed the theoretical framework that is captured within the review. EST noted that one's development is influenced by five environmental systems: (a) microsystems, which include activities, social roles, and relationships by the individual (e.g., daughter, friend, student); (b) mesosystems, which are interactions within settings in which the individual is involved (e.g., home/school, home/community, school/community); (c) exosystems, which involve interactions within situations that do not specifically influence the individual (e.g., members of school board, neighbors, community members); (4) macrosystems, which contain the cultural environment of settings that indirectly or directly affect the individual (e.g. laws); and (5) chronosystems, which are major events and 
transitions that potentially occur within one's life (e.g. divorce, natural disasters, wars)

(Bronfenbrenner, 1993). Within ecological theory, there is an emphasis backed by

Bronfenbrenner highlighting the importance of interpersonal interactions within the

environmental systems. This theory is complex, as is behavior and the communication it gives

school officials. Within schools, MTSS serves as a framework to support both students and staff.

Thus, having teachers and staff complete a book study together and collaboratively learn from each other supports the EST in a socio-ecological setting supporting both students and teachers. Social-ecology emphasizes the "fit" between an individual and their environment (McLaren \& Hawe, 2005). With this fit, it is important to consider the complexity of classrooms, other students, and teachers within. Considering trauma and the effects, the social-ecological model focuses on a "systemic framework for looking at individuals, families, and communities affected by trauma in general: it highlights the bidirectional influence that multiple contexts can have on the provision of behavioral health services to people who have experienced trauma" (SAMHSA, 2014b, p. 8). Trauma impacts individuals differently, however, it is important to understand that traumatic experiences and their importance tie closely into behavioral health problems, front-line professionals and community-based programs can begin to build a trauma-informed environment across the continuum of care. Bronfenbrenner's EST both affects how staff members approach students, as well as supports the complexity of trauma and how it impacts decision-making (Figure 3). EST emphasizes positive relationships with students and recognized that behavior is complex and a form of communication.

One can conclude from Brown's work that relationships are complicated, take time to form, and need support. It takes courage to build authentic connections with students, staff, parents, and other members of the school community. Brown (2012) accentuated the critical role 
of exercising empathy, understanding what students, co-workers, parents, etc. bring to the table each day and having vulnerable conversations. This also may mean that teachers need to reframe their story and recognize that students are doing their best. Furthermore, connection, integrity, and love are three characteristics at the center of Brown's work. Connection, according to Brown (2012), is centered on being seen, heard, and valued without any judgment (Brown, 2012). This can be difficult to do within a classroom setting or can be misunderstood from students given the tone or words that are used. This idea that connection is essential to having a positive relationship aligns with Bronfenbrenner's theory. Integrity focuses on courage over comfort, which I consider when trying new behavioral strategies over using the same punitive consequences that have not worked in the past. Love is something that is nurtured and grown, just as relationships are. Bronfenbrenner's and Brown's theories both form a notion of how trauma can be addressed from a relational standpoint. Thus, I chose to incorporate Brown's theory into this study since relationships must remain at the center of positive educational situations.

Bronfenbrenner's Ecological Systems Theory and Brown's Model of Interpersonal Connections, along with equity and ethics in education, connect the scope and scale of this problem of practice. These issues are intense; thus, determination and commitment are needed to positively influence the methods used to teach students on a daily basis. Relationships are a large part of working with students. Considering trauma and the effects, the social-ecological model focuses on the framework regarding trauma and the supports that are in place to assist.

\section{CICO}

Problem-Solving Team meetings were held monthly, or at times more frequently as needed or requested by the teacher. Specific students who experienced traumatic episodes were 
the focal point of meetings, interventions, and communication. A data collection tool, CICO daily card, was utilized in order to track daily progress on the desired goals and targets (See Figure 2). Data was entered by the CICO mentor on a weekly or daily basis based on the CICO chart the student carried with them. These were collected weekly to analyze and assess progress. The CICO coach reaffirmed the data and de-identified it to coordinate the study. The researcher met with these teachers and staff members on a weekly basis. These tools were gathered each week in order to better understand staff concerns, highlight successes, and make additional decisions in the best interest of the students. Progress was noted and shared. The goal is for a student to obtain $80 \%$ or more of their daily points based off of goals the team has decided on. The student carries the CICO card to each class. Each teacher will circle the number that corresponds to how the student either achieved or did not achieve the goal.

\section{Relationships Matter}

Research notes that there are documented cases of students who are currently or who have been exposed to some form of abuse (Kracke \& Hahn, 2008). These experiences, traumatic or not, can negatively impact a student's ability to form relationships, regulate emotional responses or outbursts, respond in a more appropriate manner, and perform academically (Cook et al., 2005). The research contends that students need adults in education who advocate for them, provide safe opportunities for learning, and offer opportunities that honor students as individuals (Cole et al., 2005). Schools now find themselves responsible for prevention and intervention for students who have experienced trauma (Cole et al., 2005). Students today require teachers and staff members to use strategies and interventions, along with a variety of skills, to meet the needs of a different and diverse population (Cole et al., 2005). 
Social and Emotional Learning (SEL) standards exist within schools, usually along with a curriculum to assist with the teaching of those standards. In my own experience, every teacher will at some point encounter students who are experiencing trauma in their personal lives, such as hunger, homelessness, or even domestic violence; therefore, these students will have additional needs beyond education while at school. Cole, O’Brien, Gadd, Ristuccia, Luray Wallace, \& Gregory, 2005, noted that when students have stress or fear, their brains trigger a chemical that causes them to have a fight, flight, or freeze response. Hence, having a curriculum to practice social situations could assist with these students and practice.

Within school systems throughout the country, there are tiers or levels for academic and behavior teams. Trauma has proved to be no different regarding a need for support. Many school districts utilize Social Emotional Learning standards, along with programs such as Second Step to ensure the standards are taught. While these programs have been put into place in schools across the country, there is little understanding of their effects. In an effort to meet the many needs students have in schools, all staff should have guidance regarding tools, supports, and professional development to address the needs of students who have experienced complex trauma (Tishelman et al., 2010). Research shows that students who are past their primary years and are already into adolescence experience possess "the most rapidly developing brain areas responsible for three core features of executive functioning necessary for autonomous functioning and engagement in relationships" (Cook et al., 2003, p. 11). The need for early intervention is real along with the supports necessary to meet the needs of all involved.

\section{Supports for Social/Emotional Learning}

During the early 2000s, discipline policies began shifting from reactive to a more proactive approach when managing student behavior (Feinstein, 2003; Horner et al., 2005). A 
proactive approach, such as Positive Behavioral Interventions and Supports (PBIS), assists with behavior among all students (Tier 1) by embedding modeling and direct teaching of appropriate behaviors, to decrease the inappropriate behaviors which leads to a more effective learning environment (Carr et al., 2002). Within the PBIS framework, all students receive universal Tier 1 supports, which include explicitly teaching behavioral expectations to students, acknowledging positive student behaviors on a consistent basis, and using data to drive educational decisions (Crone et al., 2010; Horner, Sugai, \& Anderson, 2010; Sugai \& Simonsen, 2012). Research shows that approximately $80 \%$ of students respond to Tier 1 supports and meet school expectations (Crone et al., 2010). Tier 2 supports include targeted interventions, such as CICO, to assist approximately $15 \%$ of students who are not responding to the universal expectations. The goal of Tier 2 is to match an individual's behavior with a research-based intervention (Horner et al., 2010). Tier 3 supports are for students who require a more intensive approach and are likely to include a Functional Behavioral Assessment (Campbell \& Anderson, 2011; Todd, Campbell, Meyer, \& Horner, 2008).

$\mathrm{CICO}$ is a Tier 2 intervention designed to decrease problem behaviors and increase academic engagement for students who have mild but inappropriate behaviors that are nonthreatening (Campbell \& Anderson, 2008; Campbell \& Anderson, 2011; Crone et al, 2010; Fairbanks, Sugai, Guardino, \& Lathrop, 2007). CICO incorporates preventative measures to decrease problem behaviors by increasing both positive adult interactions and frequent positive reinforcement for appropriate behaviors within multiple intervals throughout the day (Campbell \& Anderson, 2011; Simonsen, Myers, \& Briere, 2011). CICO gives students an opportunity to make meaningful connections with adults and also provides a structured process for frequent feedback on behavioral expectations (Campbell \& Anderson, 2011; Fairbanks et al., 2007). 
SEL incorporates at least three tiers of systems of support (Crone et al., 2010) that help promote a healthy culture and minimize behavioral issues (Lewis \& Sugai, 1999; Scheffler \& Aksamit, 2006). Much of the research on SEL highlights CICO as an effective Tier 2 behavioral support (Campbell \& Anderson, 2011; Hawken \& Horner, 2003; Todd et al., 2008; Simonsen et al., 2011). CICO is a multi-step daily intervention that requires students to check in with a caring adult at multiple points in the school day, receiving verbal prompts and positive praise regarding the expected behaviors (Crone et al., 2010). Classroom teachers begin each morning with feedback, followed by check-ins with the students at different intervals throughout the day. At the end of the day, the students check out with their mentor/caring adult to have a conversation about their performance throughout the day regarding their target behaviors (Crone et al., 2010). Following this discussion, the CICO card is taken home to be signed by the guardian and returned to school the next day for their morning meeting with their caring adult (Crone et al., 2010).

$\mathrm{CICO}$ is a proactive intervention that begins with the classroom teacher and other problem-solving team members deciding upon target behaviors that need to be reduced through constant monitoring and increasing prosocial behaviors (Campbell \& Anderson, 2011; Simonsen et al., 2011; Todd et al., 2008). There are at least three main purposes of CICO: improving student engagement, increasing prosocial behavior, and positively affecting educational outcomes in the classroom (Campbell \& Anderson, 2011). Problem-Solving teams should then meet regularly to look at the data to make sure that students are making adequate progress (approximately $80 \%$ for the majority of the time) and to decide if there are any changes that need to be made to this intervention (Filter et al., 2007; Todd et al., 2008). 


\section{Why CICO?}

A study by McIntosh, Campbell, Carter, and Dickey (2009) implemented CICO with 34 students in six schools in the Pacific Northwest and uncovered a decline in office referrals, decreases in negative behaviors, and increases in other appropriate behaviors, including sharing and volunteering. Another study of CICO implementation involving four students in a suburban elementary school found that there was an increase in academic achievement and a reduction in problematic behaviors for all four students studied (Campbell \& Anderson, 2011). Furthermore, an investigation of CICO implementation in a rural school revealed a decline in office referrals and a decrease in the number of inappropriate behaviors for four children within the primary grades (Todd et al., 2008). Overall, research proves that CICO can improve all aspects of education for students, especially those who have a background of traumatic experiences.

\section{Social Importance}

Social validity, or social importance, and acceptability of interventions by stakeholders (e.g., parents, students, teachers) are critical for the continued implementation and effectiveness of interventions at hand (Cooper, Heron, \& Heward, 2007; Wolf, 1978). Several studies indicated that CICO implementation within school settings reported high ratings for social validity (Filter et al., 2007; Hawken \& Horner, 2003; Hawken, MacLeod, \& Rawlings, 2007; Hawken, O’Neill, \& MacLeod, 2011; Lane, Capizzi, Fisher, \& Ennis, 2012; Mong, Johnson, \& Mong, 2011; Simonsen et al., 2011; Todd et al., 2008). In a descriptive study comparing student discipline rates prior to and following CICO intervention, 17 faculty and staff were asked to rate the effectiveness and efficiency of CICO using a 6-point Likert scale (Filter et al., 2007). The results of this study revealed satisfactory reviews of CICO from most of those who were surveyed. Overall ratings were a 4 or higher regarding ease of implementation, importance of 
effects, and preference of the CICO compared to any other interventions (Filter et al., 2007).

These findings bode well for administrators looking to utilize measures such as CICO to improve school culture and intervention outcomes.

\section{Limitations of CICO}

Within published research, there is a small sampling of evidence noting that CICO can reduce problematic behaviors for secondary students (Ennis, Jolivette, Swoszowski, \& Johnson, 2012; Mitchell, Adamson, \& McKenna; 2017). Most of those who participated were male; research on implementing CICO with female students is sparse (Mitchell et al., 2017). Due to limited oversight of CICO implementation by researchers or administrators, unless research or case studies are being conducted, school staff utilizing CICO may modify the procedures and extend punishments to address problem behaviors (e.g., detentions, grade demotions) which could negatively impact the fidelity of CICO implementation and ultimately the effectiveness of the intervention (Ennis et al., 2012).

\section{Teachers and Parents: Support and Involvement}

Critical for success with CICO is both teacher support and parental involvement (Hernandez, 2005; McCracken, 2004; Zins \& Elias, 2006). Daily parent communication required in the CICO intervention allows a pathway for parental involvement to support both the child and the teachers involved in changing the trajectory of unwanted behaviors in the classroom and at school. Students whose parents actively participate in their education usually have higher grades and test scores, a lower rate of absenteeism, and show more positive behaviors (Anderson $\&$ Minke, 2007). Parents are an additional source of support and can influence their child's behavior (McNeal, 2001). 
Positive, healthy relationships are a necessity to effectively support students and teach them skills needed to be successful on a variety of levels: academically, socially, emotionally, and behaviorally. Teachers and staff should strive to foster meaningful relationships with students, as the presence of at least one caring adult has all of the possibilities of making a significant difference in a student's life (Hupfeld, 2010; Repetto, Cavanaugh, Wayer, \& Liu, 2010). Each day, teachers have interactions with students which can be immensely powerful and increase the likelihood of a student's success or failure (Demaray \& Malecki, 2002). In this way, CICO has the opportunity to bolster teacher-student relationships through multiple contacts throughout the day.

\section{Teacher Response}

A study by Alsic et al. (2012), involved 765 teachers in the Netherlands and focused on teachers' perceptions of trauma-informed practices. The study indicated that more than half of the teachers who were surveyed found it tough to avoid getting emotionally involved when working with children of trauma. The teachers also described their role as the teacher within the classroom to be difficult, as opposed to providing a mental health expert for their students. Teachers who were surveyed found it difficult to understand or recognize when children need mental health assistance from a provider versus services from within the school, and they did not know the best ways to support a child after a traumatic event. These issues make it difficult for children who have had traumatic experiences to meet all the classroom expectations in a consistent way (Bloom, 1999; Wisconsin Department of Public Instruction, 2012).

A teacher's response to a difficult and/or disruptive behavior can negatively affect a classroom's environment and potentially be challenging for all involved. The effects of trauma on students are not just a direct result of the specific event, but instead arise from how a student's 
mind and/or body reacts to the traumatic experience (van der Kolk, 2005). These traumas can in fact negatively impact any and all aspects of a child's development. Hence, professional development opportunities are important for staff to know the correct response when it comes to behavioral situations. Many teachers who were surveyed by Westling (2010) noted that challenging behaviors take up the majority of their time, increase their stress levels, and minimize learning for the child involved, as well as the other students within the classroom. Thus, teachers often feel as though they are even less successful or effective.

\section{Healthy Relationships}

Trauma can negatively impact a student's functioning at school and beyond. Following trauma, children may struggle with trusting their peers and/or adults, which can manifest in various ways, especially as problematic behavior. Tishelman et al., (2010) explained that "chronic childhood trauma interferes with the capacity to integrate sensory, emotional, and cognitive information into a cohesive whole and set the stage for unfocused and irrelevant responses to subsequent stress" (p. 285). This notion is expanded upon by O'Neil, Guenette, and Kichenham (2010):

The core of attachment is the regulation of emotional experiences. There is a small window of time within a child's development when emotional stimulation allows children to identify appropriate emotions later in their lives...childhood abuse and neglect profoundly distort and impair self-regulation, interfering in the development of affect regulation and tolerance (p. 192).

Therefore, students with a history of trauma may have difficulty trusting teachers, authority figures, or peers. They may also isolate themselves or be drawn into unhealthy romantic relationships. The National Scientific Council on the Developing Child (2010) revealed 
that early introduction to situations that "produce persistent fear and chronic anxiety can have lifelong consequences by disrupting the developing architecture of the brain which can lead to both immediate and long term physical and psychological problems" (p. 1). Thus, with even a basic understanding of what students with trauma experience, teachers can better serve their specific needs in the classroom, ensuring they learn and succeed in multiple aspects.

\section{Professional Development}

Multiple pieces of evidence prove that trauma is everywhere and can affect a person's life in various ways. Fallot and Harris (2001) contended that children can often heal from traumatic events through trauma-informed care (TIC) since it can meet the diverse needs of a traumatized individual (p. 2). TIC centers on an "understanding of the prevalence and impact of trauma and the complex paths to healing and recovery," and is "designed specifically to avoid retraumatizing those who seek assistance as well as staff working in service settings" (Harris \& Fallot, Eds., 2001, p.2). Hence, trauma-informed practices involve the use of understanding, relationships, and care regarding trauma by educators to make modifications that will support the student's development within the classroom and school (Evers, 2012). It is imperative that staff members recognize and understand trauma to avoid triggering a response based on the students' traumatic experiences. Blodgett, Lawyer, Gates, Turner, and Wagner (2012) argued that "given the demands facing educators in schools, there is little room for leaving any staff members in the educational system disengaged and frustrated" (p. 15). This requires a change in mindset, an understanding of the brain, and a need for changes in systems within schools.

Noting that children spend a large amount of their day in school, the concept of TIC is essential for educators. Cole, Eisner, Gregory, and Ristuccia (2013) defined a trauma-sensitive school as "one in which all students feel safe, welcomed, and supported and where addressing 
trauma's impact on learning on a school-wide basis is at the center of its educational mission" ( $p$. 11). Without trauma awareness or acknowledgment of a student's trauma history, teachers and staff are unable to make the connection between that student's behavior and the traumatic experiences. In this way, the work within this study to understand trauma, prioritize professional development for staff within school programs, analyze school wide and classroom practices, and develop leadership to create a welcoming environment for trauma-sensitive learning, is extremely important in order to close any of these gaps in education.

\section{Equity}

One significant impact on children is their family's income or socio-economic status.

Okpala (2002) mentioned that the socioeconomic status of a student is an important predictor of achievement in school. According to Hodgkinson and Goldberg (2000), parents' education level and household income can often predict $45 \%$ of the national assessment scores without knowing anything about race, which means that socioeconomic status is twice as predictive as race.

Consequently, if students are living in a home below the poverty line, they often may not have access to tools they need to be successful in the classroom. As a principal within a low-income school, I have observed this within our school. Children are not in control of which family they are born into, but that factor can result in reduced opportunities and experiences. Therefore, the playing field is not equal across districts, schools, and the state. Students who have experienced traumatic events in their lives often come to school and are not able to handle the academic and social demands placed on them. Schools play a significant role in the adjustment of traumatized students and often serve as a buffer from the entire effects of adversity (Adelman \& Taylor, 2008). 


\section{Critical Race Theory}

Nationally, people of color are more likely to live in poverty than their white peers. While 11.6 percent of white Americans live in poverty, 25.8 percent of Black, 23.2 percent of Latino, and 27 percent of American Indian and Alaska Natives live in poverty (Office of Civil Rights, 2000). Families of color are also between 6 and 9 times more likely than white families to live in areas of concentrated poverty, exacerbating the effects of poverty and impeding opportunities to improve financial situations (Office of Civil Rights, 2000). Economic status is the biggest predictor of educational success, which is another issue of equity. There is a large quantity of evidence that shows that academic underachievement exists for many Black males in Pre-K through grade 12 schools; however, social and emotional challenges exist for these individuals as well. Black males currently make up approximately 7\% of the nation's PreK-12 student population, yet they make up a disproportionate percentage of students who are in special education classes, alternative schools, and remedial classrooms (Office of Civil Rights, 2000).

Students who live in poor areas face many challenges which can affect their learning and development. Santiago, Stump, and Wadsworth (2011) state, "living with persistent poverty damages one's psychological health" (p. 218). Many students in the US grow up in a poverty situation. There is research that supports that "growing up in low-income, urban environments exposes children to severe and ongoing trauma" (Kiser, 2007, p. 211). Students in these living situations are more likely to experience stresses such as chaos, family conflict, violence, incarceration, death of a family member, mistreatment and or neglect than their peers in a more affluent community (Kiser, 2007). 


\section{Ethical Consideration}

Due to the prevalence of trauma, the loss of skilled educators could prove to be a large problem for the profession of teaching. Teacher stress, burnout, and anxiety, particularly after a traumatic event, play a part in this desertion of the profession and an inability to engage in meaningful pedagogy (Agaibi \& Wilson, 2005). This work is taxing, and the challenges are real. Consideration must be given to the ethical dilemma of choosing between the right thing to do for the students versus the staff. For students, the ideal approach is to get to the bottom of the behavioral challenge rather than just sending the student out of the classroom for someone else, usually an administrator, to handle. In my experience, there are students in classrooms today have complex needs. Students of trauma often come to school in a heightened state which can then lead to behavior issues and for them to live in a flight or fight survival mode (Blodgett \& Turner, 2012). This state then negatively impacts learning (Blodgett \& Turner, 2012). On the other hand, teachers then become exhausted and frustrated from a perceived lack of support from administration or others within schools. Rossin and Hull (2013) made the following claim:

The creation of a safe and supportive school environment for students impacted by traumatic experience also enhances the learning environment for all students. When we create safe and supportive school communities, the benefits to all children are significant...regardless of exposure to trauma. (p. 254)

Inadvertently, data from mark charts and office referrals often reveals that most behaviors are occurring in the classroom each day rather than other areas of the school, such as in the gym, cafeteria, buses, and the hallway. Classroom teachers become physically and emotionally drained by these behavioral issues; therefore, ethics comes into play when teachers and support staff do not make the best decisions or have the most appropriate responses when behavior occurs due to 
this stress and fatigue. The continued expectation that teachers must solve behavioral crises each day contributes to the decline of the profession overall. It is important to identify, acknowledge, and address student issues from the beginning by obtaining input from staff who have the understanding or knowledge of the student (Cole et al., 2005).

As schools work to become more adept at implementing trauma-sensitive practices, teachers and staff need to understand that students who have experienced trauma can respond differently and their personal histories will influence how they interact within the school itself. When a staff member is identifying and evaluating a student who may have been involved in a traumatic event, schools should: (a) understand different hypotheses of trauma when working with challenging students; (b) consider the implications regarding the research of the brain and trauma; (c) choose a strategy that best meets the needs of the student; and (d) utilize data with the hypothesis at the core (Tishelman et al., 2010; Blodgett, Turner, \& Harrington, 2010).

However, that creates a large burden for staff members to bear. Westling (2010) shared results from his survey which revealed that approximately $44 \%$ of the teachers surveyed agreed that challenging behaviors makes them consider quitting their jobs. Therefore, it is imperative that teachers who work in areas of high poverty and trauma be supported and be provided resources to effectively deal with challenging behaviors.

\section{Restorative Practices}

Brené Brown's (2012) model of interpersonal connection spans a continuum, ranging from empathy (most connected) to shame (least connected). According to her shame-resilience curriculum, vulnerability is the key to helping educators connect with students, which in turn yields empathy, and can overcome the destructive impact of shame. Thus, understanding and empathy from a caring adult can help contextualize symptoms of trauma as abnormal behaviors, 
not misconduct. Brown (2012) noted this is a vulnerability issue. Having a supportive environment, where students feel safe and belonging is not threatened, students could thrive and take chances (Brown, 2012). This is where a caring relationship will assist, especially with empathy and listening. To date, many schools have turned to Restorative Justice or Restorative Practices to effectively work through the causes of behavior and understand next steps, which focus on rebuilding the relationship between the victim and the offender. Educators strive to help students grow academically and if they are not moving forward, early interventions are put in place. Regarding behavior, teachers often feel as though the students should come to school knowing how to behave, even if there are different standards at home and at school. Therefore, a disconnect begins. Managing student's emotional outbursts and regulation is important when assisting the student and to maintain a peaceful classroom (Downey, 2007). Trauma changes the rules in any game, with the person's functioning and development typically altered and now formed around the traumatic event (Hodas, 2006). Rossin and Hull (2013) expanded on this same idea:

The reality of childhood trauma is that it effects a significant proportion of the school aged population, and its influences are considerable within the school setting...the influences are strongly moderated by the environment in the development takes place. As such, schools offer remarkable opportunities to address the needs of the substantial youth population whose lives have been affected by traumatic stress. (p.9)

As the research reveals, the effects of trauma within the school setting must be proactively addressed.

In order for students to be receptive to new learning, there needs to be a supportive ecosystem based on social and emotional development in schools, which includes awareness 
among educators, a trauma-informed MTSS, and a school-wide SEL curriculum taught by teachers, like the Second Step Program. Addressing the many needs of students who have experienced trauma is a challenge that continues to affect our schools. Schools play a large role for students who have experienced traumatic events; therefore, schools serve as a buffer from the effects of adversity (Adelman \& Taylor, 2008). The literature provides teachers and staff with guidance on school-wide frameworks, such as the Positive Behavioral Support Systems (PBIS) and research-based practices. The notion is that when teachers and staff members understand the complexity of trauma and have the skills and knowledge to address it, learning environments will be created that are safe and nurturing. As stated by Blodgett et al. (2012), "When students feel safe, they can calm down and learn" (p. 6).

\section{Relationship of Study to Theory and Research}

In working with children who have experienced trauma, Anne Gearity (2009) noted that there are common behavioral characteristics of traumatized children. Traumatized children can potentially have interactions with adults that are confusing and can interfere with classroom behavior. For example, students might expect a harsh reaction from adults they work with, or they may assume that the staff member is ignoring their needs and, therefore, will not ask for assistance when they are struggling (Gearity, 2009). This same study showed that quite often requests that are made in the classroom setting for compliance turn into power struggles, which better informs the case that educators need additional training in even the foundational aspects of classroom management, relationship building, and meeting the immediate needs of students. Within a school utilizing TIC, it is extremely important that staff be trained in childhood trauma, positive supports and response systems, promotion of success in learning, and safe/supportive 
classrooms. Having a safe and stable school culture is key to the healing process for children of trauma (Brunzell et al., 2015).

Children who have experienced trauma can have difficulty managing their emotions or self-soothing when stressed. Teachers and staff need professional development in order to assist with these feelings and situations beyond the SEL curriculum or standards for continued learning for all. As schools work to make plans for individual students, goals are established, such as targets within CICO, especially when the student has experienced trauma. Interventions, such as $\mathrm{CICO}$, are woven into the student's daily activities in the classroom, cafeteria, hallways, specials, and recess. Blodgett et al. (2010) explained that "this enables children to feel academically, socially, emotionally, and physically safe wherever they go in school. When children feel safe, they can calm down and learn" (p. 6). When faced with a consistent flow of stress chemicals within their bodies, or reliving traumatic events, students can fail to learn how to calm themselves down or regulate their feelings thus interrupting the learning process for many (Tishelman et al., 2010). These emotions can manifest into deeper or more long-term mental challenges if they are unsure of how to deal with the emotions they are feeling and can "exhibit a wide range of problem behaviors, including aggression, poor peer relations, and emotional dysregulation" (Crozier \& Barth, 2005, p. 198). Students are often unable to identify their internal emotional experiences; thus having events that are predicted, supporting vocabulary for emotional experiences and making connections with their own emotions, coping techniques, and the impact or the past or current situations are all pieces of the puzzle when supporting safety within the classroom (Blaustein \& Kinniburgh, 2010; Arvidson et al., 2011). 


\section{Summary}

The literature provides many examples of students whose needs are not being met. It is imperative in schools today to have caring, trained, and motivated adults in order to make progress in all areas. Existing practices must be examined, and plans should be made to support all students within the schools and their environment. Relationships, interventions, and professional development are all pieces of this puzzle. CICO is one promising approach that provides educators with a tool for centering relationships to support and nurture, reducing the struggles experienced by the trauma-informed student.

Professional development for all, including secretaries, janitors, food service staff, and teachers/paraprofessionals, needs to be consistent and differentiated to effectively work with all students. By utilizing an ecological approach with students who have experienced trauma, the understanding is that there are many levels that influence a student's development, including the parents, family, school, and additional stakeholders all who have relationships with the student Blodgett, Turner, \& Harrington, (2010) . A review process is essential for data analysis with all teams understanding the function. Support looks different given the behavior that is displayed. Having a team system is important in creating levels and systems of support. It is essential to know and understand the function, what the behavior is communicating, and how to effectively respond to it. Involving all stakeholders and the communication of the outcomes is critical for developing next steps. At the root of the issue is the need for positive relationships, trust, and support. 


\section{CHAPTER III: RESEARCH DESIGN AND METHODS}

\section{Introduction}

This chapter focuses on the methodology used in this study. The purpose statement is revisited followed by a restatement of the research questions. Specific research procedures are also discussed, including why the mixed methods research design was used for this study as well as how the sample of participants were selected. Additionally, this chapter covers the data analysis employed, and the Cycles of Inquiry as a mode to further information. Finally, validity/trustworthiness and authenticity procedures, and ethical issues are addressed.

\section{Purpose}

The purpose of this study is to examine how the use of CICO by teachers coupled with the book study helped improve practice and student behavior at Shandy Elementary School. Often, students who have experienced trauma are noted to need additional supports, which CICO is one. CICO data is reviewed to show how students performed at school with desired goals, weekly progress updates, and a relationship with an additional caring adult, the CICO mentor. [Teaching practices are an important component of understanding responses of students in order to further their academic and behavioral advances.

\section{Study of the School Context}

Shandy Elementary School is a Kindergarten through fifth grade building located in Bloomington, Illinois. There are approximately 364 students currently enrolled. Currently, $8 \%$ of our school population is considered homeless and the mobility rate stands at $14 \%$. Currently, the student body is comprised of mainly minoritized students with only $29.4 \%$ being white. Additionally, over $80 \%$ of students come from low-income households. Due to these demographics, my theory of action supports the need for understanding de-escalation techniques, 
including building solid relationships with our students, especially those who have trauma in their lives. The need for relationship-based interventions, such as CICO, paralleled with professional development for staff regarding trauma, brain, and relationships is a necessity as students who are impacted by trauma, even minor events, continue to enroll in our schools. With COVID 19, trauma could be even more prevalent as students have been away from school since mid-March and have not been in a classroom setting with structure for quite some time. Trauma, as noted in earlier chapters, can be present in many different forms.

Being the principal of Shandy Elementary, I see how time is an important factor considering how much actual time behavior takes out of daily schedules, routines, academics, and structures. Thus, having a positive relationship matter from the start, especially those supported with CICO. CICO can include multiple layers of relationships and staff to utilize within a school setting. CICO becomes a tool that is used school-wide, not just a singular trick a teacher has in their tool basket. Teaching practices must be reviewed and considered, especially de-escalation techniques in order to build capacity to handle childhood trauma in schools. There are older practices, such as administering punitive consequences, yelling at a student, and sending a student out of the classroom for the remainder of the day, which are embedded in the culture of the school and can elicit more trauma due to the non-relational nature of the techniques. There are instances every day in which our students need more than we are giving them. For example, when a student runs around the classroom and throws an item in frustration, the goal is to seek a calm state rather than pushing the student out of the classroom and shutting the door. The main objective is to increase positive relationships and academic achievement, focusing on these win-wins and preventing trauma-induced behaviors from nullifying our efforts to support all the students. 
Within the district, Tier 1 implementation of interventions was the focus for classroom teachers. Tier One needed to be in place for all students and followed for the first 45 days to obtain a baseline and fully teach the expectations and routines to all students. Following the first 45 days of school, Tier 2 interventions were put into place. This explains why students were not on CICO prior to November. Students who had office referrals or an excessive number of marks from their classroom behavior charts were discussed in Problem-Solving Team meetings with the classroom teachers. These students were either brought to the table by a classroom teacher, principal, support staff, or the Tier 2 coach. From there, adding students to CICO was discussed and decided. Parent letters were then sent home regarding CICO and the steps in place. Upon approval, CICO was then reviewed with the student, teacher, and CICO mentor.

\section{Role of Researcher}

In working with a variety of stakeholders, it was essential to understand that my role involved researching best practices, supporting stakeholders, and looking at the data from a variety of angles without bias. On the flip side, as the principal, my job remained to support the staff with a variety of needs, which led to conducting the book study at the same time as implementing interventions in order to create opportunities for staff reflection during this process. Trauma is a sensitive subject within our school as teachers want to teach without the constant interruption that trauma can bring. My hope was that teachers would uncover details regarding trauma from the book study and be reflective about practices that they could essentially change, thus positively affecting the learning environment and academic achievement.

Being a researcher for this project and knowing CICO data can change given a variety of circumstances, I continued to monitor the data that was input each week. I made agendas for the 
Problem-Solving meetings with the CICO coach on a bi-weekly basis. I provided this information along with data recaps for all staff. Knowing the data would appear in the research, staff did not question it and all agreed to be a part of the study moving forward. All staff knew and were reminded that they could opt out at any point without any penalty. Due to COVID 19, we moved to Zoom meetings following March 16, staff knew and were reminded that they could leave a meeting without consequences.

Each problem-solving meeting was held in our conference room, room 8 . We had a large table in the center of the room and all the staff who attended sat around this table. There was no pre-arranged seating. All staff could hear and see everyone around this table. Our meetings took place either prior to school beginning at 7:30am or at 3:30pm following dismissal. Each meeting was approximately one hour long. Problem-Solving Meetings occurred once per month, unless we needed an additional meeting due to teacher request.

\section{CICO}

Each student who was designated to be on CICO met with their CICO mentor each morning prior to going to class. These meetings lasted less than five minutes. During the meeting, their CICO goals were reviewed and positive comments about the day before were shared. These meetings allowed for a brief but positive interaction with a caring adult outside of their classroom teacher, hence creating a new, affirming relationship. These meetings also afforded an opportunity for reminders about the expected or appropriate behaviors throughout the day.

Teachers provided students on CICO scheduled and specific feedback on their CICO cards. Students had opportunities to earn points for each goal that was established during Problem-Solving Team meetings. These were circled on their card. Teacher feedback to the 
student was expected in increments throughout the day. These increments were separated by subject or class. Specifically, teachers were to give positive and specific praise for appropriate or expected behavior. Students were assigned a score of a 0,1 , or 2 points on their CICO card. A score of 0 noted that the student's goal was not met during this time frame. A score of 1 indicated that this goal was partially met, and a score of 2 showed that the goal was achieved If they did not earn the points, corrective feedback was offered.

Each student on CICO checked-out with their mentor at the end of the school day. During this session, CICO mentors reviewed their student's CICO card and talked about what went well and if there was anything the student could have improved. The CICO mentor, who is chosen from input within the problem solving team and classroom teacher, would then added up their points to determine if the student met their goal. If the point target was not met, the CICO mentor provided a chance to review the targeted behavior and how they could achieve maximum points in order to do so.

CICO mentors entered daily totals for their individual students on a CICO Data Tracking document that was housed with the CICO coach. This data was reviewed weekly with the Problem-Solving Team and the student's teachers to make sure that decisions were data-driven and connected to behavior. In discussion with the student's teachers, attendance, mark chart data, and ODRs were reviewed and academic concerns were addressed if necessary. During this time, the Problem-Solving Team considered adding interventions, tweaking CICO goals, or dismissing interventions based on data. Classroom teachers and CICO mentors conferred with the individual students when meetings would occur and communicated with parents to ask for their thoughts and concerns. 
Each student's CICO cards were determined based on goals from the classroom teachers. Each student's card was different and based on their needs. Scores were updated electronically on a daily or weekly basis. Graphs were sent home to parents regarding progress. There were many opportunities throughout the day for students to receive feedback and earn points for expected behaviors, such as CICO with their mentor, hourly intervals with their teacher, and a reflection time with parents regarding how their day went. It is important to note that teachers were not given any additional training on CICO within the school setting; however, within the study, teachers were given the Help for Billy book to continue to look at trauma and address behavioral concerns both independently and as a grade level team. Individual teams decided on which chapter they would present to the staff as a team.

\section{COVID-19}

On March 16, 2020, we were provided with an Institute Day for teachers and staff to be back in the buildings to prepare for their time at home due to the closing of schools across the state of Illinois. At that point, the Coronavirus numbers had spiked, causing concerns for safety and the closure of schools by Governor Pritzker. The original thought was that we would be back in school once there was a decline in numbers and it was safe to come back. With the Coronavirus being new and a serious health issue, there were many unknowns regarding the prevention and the spread of this virus. Given these safety issues, educators had to think of a plan to educate and engage students. Within a short period of time, our district went to an on-line format and also sent home choice boards with work for students to complete. CICO was halted at this point since it was an intervention that could not be completed with integrity given the current circumstances. For the remainder of Spring, 2020, we never went back into the classrooms. With this, CICO data was no longer collected and therefore I was unable to see what was impacting classrooms 
given that the professional development component continued even though students were no longer physically in our classrooms or school.

\section{Research Questions}

With pressures from every direction, teachers remain committed to teaching students. For meaningful learning to occur, behavior management must be solid, practices must be implemented with integrity, communication between home and school must be happening, and students must feel safe within their environment. De-escalation practices reflect respect for the whole child in preserving their dignity. Unfortunately, there is not one-hundred percent commitment to trauma-sensitive instruction at Shandy, and teachers resort back to old, ineffective practices and, in fact, enhance the trauma at hand from time to time. School-wide factors that were considered through committees, especially the MTSS Tier One team, revolved around a House System in which all students were put into different houses for a positive climate and culture, similar to that of Ron Clark (2003), using influences such as positive office referrals and a positive mark system. In working with a team, I described the de-escalation and relationship practices that enhance teacher-student relationships, diminish the effects of trauma on student learning, and overall benefit our students. To this end, I addressed the following research questions:

1. To what extent did the implementation of one trauma-influenced practice, Check In/Check Out (CICO), help change behaviors within the classroom setting at Shandy Elementary School?

2. In what ways did the addition of a trauma-influenced book study to CICO inform teachers and staff to alter their professional practice to achieve better student behavioral outcomes at Shandy Elementary School? 
3. What other forms of trauma-influenced practice supports do teachers at Shandy

Elementary School say they need in order to better their practice in student behaviors and responses?

\section{CPED}

Curriculum and coursework were designed with a strong influence from the principles developed by the Carnegie Project on the Education Doctorate (CPED) through the EdD program at Illinois State University. It is noted that members of CPED constructed the set of "working principles" that would provide a strong foundation for institutions to develop a CPEDbased EdD program to set the stage for future work. Courses through the EdD program revisited components of CPED's principles that helped to guide the development of the doctoral program. Each course consisted of theoretical and practical components, often leading to fieldwork experiences or prepared presentations directly related to solving problems within the field of educational leadership. In addition to the team-building projects, the concept of exploring issues through lenses of equity, ethics, and social justice was introduced early, keeping CPED's working principles at the heart of any issue. Given CPED's influence, it connected with the study in the sense that one intervention, CICO and professional development in regards to trauma, is a real concern from my perspective for Tier Two interventions that are conducted within school settings. The systems in place guide towards improvement for all students, therefore making CICO, trauma, and professional development a practical problem.

\section{Dissertation in Practice}

Dissertation in practice and coursework focused on a design shift in the program. A great deal of time was spent working on activities which required us to gather, analyze, and interpret qualitative and quantitative data in preparation for the dissertation process. The dissertation in 
practice encounters a complex problem of practice such as CICO, professional development, and supporting students and staff where trauma-impacted students are to learn and grow along with their peers. CICO is an opportunity to review data along with comments from staff throughout the day. Currently, there are several de-escalation approaches in use; however, there are some staff members who refrain from using multiple strategies. Some de-escalation techniques include empathy, respect of personal space and time, nonverbal communication attempts that are nonthreatening, a focus on feelings, limit-setting options, positive relationships with students, and reflection. Consequently, these all take time, and classroom teachers are often on the defense about time and the need to instruct others, so they tend to call for assistance. Overreacting is one of the biggest issues I see when students are having behavioral struggles. Additionally, when one student is having behavioral issues, time is taken away from the other students and their learning is impacted. It is almost an immediate reaction to avoid dealing with the individual student at hand and to call for assistance. Furthermore, once administration steps in, staff sometimes struggle because they feel as though there is a lack of consequence for the student who is having the behavioral issue, even though they have been away from their learning environment.

\section{Problem of Practice}

Trauma is a prevalent issue in schools today. Briere and Spinazzola (2005) noted that much of the information regarding trauma points out that the development of distress from a traumatic event is usually associated "with a life history of multiple interpersonal victimizations experiences, often beginning with extended childhood abuse and neglect, and associated disruption of the parent-child attachment system” (p. 401). Previous research discovered that many educators do not believe they are equipped with the knowledge and skills to handle students' traumatic experiences (Alisic, 2012). Teachers have a variety of standards to teach, 
including SEL standards; however, curriculum sets are difficult to find and can be expensive. Professional development regarding trauma and how to effectively respond to students' needs is an essential component. Plus, there is a pressing need to support staff members with traumasensitive instruction. This work is challenging, and results are not usually immediate, leaving a variety of stakeholders frustrated and unsure of what steps to take next. Teachers and staff members play a vital role in helping students to recover from trauma or to utilize strategies when they are upset; yet, there is research that proves elementary school teachers and staff members are uncertain regarding this responsibility and how to assist students effectively following traumatic experiences (Alisic et al., 2012).

It is imperative for teachers to understand trauma and how to prevent re-traumatizing students by not escalating situations where students are frustrated. This requires a shift in mindset away from their previous views on student discipline to an updated understanding that students act out due to previous traumatic incidents in which their brains have been re-shaped. This is again how CICO can be used to assist with behavioral needs. CICO targets the behavior warranted, provides feedback to the student throughout the day, and involves daily communication with at least one family member. School staff should make sure not to forget about the students who fly under the radar as they may not exhibit problematic behaviors. Schools often focus on a growth mindset for both students and staff. The power of "yet" has been essential in understanding how to positively respond to trauma and students hence having the growth mindset and sharing with students. The need to lead the change in fundamental practices and meeting students where they are, including getting teachers to grasp the brain research and how trauma has impacted children's learning. Students honestly cannot always regulate their responses and can have little control while trying hard not to push teachers' buttons. The 
response a student gives is not meant to trigger a negative reaction from the teacher. Student responses lie in the communication they receive from others with whom they have interacted, thus making it difficult when dealing with anyone who has had a traumatic experience.

\section{Cycle of Inquiry}

Cycles of Inquiry is a term applied to many continuous improvement attempts. The Cycles of Inquiry for Instructional Leadership developed by Dr. Shelby Cosner is unique in the design to seek a more thorough understanding of student learning problems and high-leverage instructional strategies for improvement (Cosner, Walker, Swanson, Hebert, \& Whalen, 2018). The Cycles of Inquiry process does not promise the magic form or tools that will fix school improvement. Rather, the processes involved are intended to shift from a School Improvement Plan to a School Improvement Process that is ongoing and extends beyond the traditional 9 month school year calendar. Cycles of Inquiry provided a framework for our Problem-Solving Team meetings, which met monthly or upon teacher request. The ultimate goal was to get to the root of the problem, whether behavior, academic, or a combination of both, and find pathways for success.

Inquiry as practice is the process of asking or reflecting upon questions that focus on complex problems of practice. By using various research, theories, and professional inquiry, staff members attempt to use innovative solutions to address the problems of practice during Problem Solving Team meetings on individual students or small groups of students. At the center of Inquiry as Practice is the ability to use data to understand the effects of research. Teachers would bring classroom data and Problem-Solving Team members would supply more Tier One data, such as Northwest Evaluation Association (NWEA) Measures of Academic Progress (MAP) scores, Dibels Benchmark scores, mark chart or Office Discipline Referral data. As such, Inquiry 
as Practice requires the ability to gather, organize, judge, aggregate, and analyze situations, literature, and data with a critical lens (Carnegie Project on the Education Doctorate [CPED], 2010). The Problem-Solving Team, along with the classroom teacher, would review data and analyze any trends. Decisions were then made in support of the student. With the intent to understand trauma using a cycle of inquiry to determine the impact it has on schools, particularly elementary schools, forming relationships, and CICO is just the beginning. CICO was often an example of an intervention that was put in place to assist students who were struggling which added another layer of data collection. This data was then broken into smaller increments of time and allowed for additional reflection. Supporting the relationships and assisting with tools in times of crisis, especially de-escalation techniques, must follow. Schools should be a safe place where learning happens, social and emotional development occurs, and problem-solving takes place.

The primary focus is the essential components of de-escalation and relationships within classrooms in order to support students. There are several teachers who do this very effectively and the hope is bring all teachers on board, without behavior negatively impacting the teacher personally.

\section{Laboratory of Practice}

Already at Shandy, trauma is a word referenced daily. Currently, we utilize Restorative Practices regularly in resolving conflicts and rebuilding the relationships between each other. One would be able to walk up and down the hallways and notice the importance of and push for growth mindset due to what is displayed on bulletin boards. Shandy teachers consistently set growth targets with student involvement and focus on the power of yet, a mindset that supports the struggle with learning (Dweck, 2006). Teachers have had many hours of professional 
development around trauma informed practices, First Aid for Mental Health, and other deescalation and relationship techniques. Relationship building is the first initial strategy utilized with our students. In fostering these relationships, consequently, we often find out about past traumatic events that have taken place or parents reveal current struggles. Sometimes these difficulties result in just conferencing and listening. Often, responses are more impactful and require additional services, hence wrapping supports around the entire family.

Laboratories of practice are tied to practical places where the identification of learning work is done in consultation with organizational leaders, university faculty, and the student/researcher. This work is not replicated in the classroom and goes beyond the traditional internship. Such an endeavor also helps students to understand that it is important to take different approaches to practice in order to get a reasonable solution to the problem at hand.

\section{Research Paradigm and Design}

As a teacher for thirteen years and a building leader for the last seven years, I continue to believe that all students can learn and should be supported no matter where they are in the process. I believe that teachers have the best of intentions and want to teach all students; however, many teachers find it challenging given students' responses to instruction and redirection. When teaching and learning are happening through my lens of evaluation and observation, there are factors that do get in the way of daily educational services being delivered, with trauma being at the center. Students react negatively to not getting their way and are disengaged from instruction due to many reasons, while parents, teachers, and staff are feeling stretched and insecure. Many students within our school experience trauma through ongoing exposure to traumatic events, such as neglect, homelessness, domestic violence, or violence within their neighborhoods. One aspect that is difficult for educators to address is that students 
do not often divulge these personal challenges in a way that can be easily understood. Pain is often masked with behavior that is aggressive, violent, and misunderstood. Students who have experienced traumatic events often struggle with negative self-talk, poor self-regulation and communication of needs, executive function challenges, and difficulties forming relationships with teachers, staff, and others (Alisic et al., 2012).

One of the biggest obstacles is shifting the mindsets of adults and systems to give support to students when they misbehave rather than punishment. In lieu of using disciplinary systems that reduce support and attention instead of addressing the behavioral issue, the goal is to utilize practices that focus on the whole child. This is definitely a mindset shift for adults who have little patience for students who provoke and push away the adults who are trying to assist them. Consequently, the focus should be de-escalation through positive relationships that are already established and improving responses when crisis situations or general misbehavior occurs.

The position I took for the purposes of this study was constructivist through the use of social learning (Bandura, 1977). Constructivist teachers and staff members encourage students and each other to constantly assess how the activity is helping them grow in their understanding of the concept (Driver, Aasoko, Leach, Mortimer, \& Scott, 1994). By questioning themselves and their strategies, getting to the root of the issue, participants in the constructivist classroom ideally become learning experts. This learning opportunity gives them more tools to keep learning, especially through Cycles of Inquiry. This research focused on team learning through shifting mindsets within a social learning process with Cycles of Inquiry at the heart of the professional norms within the school that focused on CICO as a discrete element in Shandy's school improvement processes. 
In my personal experience, there is typically an underlying reason behind trauma and the responses that come from staff and students. Utilizing qualitative research, specifically Creswell (2009), various methods can be implemented to examine the results of the impact of relationships and the role professional development plays in a school setting. Beginning with the Building Leadership Team and our Problem-Solving Team, Cycles of Inquiry continued to be a model to get to the root of the issue.

The quantitative portion of this study utilized data collection, including but not limited to the following: demographics on the students who are trauma-influenced or noted by their behavior through mark chart information taken by the teachers, office referrals, suspensions, and attendance information. This study was mixed method in nature, sequential, with analysis of data around behavioral data incorporated. The study centered on the following essential components of a qualitative approach as outlined by Creswell (2014). It was important to begin by utilizing a variety of data points (CICO data, Mark charts, office discipline referrals, attendance, and academic data and analyzing data, through Cycles of Inquiry to ensure a qualitative analysis within problem solving meetings. Within the problem solving meetings, the root cause for the academic or behavioral concern was sought after.

This study aimed to ensure a greater depth of understanding in regards to the qualitative data collection method by including Cycles of Inquiry with a team of educators within a problem-solving team format, reviewing progress through problem solving meetings or data analysis of CICO data, and discussing with teachers the components of their presentations and the rank ordering of interventions. 


\section{Students and Staff}

Thirteen students were identified as needing Tier 2 assistance, or CICO, based on their mark charts or office discipline referrals (ODRs). These students were de-identified for confidentiality purposes in this dissertation. Teachers who had behavioral or academic concerns in regard to individual or groups of students requested a meeting with the Tier 2 team following the allotted time frame of establishing Tier 1 protocols to have students put on CICO. Three students were in Kindergarten, one student was in first grade, one student was in second grade, one student was in fourth grade, and seven students were in the fifth grade. Along with assistance for teachers came an opportunity for staff through a book study.

There were 32 teachers who participated in the book study, Help for Billy. This book study was recommended to me by a colleague. There are three Title One teachers, four special education teachers, four specialists (art, music, physical education, and Library Media Center specialist), one speech teacher, one social worker and one psychologist, along with three teachers in each grade level (Kindergarten through fifth grade). All teachers participated in a book study of Help for Billy (Forbes, 2012) regarding trauma and understanding how to best work with students who have experienced trauma. Teachers remained in their grade level team. Special Education teachers stayed together in one group, along with Title One teachers. All specialists listed above formed a group as well.

Within this book study, there were eleven groups to present twelve chapters. Teachers were given time to read their chosen chapter and then plan with their team during School Improvement Days and staff meetings. Presentations were made throughout the Spring semester in 2019 during faculty meetings and School Improvement Days. Teachers created presentations based on the chapter they selected. These presentations were intended for all staff, including 
paraprofessionals, lunchroom supervisors, custodial staff, and secretaries. Due to COVID-19, we never came back to the building in the Spring 2020 to apply in person what was learned during the book study.

Following the final book study presentation on the last day of school in 2019, teachers met in groups of three via Zoom to complete a rank ordering of services and interventions based on their perceived effectiveness that were completed throughout the 2019-2020 school year, including the book study and CICO. The hope was that teachers would take the professional development from the book study and connect it to their relationships with students, especially the students who tested their patience the most, to further enhance their connections and produce a positive spike in the students' responses through CICO. Consequently, with COVID 19, the book study was completed but students were no longer in their physical classroom space and unable to continue CICO. To adjust for the change in circumstances, the study shifted from collecting direct evidence of changes to teacher practice resulting from the CICO book study to relying on teacher reports as primary evidentiary sources.

\section{Data Collection Procedures}

Cycles of Inquiry, through our work in Problem-Solving Meetings, in which we met on individual students or small groups of students, provided information from discussions, meetings, and data through the approach of finding the root cause or issue with the behavioral or academic concern brought to the table by the teacher. Cycles of Inquiry also focused on what teachers and staff already do that supports students and noted what is working regarding deescalation practices, relationships, and trauma-informed practices in order to advance the students they serve. 
CICO data for individual students was reviewed every two weeks. This data has been deidentified to ensure that each student's confidentiality is protected. (This study was reviewed and approved by Illinois State University's Institutional Review Board as human subjects research). If the student achieved $80 \%$ of their daily points on their targeted goals or higher daily, the intervention was deemed effective and was continued with the goal of weaning from CICO. If the data showed that the intervention was not working as the student was not meeting their $80 \%$ goal, the Problem-Solving Team reconvened to determine what needed to be tweaked in order to make sure progress was taking place.

Data collection included attendance, behavioral mark charts, ODRs, and CICO data. This data was housed with a CICO coach, who was appointed by the administrator. This person was responsible for the management and implementation of CICO interventions. The CICO coach established rapport with students on CICO, teachers who were implementing within the classroom, CICO mentors for students, and family members. In addition, this coach coordinated the CICO process, oversaw the daily entries regarding CICO data, organized student data for meetings, served as the contact person, and de-identified the data for this study. Training sessions for CICO were given by the CICO coach.

On March 16, 2020, District 87 provided an Institute Day for teachers and staff to be back in the buildings to prepare for their time at home. At that point, the novel coronavirus numbers had spiked, causing concern and Governor Pritzker to close schools. The original thought was that we would be back in school once there was a decline in numbers and it was safe to come back. With this Coronavirus being new and a serious health issue, there were many unknowns regarding the prevention and the spread of this virus. Given these safety issues, educators had to think of a plan to educate and engage. Within a short period of time, our district 
went to remote instruction formats. CICO was halted at this point since it was an intervention that could not be completed. We completed the remainder of the year remotely unable to implement CICO and see it to fruition.

Data collection was set up to gather one of the tri-copied CICO card each day. Each CICO student would carry their CICO card from class to class. Teachers would fill in their progress on their individualized targets to be reviewed by the CICO mentor. The CICO mentor inputted the information on at least a weekly basis. One of the tri-copied sheets went home with the student in order to be reviewed and signed by parents. This sheet was brought back to school the next school day and given to the CICO mentor. Teachers kept one copy of the tri-copied sheets for their records to bring to problem-solving meetings for review. The goal was to have each individual student achieve $80 \%$ or more each day and to continue this for at least two weeks. No student began CICO prior to December 9, 2019, so actual data collection extended from December 19 to March 16, 2020 with a (time in days) break for the winter holidays.

Teachers were asked to complete individual student CICO cards daily for their student(s) who were enrolled in CICO and attend a brief training session. Training sessions were held once CICO began, in late fall of 2019, and continued as new students enrolled in CICO. A more extensive training, with a trainer at the district level, was offered in the first semester in regards to CICO.

CICO sheets were tracked by the CICO mentor and reported out at Problem Solving meetings. Also, teachers had access to the CICO folder so they could track their individual student's progress on a weekly basis. The CICO coach de-identified the data and shared with the principle investigator for purposes of this study. After the CICO cards were collected, the data was entered in a Google form. Problem-Solving meetings were held on a bi-weekly basis, as 
needed. At least one Problem-Solving Meeting occurred each month. Attendance data and ODR information was input by the CICO coach who then shared with the principle investigator. Again, this data was de-identified to protect the confidentiality of the students who were involved in this study.

Furthermore, another source of data were the breakout room sheets were developed and distributed to thirteen breakout rooms for staff at the last staff meeting of the year. Due to COVID-19, breakout rooms had to be utilized to get this information. The CICO coach randomly assigned teachers to those breakout rooms. Once in the sessions, the discussion centered on the supports available, followed by a ranking of the interventions listed. Staff members were reminded that if they felt uncomfortable with this activity, they could leave at any time without penalty. All thirteen breakout room sheets were completed.

Next, teachers collaborated within their grade level groups based on their chosen chapter from Help for Billy, focusing on the CICO intervention in order to better understand what further professional development was needed, add an element of reflection for teachers regarding their students and classroom instruction, and gain more information regarding trauma, relationships, and de-escalation techniques in order to achieve better academic outcomes.

\section{Fidelity}

CICO mentors and teachers were given best practices and a checklist within the beginning training regarding the steps needed to effectively implement CICO within their classrooms (see Appendix A). The plan was to do spot checks during CICO, either in the morning or at the end of the day, to review the students. However, COVID 19 emerged, shutting down schools, and the fidelity checks were not all completed. Data was not collected during baseline or maintenance periods. 
In addition, teacher data was collected within the results of the Rank Ordering Exercise. Teachers and staff were randomly put into breakout rooms and collaborated through discussion together to rank order our interventions in the order of effectiveness as they perceived. Additional data was expressed through open ended questions for further analysis and insight in the form of comments.

\section{Maintenance}

The purpose of maintenance was to decide how the student behavior was affected once the intervention was eliminated as part of their plan. Students were not able to leave intervention and move to maintenance until they had at least a two-week period of time with $80 \%$ achievement of goals. Prior to COVID 19, we did not have any students who were able to enter maintenance.

\section{Ethical Consideration}

Confidentiality of teachers who participated in the study was of utmost importance. Approval and consent were sought through the IRB process. A letter of consent was used to obtain consent to participate in the study. This letter stated that the participation in the study would be voluntary and that there would be no penalty if someone chose to skip any parts of the study, not participate, or withdraw at any time. It was also noted that any who decided to participate in this study would engage in a book study, a presentation, rank ordering of interventions activity, CICO participation, none of which were out-of-the-ordinary expectations among the teaching staff. In total, involvement in this study lasted approximately 90 days. I do not anticipate any risks beyond those that would occur in everyday life. If there were any triggers during this study, we planned to utilize the social worker and/or school psychologist to assist. To 
reduce these risks, the school social worker and school psychologist agreed to be available during the research.

One possible ethical issue concerned a supervisor enlisting participation from teachers or staff in connection with students who were struggling or not making academic or behavioral gains. Staff could have felt as though the results would impact their performance rating, since the principal is their formal evaluator. Another intention of the study was to bring forth a realization that behavior is a form of communication, and it is not a personal attack on the staff experiencing the response with the student. The ideal approach is to de-escalate the student and maintain a positive relationship between the adult and student.

Furthermore, students could also have felt as though information they shared could be held against them or that they would be thought of differently. This could be a vulnerability issue between staff and students. Thus, confidentiality between staff, students, and families was considered a priority. Families were not a part of the data collection, however, they were often invited to Problem Solving Meetings and had input with interventions that pertained to their child.

\section{Data Analysis Procedures}

Each individual CICO card was designed based on the following four expectations for citizenship within our school: being ready, respectful, responsible, and safe. Every student had either three or four goals noted on their CICO cards. There were four students who had sheets that were individualized meaning that this was an enhancement to their original CICO card to assist with data. Each students' totals were reviewed to look for any outliers or reasons for the changes during Problem-Solving Team meetings that occurred monthly. 
With CICO, the hope is to identify areas of growth for each student and also provide more positive feedback at multiple times within the school day. This feedback is critical for the student and the family to provide additional information regarding their day, what went well, and what they can improve on for the next day. These CICO cards also target different times of the day or classes when issues are arising. All of this data and information is then used to tweak goals, communicate, and provide feedback on progress. Also, another purpose of CICO is to place the student with a mentor who has a positive relationship with that child. Again, the intention is to enhance the positive connection with the classroom teacher as well. In essence, the data was tallied to determine scores.

\section{Book Study Data}

In addition, following the Help for Billy book study and presentations, all teachers were given a list of interventions and supports that have been used throughout the year. These interventions included the following: routines/expectations, positive relationships, silent signals/proximity, pre-correcting and prompting, Second Step/SEL curriculum, quiet corrections/respectful re-directions, Restorative Practices, CICO, breaks in other classrooms, positive praise, tangible rewards, peer (teacher to teacher) observations, book study (Help for Billy), trauma-informed/trauma-certified, and Intensive Family and Support Services (IFSS) through Baby Fold. Upon completion of the breakout room experience, these results were submitted and they were tallied based on the order the teachers and staff put the interventions in. In addition, following the Help for Billy book study and presentations, all teachers were given a list of interventions and supports. Within groups of three, they had to rank order the effectiveness of the supports that were listed. The groups completed this activity through a final end-of-year Zoom meeting. Following the presentations of the book study, Help for Billy, staff completed a 
Rank Ordering exercise in regards to interventions that were in place at Shandy Elementary. Qualitative data was collected from the responses based on what teachers would continue, change, or additional supports that were needed. Themes emerged from the responses and were noted.

\section{CICO Data Analysis}

Data was analyzed on a daily and weekly basis regarding the implementation of CICO for individual students. Visual analysis was noted by using graphs based on the number of points a student earned each day. Decisions focused on the extent to which the independent variable affected the primary dependent variable. For example, data was tallied and presented in charts for each student on a weekly basis and compared between the baseline and intervention phase. Data was visually analyzed for changes and trends.

Figure 2 provides an example of a CICO card. The expectations are noted on the left side

of the card. The CICO mentor went over these expectations at the beginning of the day to ensure that the student knew what was expected of him/her. Data collection began following the first 45 days of school, once Tier One interventions were in place and had a chance to be effective. Data continued to be collected until we stopped coming to in-person schooling, on March 19, 2020. Listed across the top of the card are either subjects or time frames. During these subjects or time frames, the classroom teacher filled in or circled the symbol that correlated with their behavior during that time. The teacher had a short conversation with the student while filling this out. The student then took this with him/her to their next, if taught by another teacher. It was the student's responsibility to bring this wherever they went, even lunch/recess. At the end of the day, the student checked-out with the CICO mentor who reviewed the day with the student. The goal was to reach $80 \%$ or above of the total point possible. $80 \%$ effectiveness was decided once the points 
are tallied on a sheet and the student's goal is to score at least $80 \%$ of their possible points for the day. Often, a small token or incentive, such as a piece of candy, was given to the students if they met their daily expected goal. The CICO mentor ripped off the top copy and sent it home with the student to be signed. The students were expected to talk to their parent/guardian about their day and have them sign it. This sheet was to be returned the next day. The CICO mentor entered the daily point total for the student. The next morning, the process began all over again with the students bringing back the signed sheets. Important factors to consider were: the length of CICO intervention, the student's success at $80 \%$ meeting their daily goals, and the student's attendance rate.

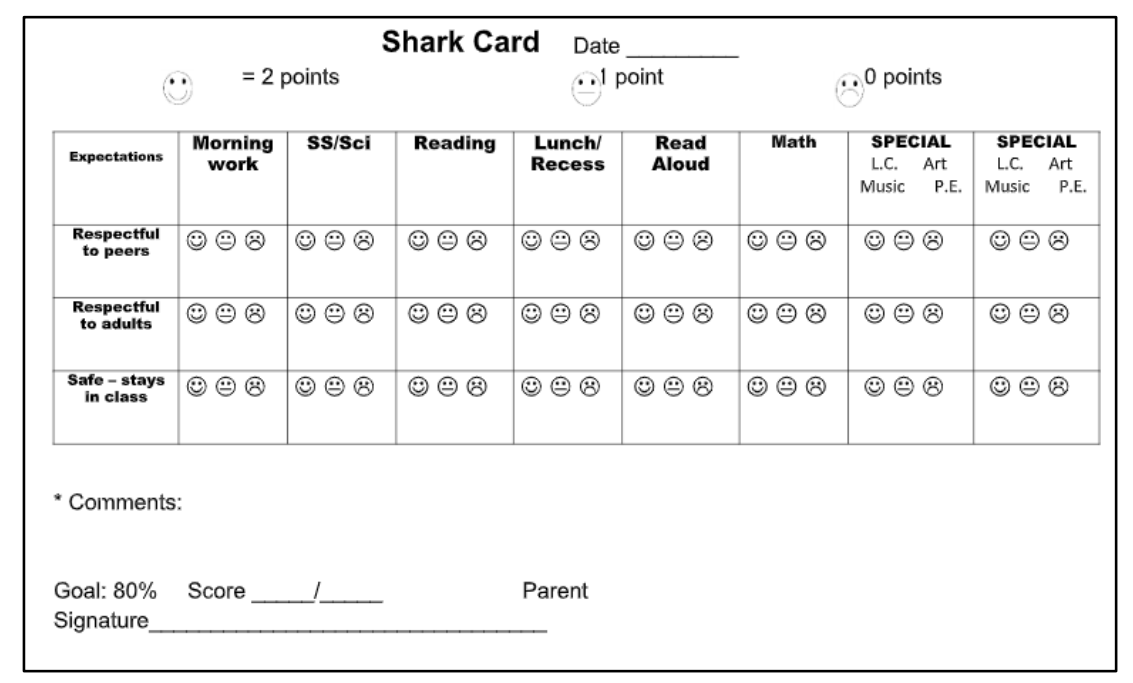

Figure 2. Sample CICO Card. This figure is an example of a card used by each student in the CICO system.

\section{Summary}

In conclusion, an understanding of both trauma itself and methods of preventing retraumatization of students is essential for all teachers, as is the development of positive relationships. This requires a shift in mindset to move away from antiquated views on student 
discipline toward a contemporary notion that students act out due to previous traumatic incidents which have re-shaped their brains. Help for Billy assisted teachers with understanding more information regarding the brain. The use of protocols, recordkeeping, observations, and cycles of inquiry culminate in gains in professional development and support for all within the school setting, yielding true results, which will be discussed in the next chapter.

With the intent to understand trauma and the impact it has on schools, particularly elementary schools, it is important to understand schools today. There is an immediate need to support staff members to use trauma-sensitive instruction. Forming relationships is just the beginning, with fostering the relationships and assisting with strategies at times of crisis to follow. Supportive relationships between all are essential. This work is challenging, and results are not usually immediate, leaving a variety of stakeholders frustrated and unsure of what to do. Teachers and staff members are extremely important in supporting their students with recovering from trauma or utilizing strategies when they are upset. However, there is research to support elementary school teachers and staff members who are uncertain regarding their roles in trauma-informed instruction and how they can help their students in a positive sense following traumatic experiences (Alisic, Bus, Dulack, Pennings, \& Splinter, 201). 


\section{CHAPTER IV: DATA ANALYSIS AND RESULTS}

\section{Introduction}

Chapter four focuses on the purpose of the study which is to consider Check In/Check Out (CICO) as a relational intervention for students impacted by trauma and explore the effectiveness of book study as professional development in support of implementing CICO. This chapter connects the findings from the data collected and the analysis of comments from staff. By utilizing a mixed methods design, which includes an analysis of the open-ended question from staff, this study allowed a Tier Two intervention, CICO, to be analyzed for success along with understanding how a book study could assist staff members with a relational approach to student behavior, including trauma. In addition to understanding $\mathrm{CICO}$ as a relational intervention, additional data points are included: length of CICO intervention, their success at $80 \%$ daily success rate, and the student's attendance rate.

\section{Participant Profiles}

Behavioral information and data were gathered for 12 students ranging in age from five to 11 years before and after the implementation of Tier 2 intervention, CICO. All of these students were recommended by their classroom teachers, principal, or the problem-solving team for additional assistance with behavior. Three students were in kindergarten, one student was in first grade, one student was in second grade, one student was in fourth grade, and six students were in fifth grade. Two of the twelve students have Individualized Education Plans (IEPs). All 12 students who were in CICO have been reportedly impacted by trauma as noted from either their classroom teacher and/or parent(s). Some of the trauma incidents that were verbalized during Problem-Solving Meetings consisted of divorce, parent/guardian in jail, Department of 
Children and Family Services (DCFS) situations, homelessness, lack of supervision on a regular basis, sibling death, and lack of food or other necessities.

\section{Student A}

The visual analysis of Student A's data revealed that on most days, this

student met the goal of at least $80 \%$ of the total possible points. Student A had a daily average of $88 \%$ which is over the $80 \%$ target for total points, deeming success, as represented in Figure 3.

Student A began the CICO intervention on February 3, 2020 and the intervention was halted on March $16^{\text {th }}$ when schools closed due to COVID-19. Student A had 0 ODRs for Quarter 1, 7 for Quarter 2, and 1 for Quarter 3. Student A missed 1 day in Quarter 1, 3 in Quarter 2, and 0 in

Quarter 3. Student A's attendance rate was 97\%. Student A had improved attendance and reduced ODRs during Quarter 3 with CICO, which indicates marked progress using the intervention.

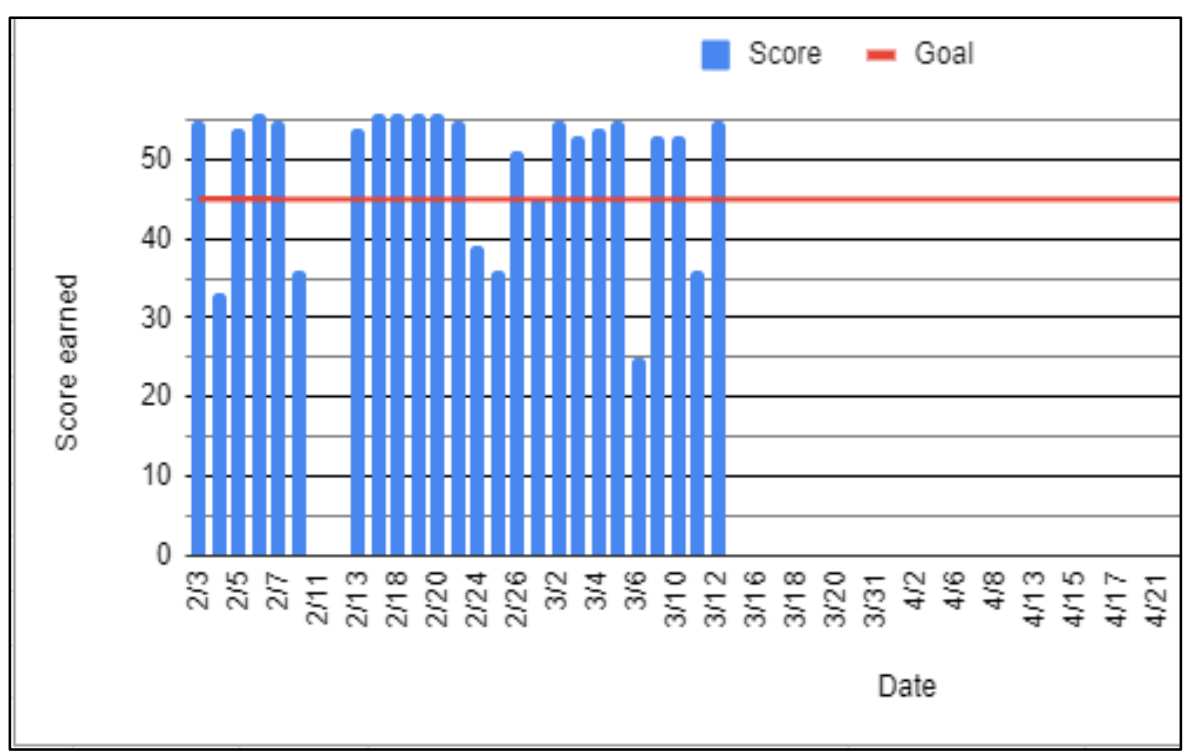

Figure 3. Student A Data. This bar graph depicts that the average daily score for Student A was $88 \%$ of the total points allowed. 


\section{Student B}

The visual analysis for Student B's data showed a 97\% average daily score for CICO overall (See Figure 4). Student B only participated in CICO for a little over a week. Student B did not begin CICO until March 4, 2020 and then school closed for COVID-19 on March 16 ${ }^{\text {th }}$ without returning to in-person learning before the end of the year. Student B had 1 ODR in Quarter 1, 0 in Quarter 2, and 1 in Quarter 3. Student B missed 1 day in Quarter 1, 4 days in Quarter 2, and 5 days in Quarter 3. Student B's overall attendance rate was 92\%. Even though there were increased absences in Quarter 3 as opposed to Quarters 1 and 2, this student's success overall in CICO was positive up to COVID19.

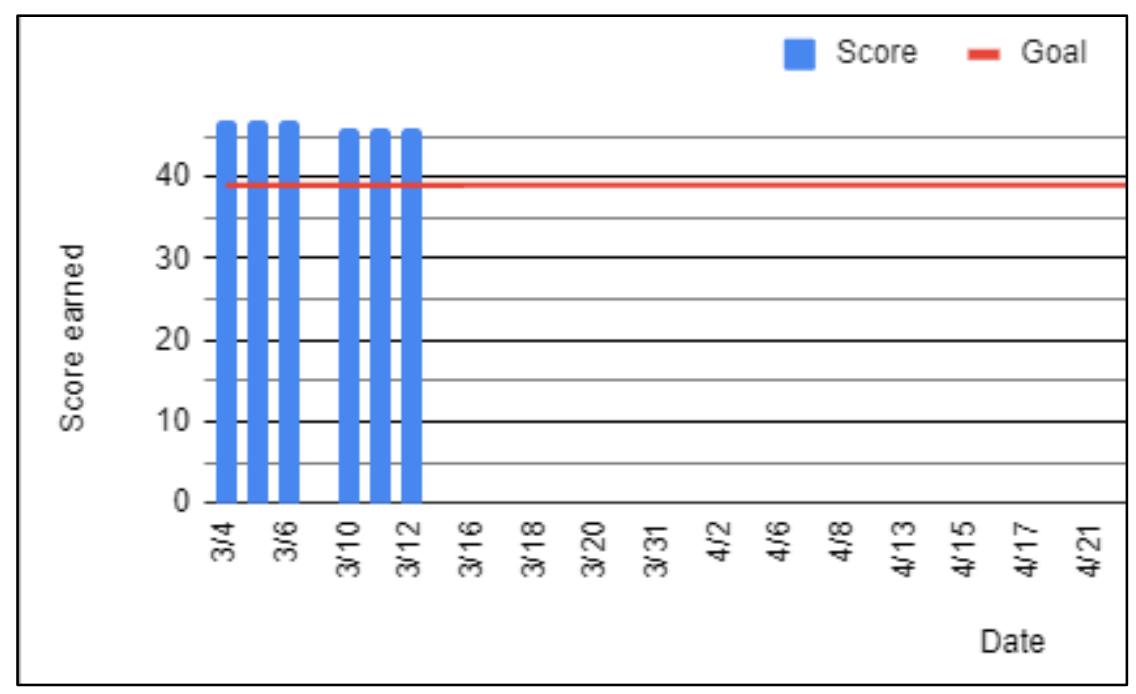

Figure 4. Student B Data. The bar graph in this figure details the average daily score for Student B at $97 \%$ of total possible points.

\section{Student C}

The visual analysis for Student C's data showed overall positive results with an exception in February where there was a decline in scores as well as in attendance. Student C's attendance 
rate was $74 \%$ for the entire year. For each quarter, this student missed at least ten school days, which was negatively impacting this student's progress in school. Although attendance continued to be an issue, the overall daily average for CICO was at a 91\%, as demonstrated in Figure 5.

Student $\mathrm{C}$ began CICO on December 16, 2020, prior to leaving for Winter Break and ended CICO on February $21^{\text {st }}$. Student C also had 12 ODRs for Quarter 2, which is very significant due to the high number of ODRs.

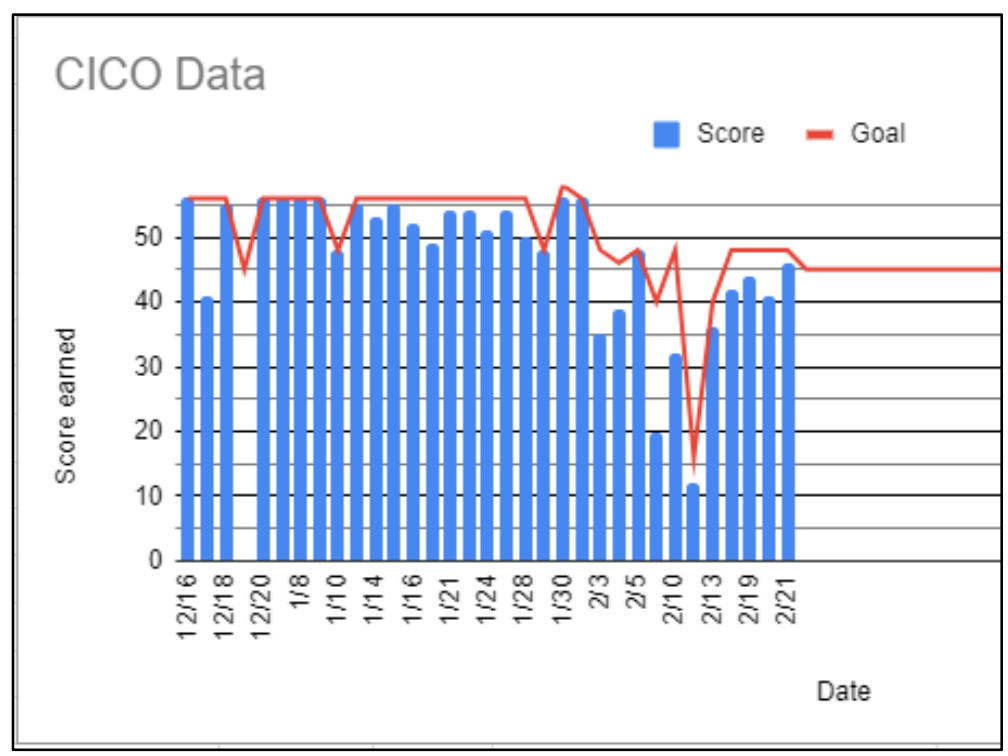

Figure 5. Student C Data. This bar graph lays out the daily scores earned by Student $C$ with an average of $91 \%$ of total points available.

\section{Student D}

The visual analysis for Student D's data showed that CICO was a positive experience for the student with an average score of $84 \%$ of total possible points. Student D's attendance rate landed at $87 \%$ for the year. Student D missed the most academic days during Quarter 2 and had only one office referral. Student D had only a $66.7 \%$ attendance rate during Quarter 2. Student D had 2 ODRs for Quarter 1 and 1 ODR for Quarter 2; however, there were no ODR's written for Student D in Quarter 3. Figure 6 reveals a drop in scores in early to mid-February and then a 
rebound. The assumption is that attendance issues could have contributed to the decrease in student success during this time. Inconsistent attendance often does not result in proper performance and can cause teachers to have to review expectations and guidelines to bring absent students back on track.

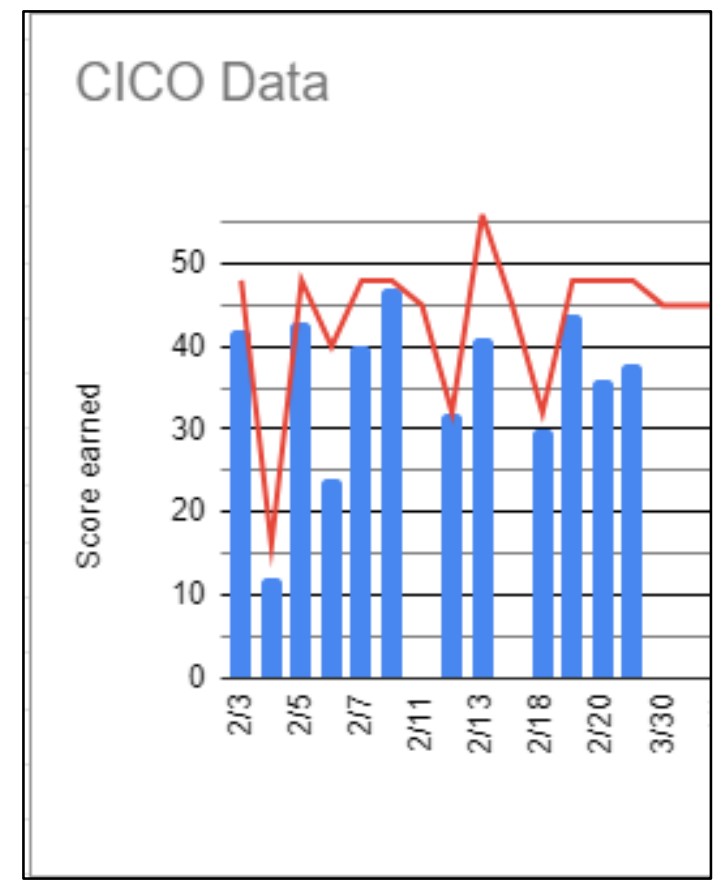

Figure 6. Student D Data. The bar graph in this figure displays the scores earned by Student D with the resulting average daily score of $84 \%$ out of the total possible points.

\section{Student E}

The visual data for Student E was not consistent, as displayed in Figure 7. Student E began CICO on January 28, 2020 with no other data collected after February $10^{\text {th }}$. Student E's average score was $56 \%$ of the total points allowable. With a goal of $80 \%$, these results were significantly below the expectations. The data was inconsistent, and sheets were not filled out or returned on a regular basis. Student $\mathrm{E}$ had an attendance rate of $98 \%$ so that did not inhibit the performance on CICO. The CICO Coach and Principal Investigator had discussions with the 
classroom teacher regarding regular data collection. Student $\mathrm{E}$ also had an increase in ODRs in Quarter 3 as compared to Quarter 1 and 2.

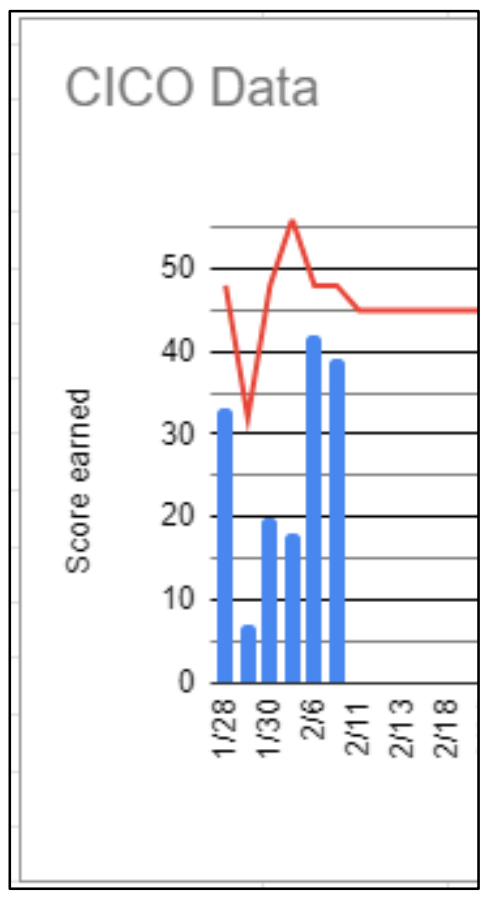

Figure 7. Student E Data. This bar graph shows the short time frame of data collection and inconsistency of scores for student $\mathrm{E}$.

\section{Student F}

Outstanding results for Student F can be seen in the visual analysis provided in Figure 8, with the average score landing at 100\% of possible points. Despite the fact that student F began CICO in late January following classroom struggles and parental concern regarding behavior, Student F had a good attendance rate at $97 \%$. Student F did have 2 ODRs in Quarter 2 which also was a factor leading to CICO. However, Student F did not receive any ODRs in Quarter 3 prior to leaving due to COVID 19. 


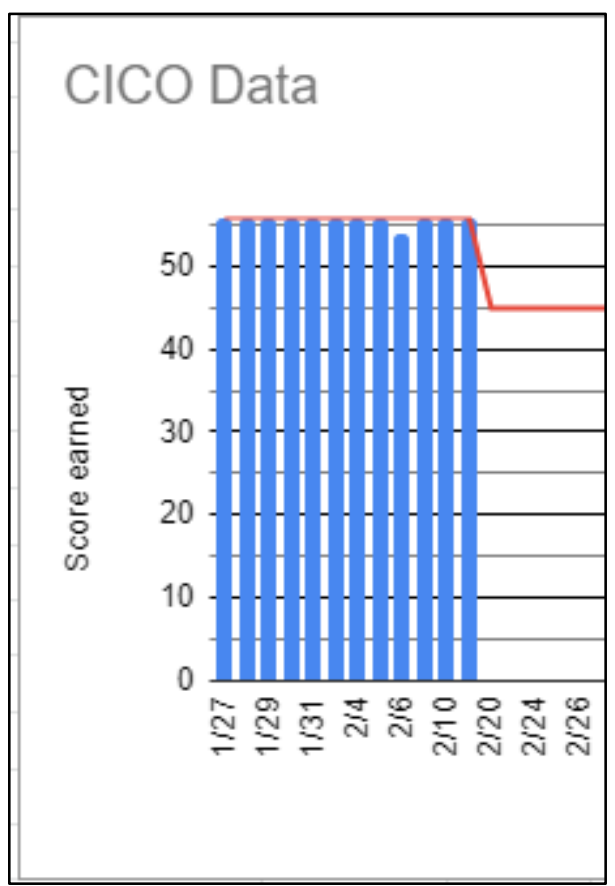

Figure 8. Student F Data. This figure includes a bar graph highlighting the scores earned by Student F, with an overall average of $100 \%$ of total points.

\section{Student G}

The visual analysis for Student G, seen in Figure 9, revealed that CICO was not extremely effective for this student. Student G's average score was a $56 \%$ of total points, deeming the intervention not successful. Also, Student $\mathrm{G}$ had an attendance rate of $81 \%$ due to several absences. Student G began CICO with a standard sheet. Following a Problem-Solving Meeting, Student G's sheet was then individualized. Shortly after modifying the card, increased time with the CICO mentor was assigned to Student G, which offered two additional check-in times each day. Student G seemed to struggle most with transitions, which prompted these two supplementary daily check-ins. Student G continued to struggle with CICO; however, due to COVID-19, no further changes were able to be made. A Problem-Solving meeting was set to occur once we returned from Spring Break. There were other extenuating circumstances that 
were also prompting more individualized supports, including a Functional Behavioral Analysis (FBA).

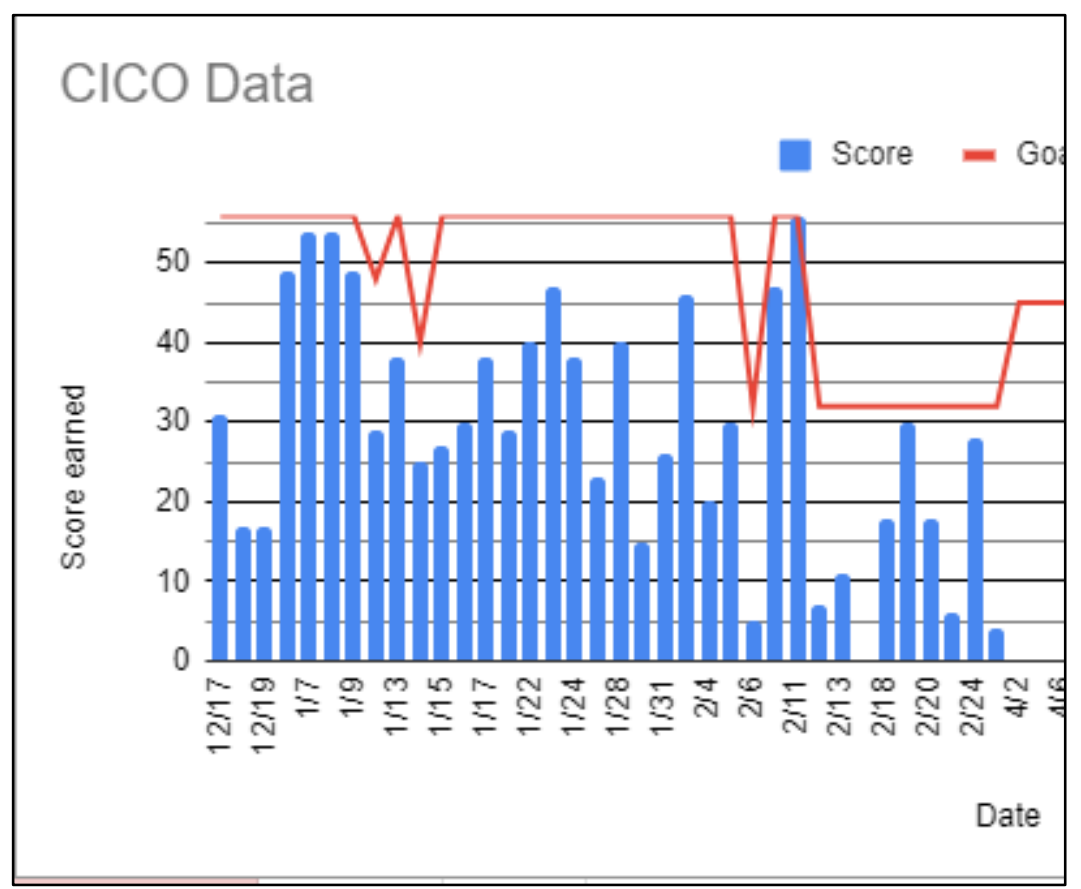

Figure 9. Student G Data. The above bar graph displays the point totals for Student G with an average daily score of $59 \%$ of the total points available.

\section{Student H}

As detailed in Figure 10, visual analysis for Student $\mathrm{H}$ showed that the average score for CICO was $77 \%$ of possible points. Student $\mathrm{H}$ had an attendance rate of $88.5 \%$, which accounts for some of the struggles with CICO. Student H had several "good days" according to the data; however, when the CICO data dropped, the points significantly decreased on particular days. Also, Student H received 3 ODRs in Quarter 1, 11 ODRs in Quarter 2, and 5 ODRs in Quarter 3. Notable behavioral issues occurred during Student H's time on CICO. In the spirit of predicting next moves based off of COVID-19, moving to a more intensive intervention would be in order for Student H. 


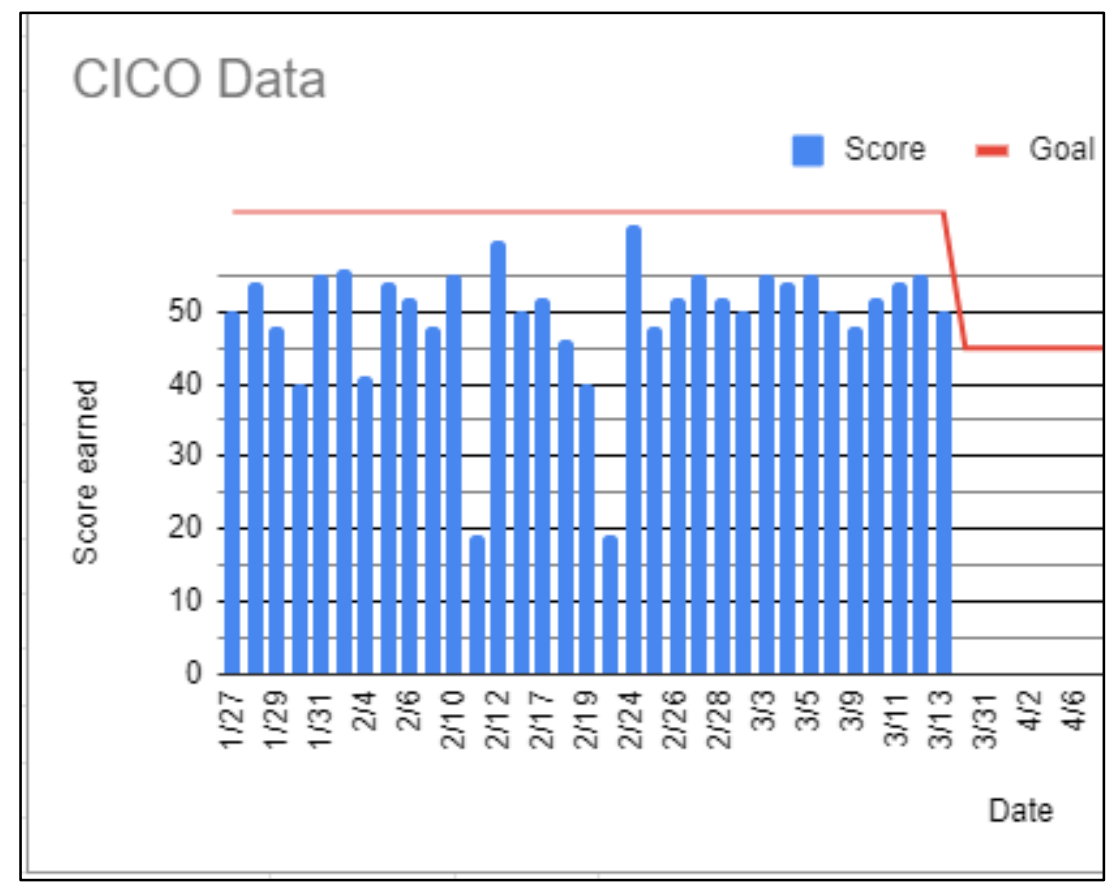

Figure 10. Student H Data. This figure is a bar graph representing the CICO scores for Student $\mathrm{H}$ whose average was a $77 \%$ of total points offered.

\section{Student I}

Student I began CICO on January 10, 2020 following winter break. Student I had an average score of $87 \%$ of total CICO points (See Figure 11). Student I's attendance was 98.4\%, a strong attendance rate for students at Shandy. Student I had 2 ODRs in Quarter 1, 0 for Quarter 2, and 7 for Quarter 3. Quarter 3 proved to be a challenging time for Student I behaviorally based these referrals. Student I would have been expected to fade out of CICO if the scores continued to remain at this level and ODRs declined once we had returned from Spring Break.

Unfortunately, due to COVID-19, this was not a possibility. 


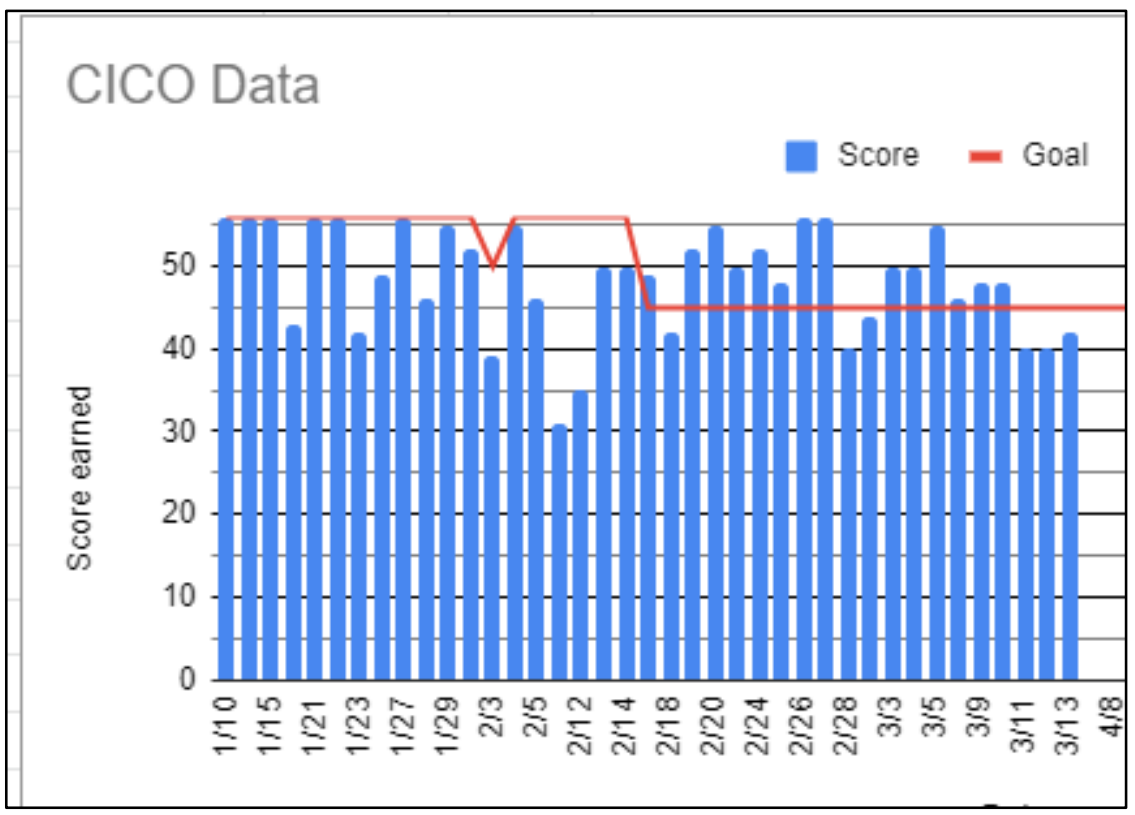

Figure 11. Student I Data. The bar graph in this figure outlines the scores obtained by Student I, which resulted in an average of $87 \%$ of the possible points.

\section{Student J}

Student J began CICO on December 9, 2020. Based on the points shown in Figure 12, the average daily score on CICO for Student J was $81 \%$. Student J's attendance rate was $89.3 \%$.

Student $\mathbf{J}$ missed 14 days throughout the year, with the majority of absences occurring in Quarter 1 and Quarter 2. Quarter 2 and 3 proved to be when Student J had the most ODRs, with 3 and 2 respectively. Student J was not on a regular card as it had been individualized following a meeting with parental support to encourage student behavior to improve. 


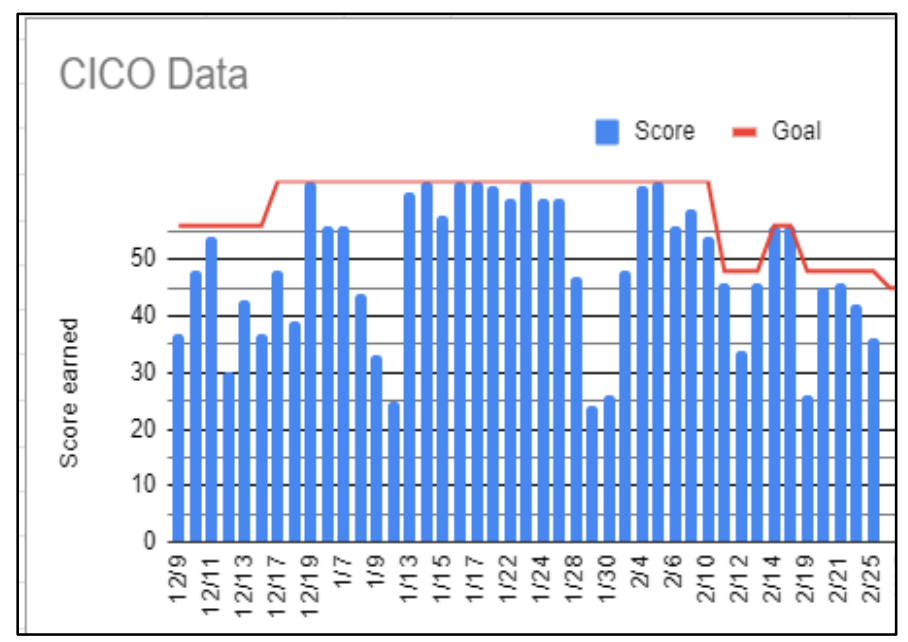

Figure 12. Student J Data. The scores earned on the individualized CICO cards for Student J are shown in this bar graph, with the average daily score calculating at $81 \%$ of total points allowed.

\section{Student K}

Student K's CICO sheets resulted in an average daily rate of $80 \%$ of total points, just barely meeting the standard goal. Student K's data showed some variance as points landed in the acceptable range on the student's good days (See Figure 13). However, when Student K struggled, the entire day was affected instead of only individual time periods. Student K also had an attendance rate of 92.3\%. Student K had 12 ODRs in Quarter 2, the main factor that prompted participation in CICO. Consequently, Quarter 3 ended with 9 ODRs for Student K. This child's card was also individualized following a parent meeting to increase daily scores. 


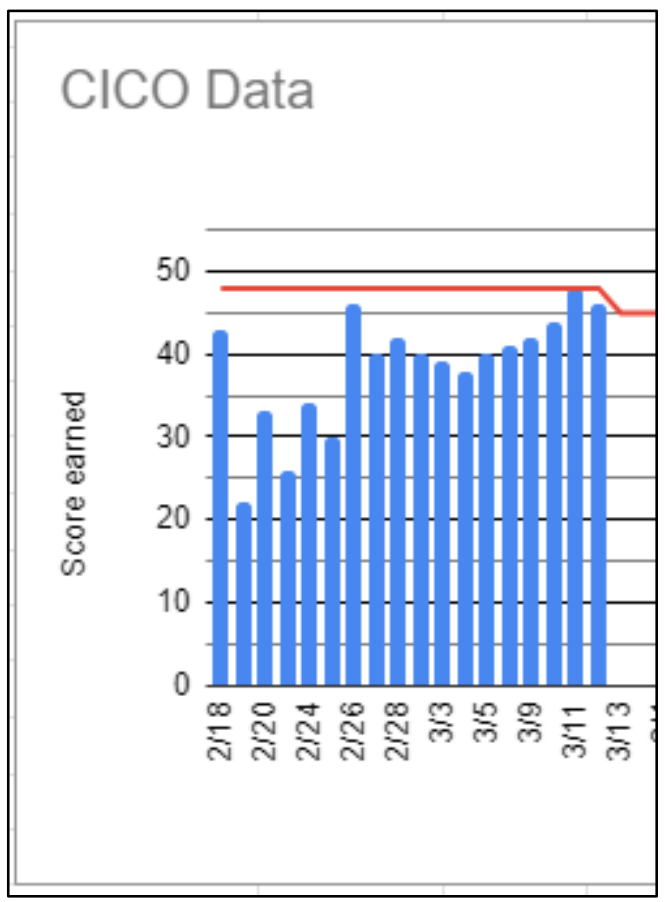

Figure 13. Student K Data. This bar graph includes the scores from CICO for Student K and an average of $80 \%$ of the allowable points.

\section{Student L}

Student L started CICO on January 8, 2020 following Winter Break. Overall, Student L’s daily average for CICO was $81 \%$ of possible points. Student L had above average attendance with a rate of 97.7\%. Student L received 5 ODRs in Quarter 2 and 7 ODRs in Quarter 3. The next step for Student L was to individualize CICO due to that increased number of ODRs.

Student L met the expected percentage of points by reaching $81 \%$. This child experienced a turbulent time during mid-January when some modification in the programming had to occur. Also, increased communication with parents prompted check-ins at home, which enhanced the effectiveness of CICO. As shown in Figure 14, CICO scores increased overall during February and March, until the COVID-19 shutdown. 


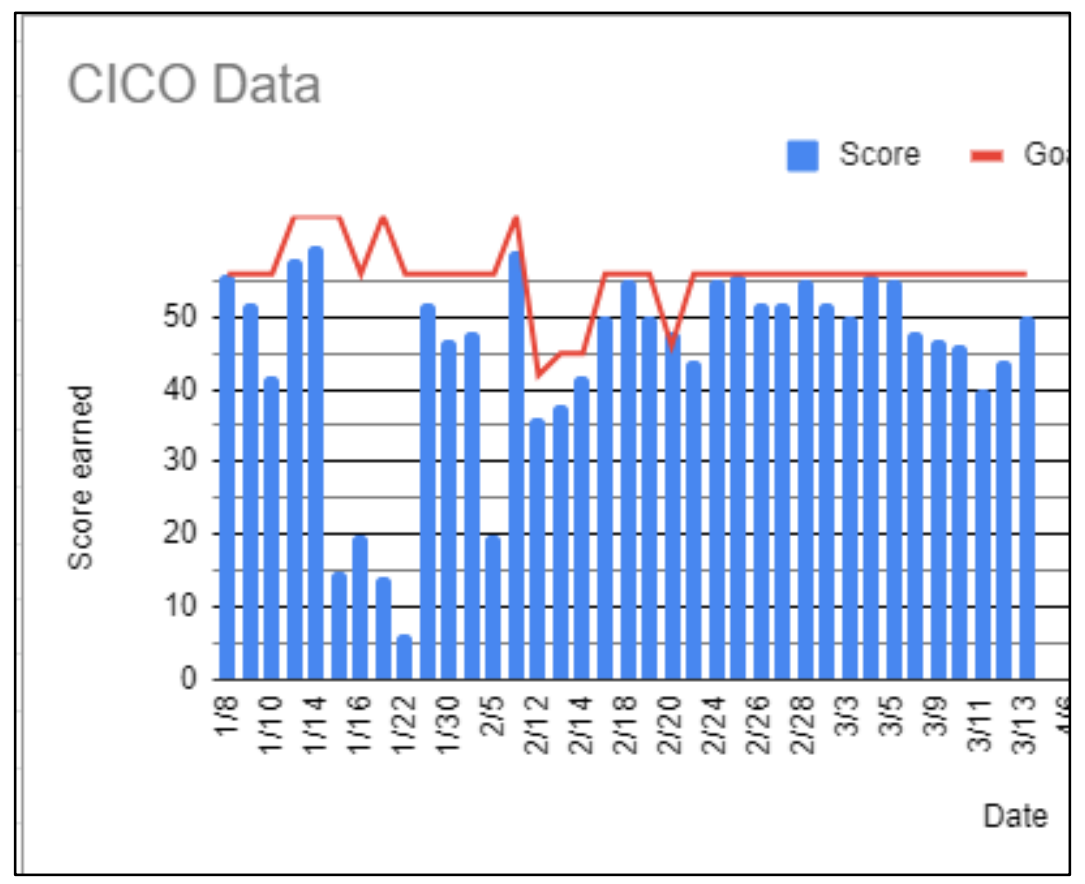

Figure 14. Student L Data. This figure's graph exhibits the CICO scores for Student L, who ended up with an overall average of $81 \%$ of the total points.

In order to promote understanding in regards to this study, it is important to connect the findings from the data collected and the analysis of comments from staff. By utilizing a mixed methods design, which includes an analysis of the open-ended questions from staff, this study allowed a Tier Two intervention, CICO, to be analyzed for success along with understanding how a book study could assist staff members with a relational approach to student behavior, including trauma and is noted in the answers to the research questions.

\section{Research Question 1}

To what extent did the implementation of one trauma-influenced practice, Check In/Check Out (CICO), help change behaviors within the classroom setting at Shandy Elementary School?

Data collected was based on the daily results of each individual student's CICO cards along with information regarding the length of the student in CICO, the number of days the 
student achieved the $80 \%$ targeted goal on their CICO card and their overall attendance rate (see Table1). Nine out of twelve students, or $75 \%$ of students completing CICO, met the daily goal of an average of $80 \%$ or more of the total points available. Only two students fell below $60 \%$ during CICO intervention. The remaining student $\mathrm{H}$ was at a $77 \%$ for the number of days they achieved $80 \%$ or better on their CICO card. Coupled with professional development with a book study regarding trauma during the same time as the implementation of interventions, the goal was for teachers and staff to focus on relationships and understanding students who were struggling behaviorally all while gaining an understanding of the functions behind student behaviors to positive impact the classroom environment. As reflected in Student A participated in CICO for 25 days with $88 \%$ accuracy and a $97 \%$ overall attendance rate. Student B was in CICO for 6 days, achieved $80 \%$ accuracy 97\% of the time, and had an overall attendance rate of 92\%. Student C was in CICO for 32 days, obtaining $91 \%$ of the days at $80 \%$ or above, and had an attendance rate of $74 \%$. Student D was in CICO for 12 days, having $84 \%$ of the days at $80 \%$ or above, and had an attendance rate of $87 \%$. Student $\mathrm{E}$ had an average daily score of $56 \%$; however, this student only participated in CICO for six days. Student F was in CICO for 12 days, achieving $100 \%$ in regards to meeting the $80 \%$ standard, and had an overall attendance rate of $97 \%$. Student G had an average daily score of 59\%, was in CICO for 35 days and had an attendance rate of $81 \%$, yet this student was on CICO for a longer period of time and the data is prompting that something needed to be changed or adjusted. It is noted that CICO was adjusted for this student to incorporate additional check-ins during the day. Student H was in CICO for 33 days, had $77 \%$ of the days achieving $80 \%$ on CICO cards or better, and had an attendance rate of $88.5 \%$. Student I was in CICO for 39 days, had $87 \%$ of the days at $80 \%$ or higher on their CICO card, and had a $98.4 \%$ overall attendance rate. Student $\mathrm{J}$ was in CICO for 43 days, had $81 \%$ of 
their days at $80 \%$ or above, and had an overall attendance rate of $89.3 \%$. Student K was in CICO for 18 days, had $80 \%$ of the days at an $80 \%$ or higher on the CICO card, and had an attendance rate of $92.3 \%$. Student L was in CICO for 37 days, had $81 \%$ of the days in CICO at $80 \%$ or higher, and had an attendance rate of $92.3 \%$. Student L was in CICO for 37 days, had $81 \%$ of the days at $80 \%$ or higher on their CICO card, and had an overall attendance rate of $97.7 \%$. What is not included in this data are the number of traumatic events that occurred during these students' participation in CICO. Trauma related to custody issues, divorces, issues with siblings, loss of a parent, and moving was experienced by some of these students during the course of this study and were reported out by either a staff member on the team or a parent. Despite the recurrence of trauma among the students, moderate success still happened with this intervention.

The goal for CICO for individual students was to obtain an $80 \%$ of the daily overall points that were available. This was measured by totaling the student's CICO card each day and obtaining an average based on the number of days the student was in CICO. Our Problem Solving Team determined that when $80 \%$ of the points are earned, behavior in the classroom was overall in check with the standards of conduct that are expected from all students. Overall, nine out of the twelve students (75\%) met the $80 \%$ daily standard. Three students had scores of $56 \%$, $59 \%$, and $77 \%$. For these students, the substitute teacher did not fill out the CICO cards on a daily basis. Without regular reflection on the CICO card, this proved to be a possible issue for reaching the $80 \%$ goal. The need to assist substitutes with this process is imperative as it did negatively affect the results of the study as noted with the three individuals above due to their data not being accurate. More training and regular review for staff members in general could alleviate these issues in the future. 
Attendance results were eye-opening for the students on CICO. Student C had the lowest attendance rate at $74 \%$; however, that child had an average of $91 \%$ of total points for CICO. One thought when reviewing the data is that since this student's attendance rate was low, the CICO average would also be below the target. This was not a correct assumption. Student $\mathrm{E}$ had a relatively high attendance rate of $98 \%$, yet the average CICO score for this student was $56 \%$, which did not indicate success. Two students, $\mathrm{K}$ and L, both had CICO averages that were $80 \%$ and $81 \%$ respectively and had attendance rates that were $92.3 \%$ and $97 \%$. Another hypothesis was that if there was a high attendance rate then the CICO average would also be significantly above $80 \%$. Attendance definitely plays a role, however, additional factors proved to be powerful in this decision of effectiveness.

Only two students fell below 60\% during CICO intervention. Student E had an average daily score of 56\%; however, this student only participated in CICO for six days. Student G had an average daily score of $59 \%$, yet this student was on CICO for a longer period of time and the data is prompting that something needed to be changed or adjusted. It is noted that CICO was adjusted for this student to incorporate additional check-ins during the day. What is not included in this data are the number of traumatic events that occurred during these students' participation in CICO whether reportedly from home or school. Trauma related to custody issues, divorce, issues with siblings, loss of a parent, and moving was experienced by some of these students, as revealed during Problem-Solving Team meetings, during the course of this study. Despite the recurrence of trauma among the students, moderate success still happened with this intervention in recognition of developing goals, established routine of $\mathrm{CICO}$, and an additional caring adult. 


\section{Table 1}

Correlation Data

\begin{tabular}{|c|c|c|c|}
\hline Student & $\begin{array}{l}\text { Length } \\
\text { of CICO } \\
\text { in days }\end{array}$ & $\begin{array}{l}\text { Percentage of days } \\
\text { student achieved at least } \\
80 \% \text { of CICO points }\end{array}$ & $\begin{array}{l}\text { Overall } \\
\text { Attendance } \\
\text { Rate from } \\
\text { 2019-2020 }\end{array}$ \\
\hline $\mathrm{A}$ & 25 & $88 \%$ & $97 \%$ \\
\hline B & 6 & $97 \%$ & $92 \%$ \\
\hline $\mathrm{C}$ & 32 & $91 \%$ & $74 \%$ \\
\hline D & 12 & $84 \%$ & $87 \%$ \\
\hline$E$ & 6 & $56 \%$ & $98 \%$ \\
\hline $\mathrm{F}$ & 12 & $100 \%$ & $97 \%$ \\
\hline G & 35 & $56 \%$ & $81 \%$ \\
\hline $\mathrm{H}$ & 33 & $77 \%$ & $88.5 \%$ \\
\hline I & 39 & $87 \%$ & $98.4 \%$ \\
\hline $\mathrm{J}$ & 43 & $81 \%$ & $89.3 \%$ \\
\hline $\mathrm{K}$ & 18 & $80 \%$ & $92.3 \%$ \\
\hline $\mathrm{L}$ & 37 & $81 \%$ & $97.7 \%$ \\
\hline
\end{tabular}

Note. Table 1 shows the student, the length of being in CICO, the percentage of days the student was able to make $80 \%$ or more of the total points on CICO, the students' overall attendance rate.

\section{Attendance Data}

Attendance results were eye-opening for the students on CICO. In my professional experience, good student attendance rates would be considered $95 \%$ or higher. These attendance rates are daily attendance rates that are housed in our data infrastructure. Student $\mathrm{C}$ had the lowest attendance rate at $74 \%$; however, that child had an average of $91 \%$ of total points for 
CICO. One thought when reviewing the data is that since this student's attendance rate was low, the CICO average would also be below the target because the student would not be in school for the relational intervention. Table 1 shows data in regards to: student involved in CICO, the length of time the student was in CICO, the number of days the student achieved at least $80 \%$ of the CICO points possible, the student's attendance rate. Student E had a relatively high attendance rate of $98 \%$, yet the average CICO score for this student was $56 \%$, which did not indicate success. Two students, $\mathrm{K}$ and L, both had CICO averages that were $80 \%$ and $81 \%$ respectively and had attendance rates that were $92.3 \%$ and $97 \%$. Student A and F both had attendance rates of $97 \%$ and their CICO achievements were $88 \%$ and $97 \%$, which was successful. Students B and I had good attendance rates of $92 \%$ and $98.4 \%$ respectfully and their CICO scores were $97 \%$ and $87 \%$, both being above the $80 \%$ mark. Students D, G, H, and J all had attendance rates that were lower $(87 \%, 81 \%, 88.5 \%$, and $89.3 \%)$ with only two students, D and $\mathrm{J}$ having success with achieving $80 \%$ on their CICO cards. Student D had an $84 \%$ and student $\mathrm{J}$ had $81 \%$. Student $\mathrm{G}$ only had a $56 \%$ and Student $\mathrm{H}$ had a $77 \%$, both considered unsuccessful in regards to achieving $80 \%$ or more of the daily points possible. Out of the twelve involved students, only five students or $61.5 \%$ of the students involved had successful attendance rates of $95 \%$ or higher. Student A was successful in CICO and had a high attendance rate. Student E, 56\% for CICO, was not considered successful with CICO yet had a high attendance rate. Student G was not successful with CICO with a $56 \%$, had a low attendance rate of $81 \%$. Student $\mathrm{H}$ was not successful in CICO with $77 \%$, had a lower attendance rate of $88.5 \%$. In the end, attendance is a factor as regular and consistent attendance should yield more success. Given that CICO is a tool for regular check-in with goals and continuing relationships, the stability of the relationship is going to matter. Student E was negatively was negatively impacted 
by the loss of data given the substitute was not filling out the sheets on a regular and consistent basis. Given all of the stressors of taking over a classroom, CICO was probably the last thing on this substitute's mind. However, this staff absence did affect the students from this particular class. Ultimately, the intervention had to stop due to this issue along with the fidelity of keeping track of the behavior within these CICO sheets.

\section{Research Question 2}

In what ways did the addition of a trauma-influenced book study on brain-based research with trauma at the center, including interventions like CICO, inform teachers and staff to alter their professional practice to achieve better student behavioral outcomes at Shandy Elementary School? The hope was that the book study would assist teachers and staff to understand that relationships are at the center of education, no matter who the student is to achieve better behaviorally which could then lend itself to achieving more academic success. The relationship then connects CICO to build upon what already exists in order to support the student. Together, teams of teachers read and reviewed chapters of Help for Billy, our book study, and later participated in sharing these chapters with the staff in their own way. The intended goal was to better understand trauma, utilize a growth mindset when learning about students who have experienced trauma, and provide support within grade levels to make better academic and behavioral gains. As noted by Evers (2012) trauma-informed practices involve the use of understanding, relationships, and care regarding trauma by educators to make modifications that will support the student's development within the classroom and school. It is imperative that staff members recognize and understand trauma to avoid triggering a response based on the students' traumatic experiences. Consequently, with COVID 19, the book study was completed but students were no longer in their physical classroom space and unable to continue CICO on a 
daily basis. Within these groups, teachers responded to how the book study would assist with their professional practice within their classroom. Teachers commented on what they would continue and what they would change once they were back in their classrooms.

\section{Table 2}

Rank Ordering Exercise Comments

\begin{tabular}{|c|c|c|}
\hline Continue & Change & Supports Needed \\
\hline $\begin{array}{l}\text { Empathy and consistency } \\
\text { w/the Billy’s }\end{array}$ & $\begin{array}{l}\text { Change response to Billy's. } \\
\text { Sometimes response is } \\
\text { sarcastic or harsh. }\end{array}$ & $\begin{array}{l}\text { All staff should be trained in } \\
\text { CPI }\end{array}$ \\
\hline Remain calm & $\begin{array}{l}\text { Utilize more staff to handle } \\
\text { problems }\end{array}$ & \\
\hline SEL curriculum & $\begin{array}{l}\text { Utilize book study } \\
\text { approaches (mindset, } \\
\text { questioning, understanding } \\
\text { brain) in a more proactive } \\
\text { way. }\end{array}$ & $\begin{array}{l}\text { Needs more updated SEL } \\
\text { curriculum }\end{array}$ \\
\hline $\begin{array}{l}\text { Help for Billy provided } \\
\text { reminders about trauma } \\
\text { informed learning that we } \\
\text { have had experience with. }\end{array}$ & $\begin{array}{l}\text { Asking more supportive } \\
\text { questions }\end{array}$ & $\begin{array}{l}\text { Problem Solving Meetings at } \\
\text { the beginning of the year } \\
\text { (immediately following after } \\
\text { the release of the MTSS } \\
\text { guidebook) }\end{array}$ \\
\hline $\begin{array}{l}\text { Keep in mind the sources of } \\
\text { behavior and the need to } \\
\text { maintain compassion and } \\
\text { understanding when behavior } \\
\text { is an issue (sometimes we are } \\
\text { good at this). }\end{array}$ & $\begin{array}{l}\text { Make changes beneficial to } \\
\text { all }\end{array}$ & $\begin{array}{l}\text { Explicit lessons on how to } \\
\text { teach students how to } \\
\text { regulate themselves-newer, } \\
\text { updated, brain based SEL } \\
\text { curriculum }\end{array}$ \\
\hline $\begin{array}{l}\text { Have frame of mind: How } \\
\text { can I help? How can I teach } \\
\text { Billy the skills he needs to } \\
\text { regulate so that later, he will } \\
\text { have the skills he needs to be } \\
\text { ready to learn. }\end{array}$ & $\begin{array}{l}\text { IFSS, Trauma Certification, } \\
\text { book study, and peer to peer } \\
\text { observations would be ranked } \\
\text { higher but these seem to be } \\
\text { something we would do once } \\
\text { everything else had been } \\
\text { tried. }\end{array}$ & $\begin{array}{l}\text { SEL curriculum is needed } \\
\text { w/in the district. We need to } \\
\text { work on teaching social skills } \\
\text { in the natural environment. } \\
\text { Start the day in each } \\
\text { classroom w/morning } \\
\text { meeting and message from } \\
\text { principal. }\end{array}$ \\
\hline
\end{tabular}

Table Continues 


\begin{tabular}{|c|c|c|}
\hline $\begin{array}{l}\text { Help for Billy was a way to } \\
\text { review all we have learned } \\
\text { regarding trauma and brain } \\
\text { research. }\end{array}$ & $\begin{array}{l}\text { Keep in mind the sources of } \\
\text { behavior and the need to } \\
\text { continue to maintain } \\
\text { compassion and } \\
\text { understanding when behavior } \\
\text { is an issue (need to improve). }\end{array}$ & $\begin{array}{l}\text { People! It's so extremely } \\
\text { difficult to give children the } \\
\text { supports and time they need if } \\
\text { we are teaching; it's hard to } \\
\text { stop teaching to give children } \\
\text { the time they need to help } \\
\text { them process through } \\
\text { situations and their feelings. }\end{array}$ \\
\hline $\begin{array}{l}\text { We don't feel that the Book } \\
\text { Study, Trauma Informed is } \\
\text { least effective, however, all } \\
\text { the above items should be } \\
\text { attempted prior to these. }\end{array}$ & $\begin{array}{l}\text { Not to be afraid to meet Billy } \\
\text { where he is vs. demand that } \\
\text { he meet my expectations right } \\
\text { away. }\end{array}$ & New SEL curriculum \\
\hline Positive relationships & $\begin{array}{l}\text { Understand the sources of } \\
\text { behavior and we need to } \\
\text { continue to have empathy and } \\
\text { compassion and } \\
\text { understanding regarding } \\
\text { behavior. }\end{array}$ & $\begin{array}{l}\text { Supports with students that } \\
\text { are experiencing trauma and } \\
\text { showing it by screaming and } \\
\text { crying which then becomes } \\
\text { trauma for all. }\end{array}$ \\
\hline $\begin{array}{l}\text { Routines, expectations, } \\
\text { positive relationships, and } \\
\text { SEL. } \\
\text { Book study was a great } \\
\text { reminder-one I will go back } \\
\text { to. }\end{array}$ & $\begin{array}{l}\text { Brain research has helped me } \\
\text { to understand that the } \\
\text { behavior isn't about me...this } \\
\text { is a behavior possibly due to } \\
\text { trauma. }\end{array}$ & $\begin{array}{l}\text { More support in } 4^{\text {th }} \text { and } 5^{\text {th }} \\
\text { grade }\end{array}$ \\
\hline $\begin{array}{l}\text { More intensive strategies that } \\
\text { are rated lower-not because } \\
\text { they are ineffective but } \\
\text { because we usually try } \\
\text { everything prior to these. }\end{array}$ & $\begin{array}{l}\text { Some staff plans to start } \\
\text { having classroom pets in } \\
2020 \text {. }\end{array}$ & $\begin{array}{l}\text { Faster response time with } \\
\text { Problem Solving Meetings. }\end{array}$ \\
\hline SEL practices, relationships & $\begin{array}{l}\text { Review IEP philosophy (from } \\
\text { the classroom teacher's } \\
\text { perspective) }\end{array}$ & $\begin{array}{l}\text { Completion of the Tier I } \\
\text { philosophy/implementation } \\
\text { (district-wide) }\end{array}$ \\
\hline $\begin{array}{l}\text { Little if no homework-book } \\
\text { study was a good reminder }\end{array}$ & & \\
\hline
\end{tabular}

Table Continues 


\begin{tabular}{|l|l|l|}
\hline $\begin{array}{l}\text { Book Study was a good } \\
\text { reminder. }\end{array}$ & & \\
\hline $\begin{array}{l}\text { Keeping in mind the } \\
\text { sources/causes of behavior, } \\
\text { maintaining compassion and } \\
\text { understanding }\end{array}$ & & \\
\hline
\end{tabular}

Note: Table 2 shows comments from staff in regards to what they would like to continue to do within their classrooms/school/district, what they would like to change, and any additional supports that they believed they needed in order to determine success.

\section{Themes from Open-Ended Questions}

Some emergent Themes from Rank Ordering Exercise open-ended questions are: five comments focused around empathy/calm/compassion and understanding for the Billy's, four comments focused on the SEL curriculum and positive relationships, four comments were focused on trauma and the book study being a good reminder, three comments were focused on the rank ordering exercise and how interventions would have been rated higher or the same and, if the interventions were ranked lower, it was not because they were ineffective, but teachers and staff try everything else prior to moving to these later ranked interventions (See Table 2).

Some examples that are mentioned in the open-ended questions as far as what staff would like to change are: one comment reflected to change response to students who struggle behaviorally in regards to sarcasm or harshness, six comments reflected with utilizing the book study approaches in a more proactive way including: asking more supportive questions, keeping in mind sources of behavior, not being afraid to meet students where they are vs. demanding that he meet the expectations right away, and understanding that behavior is "Not about me" and taking it personally, understanding that it could be due to trauma, the utilization of more staff along with tweaking incentive or having classroom pets, and reviewing the IEP philosophy in 
regards to the teacher's perspective. The book study assisted staff with a learning experience to make connections to what they experience each day.

The emergent themes in regards to what supports are currently needed did not reflect the hypothesis for question two in regards to the relationship of the adult and the student, yet the results showed: four comments in regards to a new or better SEL curriculum, two comments about having additional supports in regards to people, and two comments in regards to additional supports for students who are experiencing issues and thus creating issues for the whole class as well as three additional comments about procedural aspects within MTSS.

\section{Continue}

Within the open-ended comments, utilizing empathy and consistence was noted. Teachers and staff wrote, "Remain calm, keep in mind the sources of behavior with compassion and understanding, and positive relationships should continue.” As expected, using Social Emotional Learning standards and curriculum was also noted as something that needed to continue. Others also noted that the book study provided good reminders about trauma-informed learning that could be utilized within classrooms.

\section{Change}

In connection with what could be changed at Shandy to be impactful, structural changes were noted. The assumption is that there was a recommendation that we change our meeting schedule to meet on students within the first 45 days of school instead of waiting until the Tier One supports have been in place long enough to ensure fidelity of implementation. Another recommendation consisted of teachers feeling that they need more understanding in regards to Individualized Education Plans (IEP's). The comment, "Review IEP philosophy (from the classroom teacher's perspective" is important to make sure that teachers feel supported with 
understanding the IEP and how they can help. This, too, could be part of a structural change to ensure more professional development for teachers to understand IEP's to better serve their students. Also, another comment was noted about remembering that behavior is a form of communication. Staff also wrote, "Change response to students who struggle with behavior." Immediately, frustration comes to mind especially when the behaviors are frequently happening and teachers really want to teach, not correct or deal with behavior. Looking to understand that this behavior is a form of communication will assist. Often, in the heat of behavioral concerns, some do forget that this behavior is communicating something and to get to the root of that communication is important. Staff noted not to "Be afraid to meet students where they are." As the staff continues to be supported with the implementation of trauma-informed practices, I feel as though this will continue to improve. Being the best professional you is important when dealing with students and their feelings.

\section{Supports Needed}

Crisis Prevention Institute (CPI) training for all, which focuses on de-escalation techniques, was a request made by teachers and staff. Currently, a crisis team is in place within Shandy to help support students who are struggling at particular moments. The crisis team has been trained in CPI and they traditional support anyone who is in crisis. This crisis team, as part of CPI, is also trained to put a student in a hold to restrain them from hurting themselves or others if absolutely necessary. Staff is mainly looking to have additional training on the deescalation side of CPI, which has been done in increments with the staff. Staff noted that they "Need more updated Social Emotional Learning Curriculum, have Problem Solving Meetings at the beginning of the year, and have explicit lessons on how to teach students how to regulate themselves." There were also many comments about obtaining a newer Social Emotional 
Learning Curriculum. As expected, there were also many comments about adding additional staff to assist with students who were having emotional outbursts. Often, staff feel as though they are being pulled in many different directions and they are unable to handle situations as quickly as they would like, and will then call for assistance from the office. Quite often, staff would have to wait until someone could get to their classroom to assist with supports as they would be busy somewhere else.

\section{Additional Themes}

Some additional emergent themes from the open-ended questions are: five comments focused around empathy/calm/compassion and understanding for the Billy's, four comments focused on the SEL curriculum and positive relationships, four comments were focused on trauma and the book study being a good reminder, three comments were focused on the rank ordering exercise and how interventions would have been rated higher or the same and that if the interventions were ranked lower it was not because they were ineffective but that teachers and staff try everything else prior to moving to these later ranked interventions.

Emergent themes that occurred from the open-ended questions as far as what staff would like to change are: one comment reflected to change response to the Billy's in regards to sarcasm or harshness, six comments reflected with utilizing the book study approaches in a more proactive way including: asking more supportive questions, keeping in mind sources of behavior, not being afraid to meet Billy where he is vs. demanding that he meet the expectations right away, and understanding that behavior is not about me and it could be due to trauma, the utilization of more staff along with tweaking incentive or having classroom pets, and reviewing the IEP philosophy in regards to the teacher's perspective. 
The emergent themes in regards to what supports are currently needed did not reflect the hypothesis for question two in regards to the relationship of the adult and the student, yet the results showed: four comments in regards to a new or better SEL curriculum, two comments about having additional supports in regards to people, and two comments in regards to additional supports for students who are experiencing issues and thus creating issues for the whole class as well as three additional comments about procedural aspects within MTSS.

\section{Research Question 3}

What other forms of trauma-influenced practice supports do teachers at Shandy Elementary School say they need in order to better their practice in student behaviors and responses?

The plan was to determine the teacher-support practices for a better SEL curriculum as Second Step has been used for years within the district. From mid-March until the end of the school year, staff participated in virtual meetings or Zoom meetings in order to continue our professional development. In the last virtual staff meeting, teachers were randomly assigned to breakout rooms to rank order the strategies and interventions/supports from list from 1 to 15 (see Table 3). The rank of 1 indicated that it was the most effective intervention, while 15 designated it was the least effective. If teachers did not feel comfortable with completing this activity, they were able to opt out without any penalty. Teachers also had the opportunity to comment on additional supports they felt as though they needed, changes they would implement due to the book study, and anything they would continue to do based on their readings and presentations.

As shown in Table 3, the interventions are listed down the left side of the table. Going across, there is one column for each group. In breakout rooms, teachers ranked the interventions/supports in order from 1 (most effective) to 15 (least effective). 


\section{Table 3}

Average Rank Ordering of Supports/Interventions

\begin{tabular}{|c|c|c|c|c|c|c|c|c|c|c|c|c|c|c|}
\hline Intervention & A & B & $\mathrm{C}$ & $\mathrm{D}$ & $\mathrm{E}$ & $\mathrm{F}$ & $\mathrm{G}$ & $\mathrm{H}$ & I & $\mathrm{J}$ & $\mathrm{K}$ & $\mathrm{L}$ & M & Avg. \\
\hline Routines/Expectations & 3 & 1 & 2 & 2 & 2 & 4 & 4 & 2 & 2 & 2 & 1 & 1 & 2 & 2.15 \\
\hline Positive Relationships & 1 & 2 & 1 & 1 & 1 & 2 & 1 & 1 & 1 & 1 & 2 & 2 & 1 & 1.3 \\
\hline Silent Signals/Proximity & 2 & 3 & 6 & 3 & 6 & 6 & 7 & 8 & 4 & 8 & 8 & 6 & 5 & 5.53 \\
\hline Pre-Correction/Prompting & 6 & 4 & 4 & 6 & 12 & 7 & 6 & 6 & 7 & 5 & 3 & 7 & 4 & 5.9 \\
\hline Second Step SEL Curriculum & 14 & 10 & 5 & 7 & 9 & 8 & 9 & 15 & 6 & 6 & 7 & 11 & 9 & 8.9 \\
\hline Quiet Corrections & 5 & 5 & 7 & 4 & 4 & 5 & 2 & 7 & 8 & 4 & 5 & 8 & 8 & 5.53 \\
\hline Restorative Practices & 10 & 6 & 3 & 12 & 7 & 10 & 8 & 4 & 3 & 9 & 11 & 9 & 3 & 7.3 \\
\hline $\mathrm{CICO}$ & 9 & 9 & 10 & 10 & 8 & 11 & 11 & 9 & 12 & 11 & 9 & 10 & 14 & 10.2 \\
\hline Breaks in Other Classrooms & 8 & 8 & 15 & 8 & 11 & 13 & 10 & 13 & 10 & 12 & 12 & 4 & 10 & 10.3 \\
\hline Positive Praise & 4 & 11 & 8 & 5 & 3 & 3 & 3 & 5 & 5 & 3 & 4 & 3 & 6 & 4.8 \\
\hline Tangible Rewards & 7 & 12 & 9 & 9 & 10 & 12 & 15 & 12 & 9 & 10 & 14 & 5 & 7 & 10.07 \\
\hline
\end{tabular}

Table Continues 
Table Continued

\begin{tabular}{|l|l|l|l|l|l|l|l|l|l|l|l|l|l|l|}
\hline Peer Observations & 15 & 14 & 13 & 14 & 13 & 14 & 12 & 11 & 14 & 15 & 13 & 12 & 12 & 13.23 \\
\hline Book Study (Help for Billy) & 13 & 7 & 14 & 15 & 14 & 15 & 13 & 4 & 13 & 13 & 15 & 13 & 15 & 12.6 \\
\hline Trauma Informed & 12 & 13 & 12 & 11 & 5 & 1 & 5 & 3 & 11 & 7 & 6 & 14 & 13 & 8.69 \\
\hline Intensive Family Support \& Services & 11 & 15 & 11 & 13 & 15 & 9 & 14 & 10 & 15 & 14 & 10 & 15 & 11 & 12.5 \\
\hline
\end{tabular}

Table 3. Overall Teacher Rankings of Interventions. This figure displays the average rankings of each intervention calculated by using the mean of all teacher responses. Note. The average rank score of the interventions/supports was calculated using the mean of all rankings provided by teachers in the breakout session. A rank score of 1 indicated the highest level of effectiveness. The overall rank is listed in order of lowest average rank score (most effective) to highest rank score (least effective).

Group 1(A) is the first column, with subsequent columns representing groups and their rank ordering the interventions by their group going in a vertical fashion. Group 1 (A) noted that positive relationships were the most important intervention, along with Groups: 3(C), 4(D), 5(E), 7(G), 8(H), 9(I), 10(J), and $13(\mathrm{M})$. Group 2(B) along with 11(K) and $12(\mathrm{~L})$ noted that routines/expectations was the number one intervention. Seven groups ranked routines and expectations as the second most important intervention. Four groups ranked positive relationships as the second most important intervention. Five groups ranked positive praise as the third most important intervention. Pre-correcting/prompting which is noting students who are doing the correct behavior was marked as fourth in three groups. Quiet corrects, which means talking to the student quietly or off to the side was also ranked fourth by three groups. Positive praise was ranked fourth by two groups. Four groups noted that in fifth within their rank ordering was quiet corrections. Positive praise was also ranked fifth by three groups. Four groups ranked 
silent signals and the use of proximity as sixth within the rank ordering experience. Four groups ranked pre-correcting and prompting as the sixth most important intervention. Staff noted that the seventh most important intervention was pre-correcting/prompting with three groups noting this and two groups noting that Second Step (a SEL curriculum) and quite corrections. CICO, the intervention at the heart of this dissertation, was noted to be in $11^{\text {th }}$ place within the rankordering exercise.

Teachers were randomly assigned to breakout rooms during the last virtual staff meeting of the year following the completion of the book study, Help for Billy. If teachers did not feel comfortable completing the rank ordering of the interventions or supports with others, they could opt out of the breakout room and do an individual ranking or leave the activity altogether without any penalty. During this breakout session, teachers were expected to rank order the interventions/supports that are available within our school from 1 to 15 , with 1 designating the most effective or most important (See Appendix B). The average ranking results are displayed in Table 3.

Of the supports listed, most were Tier 1 interventions, which are available to all students: positive relationship, routines, positive praise, quiet corrections, silent signals, pre-correcting, Second Step, tangible rewards, and breaks in other classrooms. All of these supports were in the top 6. A Tier 2 support on the list was CICO. It was ranked $11^{\text {th }}$ in comparison to the additional interventions. Peer observations, ranked $15^{\text {th }}$, are often suggested to teachers during principal to teacher conferences, especially during evaluation conferences with teachers.

It was not a surprise that positive relationships were ranked first as the most effective intervention or support as educators are aware that learning is a struggle without a relationship with a student. The surprise was that CICO was ranked lower and was not in the top ten, making 
one consider that the connection between relationships and CICO was not there. It was ranked on an average of 1.3 (See table 3) as noted from the average rank ordering of interventions. At the beginning of the school year, the focus was on building strong relationships, with establishing routines and expectations being ranked second. The intention is to continue fostering those relationships throughout the entire year. Positive praise is a natural choice to come next, given that with growth mindset the hope is that teachers will ensure development through encouragement. Protecting the relationships stems from quiet corrections of the behavior. Quiet corrections and silent signals are tied within the ranking. Both of these supports go together given that by not drawing a lot of attention to negative behaviors or their consequences can assist in protecting the student/staff relationship. On the other hand, it was most surprising that precorrecting was not more closely related to routines and expectations.

Keeping with relationship building and learning about students and their lives, many teachers have built in morning check-in circles with their entire class, promoting Restorative Practices, while others have delved deeper into these practices through relationship repairing during lunch/recess and other times within the school day. On a regular basis, teachers are given professional development opportunities through a weekly update distributed by the principal investigator. Quiet often, trauma is the major lens of these opportunities. More extensively, the entire staff was trained in Trauma Informed Certification three years prior to this study.

Tangible rewards, often associated with CICO when students have met their goals, is ranked in $10^{\text {th }}$ place. This placement makes sense since tangible rewards and CICO are closely rated as they relate to achieving individual goals. In fact, students often receive tangible rewards on a daily basis when they meet their CICO scores. 
The book study was ranked 14th, which was shocking given that presentations continued through COVID-19 and weekly staff meetings. The goal of the book study was to give staff an opportunity to reflect on their practices, review current mark chart and ODR data, and make changes based on this information. Presenting virtually did prove to be challenging due to the nature of discussion. Plus, some staff members were not comfortable with the Zoom format and thus may not have participated as much as they would have in a face to face setting. Based on the additional comments that staff provided, it does show that the book study proved to be a good reminder and that staff did reflect on the information provided.

Peer to peer observations landed in last place. This correlates with the number of peer to peer observations that occur throughout the school year. At the beginning of the year, teachers are given observation passes which can be turned in to the principal in order to get coverage to be able to observe another teacher. We have continued to try to increase this opportunity each year and boost willingness for others to give this a try. Quite often, this recommendation comes from an evaluation meeting in which the evaluator suggests that the teacher to go to a particular classroom to observe a colleague. It is no surprise that this was ranked last given the limited amount of observations that can occur.

In addition to the rank ordering exercise, there were two open-ended questions. The first asked what other forms of supports the staff members required to assist students with behaviors and responses. The second inquired how did or how will the book study affect professional practice within their classrooms, as well as what they will continue or change once returning to their classrooms. Both of these questions were referenced above within Research Question 1 and 2. Teachers had an opportunity to note what they needed and be reflective of their practices. Again, teachers were able to opt out of completing this section by leaving the questions blank. 
Furthermore, additional questions were asked to be answered while in the break out rooms. These questions were: What other forms of supports do you need in order to assist students with behaviors and responses? How did or how will the book study assist with professional practice within your classroom? What will you continue or change once you are back in the classroom? The responses were discussed and recorded on the same sheet as the rank ordering exercise. Some themes were: tweak classroom incentives, some of these interventions could have been equal or higher if they had the opportunity to rank them in this way, we don't feel this is least effective (IFSS, book study, or observation.), as the classroom teacher I am going to work on my relationship prior to using IFSS, an observation, or the book study. Teachers noted they would continue to use the SEL curriculum as they were instructed to do. Several groups noted that a new SEL curriculum should be considered. The rank ordering exercise prompted discussions within the random teams of teachers in order to move forward and think through what can be done to help our students and staff, especially during challenging times. Ultimately, I think that having to finish a book study via Zoom during a pandemic and/or a traumatic time proved that educators must look at trauma through a different lens given there was additional time in the day to connect with students.

\section{Conclusion}

As noted in the introduction, this chapter was focused on providing information on CICO as a relational intervention, studying the effectiveness of the book study as professional development, and the data findings. CICO data was provided for each student. Ultimately, one of the outcomes I gleaned from this data is to show how CICO is a relational tool. Initially, a teacher brings a student to the Problem-Solving Team because there are either behavioral, academic, or both concerns. CICO is traditionally an option for students who are struggling. The 
relationship with the teacher who brings the student to the team is often hurting, if it is due to behavior, and is looking for an opportunity to support. Having a CICO mentor to check in with each day at multiple points allows for a relationship to continue and for conversations to be had. Going back and communicating with the classroom teacher is important in order to strengthen the relationship for even better outcomes in the classroom.

The effectiveness of the book study as professional development was reviewed. In the rank ordering exercise, the book study did not fare well. Honestly, during a pandemic when we were struggling to find ways to engage students, feed students, get materials ready to continue educating our students, a book study probably felt like one more thing teachers had to do and was not looked at as a way to continue professional development like it would be in a normal year. One comment left in the open-ended section was "Book study is not least effective yet other interventions should be tried first." Another comment that was made, "More intensive strategies that are rated lower-not because they are ineffective but usually everything else is tried prior" supported the claim that the rank ordering exercise really showed that the Tier One supports and interventions were ranked higher because that is how they are in our current system. Other interventions are ranked lower because they are in a different tier. Another comment, "IFSS, Trauma Certification, book study, and peer to peer observations would be ranked higher once other interventions had been tried" also supported the thought of tiered interventions and doing Tier One interventions first. CICO also ranked lower in the rank ordering exercise, also supporting the thought of trying other interventions before moving to a Tier Two Intervention, which is CICO. This also supported the realization that we really do a lot of interventions and support to help our students and staff, which made it difficult to rank order the interventions. Many of them could have been rated equal or higher if the option was available. 
Chapter V, a summary of the research findings along with implications for practice are noted. Along with understanding relationships in regards to CICO, professional development will be evaluated along the lines of what teachers feel they need in order to be successful in the classroom with disruptive students in order to move forward with success, both academically and behaviorally. 


\section{CHAPTER V: ANALYSIS, DISCUSSION, AND RECOMMENDATIONS \\ Introduction}

This chapter contains a summary of the teacher's perceptions, answers to research questions, limitations, recommendations implications, and recommendations for future research. The purposes of this study were to understand trauma, evaluate CICO and the processes involved, highlight the need for relationships, and determine the professional development teachers feel they need in order to better serve their students throughout a book study and rank ordering exercise. The study was focused to recognize that relationships are a large factor in determining success with supporting CICO and students in order to benefit the student, In the long run, the relationships between children and adult can leverage academic achievement, and this is theorized as particularly significant for children who live with or have experienced trauma.

In the current study, CICO data was gathered and analyzed. In a parallel process, a rank ordering exercise for staff provided an overview of how they view the supports available for forging strong relationships with children of the sort that can support trauma-informed practice. Within a trauma-informed care school, it is extremely important that staff be trained in childhood trauma, positive supports including CICO and other response systems, promotion of success in learning, and safe/supportive classrooms. Having a safe and stable school culture is key to the healing process for children of trauma (Brunzell et al., 2015).

The CICO findings are suggestive of how this single tool can support a safe school environment and a reduction in acting out measured in office referrals as a proxy for improved behavior and as one possible contributor in a variety of tools shared by teachers in a rank order exercise. In turn, a reduction of office referrals served as a proxy for observing improved 
student-teacher relationships. Because of so many other confounding interventions in Tiers 1 and 2 of MTSS and the alterations to the study forced by Covid, it is impossible to say that CICO is any sort of controlling factor in how well the trauma-informed student participants. The study did suggest that when the CICO process is disrupted by a teacher's absence or lack of fidelity in fulfilling the CICO process confounds a fuller understanding of the role of CICO.

Understanding the specific role of $\mathrm{CICO}$ in the collection of interventions and initiatives, including such well-known programs as Restorative Practice and Social-Emotional Learning, requires a clearer focus on this one practice that is impossible to achieve in a school-setting where many research-based practices are in place.

To complement the CICO data collected for each participating student, teachers were asked to rank order the supports their work required, drawing from a list of 15 practices in place at Shady Elementary School. The teachers' rank order of interventions suggests that CICO fits into a pattern of other practices and approaches, but it is not one that rises to the top of teacher perceptions of helpful supports for trauma-informed practice. The teacher rankings really reflected how our MTSS Systems of Support are set up. Initially, teachers are to try interventions at a Tier One level, supporting all students. When difficulty arises, Tier Two Interventions are brought in, such as CICO. The book study helped to get teachers and staff working together as a team, reflecting on their practices, and provided an opportunity for them to use their voice to make suggestions or ask for some next steps in the forms of support needed.

CICO is one tool for teachers to build relationships that provides an opportunity to reconsider the issues regarding trauma and students, identify what ongoing professional development teachers and staff need. Through book study focused around trauma and the brain, 
teachers and staff found a pathway to come together and have real discussion across grade levels and specialties.

\section{Teacher Perceptions: The Rank Ordering Exercise}

It was not a surprise that positive relationships were ranked first as the most effective intervention or support as educators are aware that learning is a struggle without a relationship with a student. The surprise was that CICO was ranked lower and was not in the top ten, making one consider that the connection between relationships and CICO was not there. It was ranked on an average of 1.3 (See table 3) as noted from the average rank ordering of interventions. At the beginning of the school year, the focus was on building strong relationships, with establishing routines and expectations being ranked second. The intention is to continue fostering those relationships throughout the entire year. Positive praise is a natural choice to come next, given that with growth mindset the hope is that teachers will ensure development through encouragement. Protecting the relationships stems from quiet corrections of the behavior. Quiet corrections and silent signals are tied within the ranking. Both supports go together given that by not drawing a lot of attention to negative behaviors or their consequences can assist in protecting the student/staff relationship. On the other hand, it was most surprising that pre-correcting was not more closely related to routines and expectations.

Keeping with relationship building and learning about students and their lives, many teachers have built in morning check-in circles with their entire class, promoting Restorative Practices, while others have delved deeper into these practices through relationship repairing during lunch/recess and other times within the school day. On a regular basis, teachers are given professional development opportunities through a weekly update distributed by the principal 
investigator. Quiet often, trauma is the major lens of these opportunities. More extensively, the entire staff was trained in Trauma Informed Certification three years prior to this study.

Tangible rewards, often associated with CICO when students have met their goals, is ranked in $10^{\text {th }}$ place. This placement makes sense since tangible rewards and CICO are closely rated as they relate to achieving individual goals. In fact, students often receive tangible rewards on a daily basis when they meet their CICO scores.

The book study was ranked 14th, which was shocking given that presentations continued through COVID-19 and weekly staff meetings. The goal of the book study was to give staff an opportunity to reflect on their practices, review current mark chart and ODR data, and make changes based on this information. Presenting virtually did prove to be challenging due to the nature of discussion. Plus, some staff members were not comfortable with the Zoom format and thus may not have participated as much as they would have in a face to face setting. Based on the additional comments that staff provided, it does show that the book study proved to be a good reminder and that staff did reflect on the information provided. Personally, I also felt as though the book study was looked at as one more thing to do and not necessarily as an opportunity for all to really reflect on the information being presented.

In addition to classroom interventions is the notion of whether teachers feel they have the required skill set to handle trauma. When students are exposed to traumatic events, especially ones that are repeated, they may have longer-lasting physical and psychological reactions to the trauma which can then significantly impact their physical and mental health (van der Kolk, Blaustein, Cook, \& Spinazzola, Eds., 2003). While reviewing answers from teachers during the rank ordering exercise, it became clear that teachers needed additional staff in the classroom to assist with behaviors, instead of trendy interventions. As noted in Table Three, four groups noted 
that they felt as though additional forms of support in the way of people were needed. Having additional staff to form relationships with students can help and assist both the teacher and the student. Research by van der Kolk et al. (2003) found that students who have experienced trauma can have difficulties with attention regulation and executive functioning skills, issues with processing new information, difficulty focusing on and completing tasks, learning issues, problems with comprehension, and problems with language development. Thus, providing additional staff to assist with these challenges in the classrooms was noted as important from the staff given that it showed up four times within Table Three.

Bronfenbrenner's ecosystemic model (1993) connected with the book study of Help for Billy as there are chapters dedicated to understanding the complexity of the brain, developmental deficits, belief systems, and regulation and dysregulation. Due to this complexity, a child's brain can be seriously impacted by trauma. Therefore, a comprehensive systems approach which allows for the development of responses at a variety of levels, as outlined in Bronfenbrenner's ecosystemic model, can account for the complexity of trauma and the impact it plays on students. Hence, although ranked last based on averages, IFSS can still be an instrumental approach in assisting students and families with trauma. As noted earlier, the Substance Abuse and Mental Health Services Administration (2014b) recommended a systemic approach to handling trauma in schools; thus, utilizing intensive services, when applicable, should be an option if need to support the whole family.

Ko et al. (2008) called for educators to incorporated trauma-informed care (TIC) since schools are often the first-place children show the need for mental health services. Once students are in school, they have to manage many demands throughout their day; plus, this is also where the impact of trauma on a student rears its ugly head in the form of tantrums, fight or flight, and 
other outward behavioral outbursts. Within a systematic review of school mental health intervention studies, Franklin et al. (2012) found that classroom teachers were the instrumental force behind over $40 \%$ of mental health interventions. Accordingly, professional development regarding trauma and the brain is extremely important. Staff also must remember not to internalize situations when students act out in their classrooms, and instead use TIC to effectively assist the children to work through their emotions.

Given that this study was cut short due to COVID, there is data that showed a pattern of most students generally reaching the $80 \%$ mark. Something that intervened in this data was attendance being a factor as well as a break in relationship when there was a substitute teacher. Ultimately, Shandy had a lot of interventions taking place so it is next to impossible to show the exact impact CICO made. According to the data, teachers do not feel as though CICO is perceived as being effective as other practices they ranked higher. In the open-ended responses, teachers noted that they wanted to continue to "keep in mind the sources or causes of behavior, maintain compassion and understanding, continue routines and expectations, build positive relationships, enhance SEL, and continue to have the frame of mind of how to help students be ready to learn." A key change that emerged from these responses was that teachers should "not be afraid to meet Billy where he is vs. demand that he meets me where I am at."

\section{Answers to Research Questions}

1. To what extent did the implementation of one trauma-influenced practice, Check In/Check Out (CICO), help change behaviors within the classroom setting at Shandy Elementary School?

The first research question focused on CICO and whether it helped to change the behaviors within the classroom settings. The data showed that CICO was successful (students 
achieved a daily average of $80 \%$ or higher) for nine out of twelve students, which equates to $75 \%$ of those who participated in the intervention. Consequently, ODRs for almost all students decreased from Quarter 2 to Quarter 3, except for four students. Thus, 66.67\% of the students showed a decrease in the number of ODRs which benefited the classrooms and teachers. CICO is also an opportunity to highlight the positives occurring in school and to target behaviors that need to be addressed. Focusing on individual behavioral goals assists with improving behaviors within the classroom. There are two factors within the variance: attendance of the student as well as teacher's absences.

2. In what ways did the addition of a trauma-influenced book study $\backslash$ inform teachers and staff to alter their professional practice to achieve better student behavioral outcomes at Shandy Elementary School?

Overall, in the ranking of the supports and interventions, the book study landed in $14^{\text {th }}$ place, with 15 indicating the lowest effectiveness. The open-ended questions following the ranking of supports helped to provide answers to this question. Several breakout rooms noted that the book study was a good reminder of information to practice within their classrooms. One comment that appeared several times was that teachers need to keep in mind the sources of behavior and the necessity of maintaining compassion and understanding as behavior is unfolding. Another breakout room mentioned that teachers and staff must adopt the frame of mind to ask themselves "How can I help? How can I give the Billy's of our school the skills that they need to regulate so that later Billy will have the skills to learn?”

Three breakout rooms shared that the book study would have been ranked higher if they had the ability to rank multiple items equal ranks, which was a helpful insight for the principle researcher. Two breakout rooms remarked that having teachers do the book study chapter 
presentations assisted with grade level buy-in and facilitated genuine discussions about what they had learned from the book study. One breakout room explained that they would no longer send students to another room as a strategy for behavioral issues based on their participation in this study.

Three breakout rooms expressed that they did not feel that IFSS and the book study should be ranked so low; however, they believed that the other options should be tried prior to these two supports/interventions. Four breakout rooms noted the importance of continuing to focus on positive relationships, routines, expectations, and supporting the SEL standards, but not necessarily Second Step.

Overall, having teachers rank order of supports revealed the value placed on Tier One approaches utilized at Shandy. Many of the higher ranked interventions were geared toward classroom and support teachers. These are reinforcements that they have readily available, such as focusing on relationships, praising students, and emphasizing routines and expectations. The more intensive strategies and supports, like IFSS and the book study, fell to the bottom of the ranking.

3. What other forms of trauma-influenced practice supports do teachers at Shandy Elementary School say they need in order to better their practice in student behaviors and responses?

Two breakout rooms stated that they desired an additional staff member in the classroom to assist with bettering their practices. Two additional breakout rooms specified that they needed more assistance from paraprofessionals when behavior occurs so that they can continue to teach. One breakout room noted that they required more help with screaming students so that the episode does not have to be traumatic for all students within the classroom. This breakout room 
also added the necessity for assistance from other adults or administrators when students continue to scream.

\section{Limitations}

There were several limitations to this study, the first being the number of students included. Only twelve students participated in the research, and this is a small representation of the entire student body, even the number of trauma-informed students at Shandy. If COVID-19 would not have taken place, I do believe that there would have been additional opportunities to add students to CICO based on referral numbers.

One of the biggest limitations of the entire study was the outbreak of COVID-19. On the fly, I had to re-design the study, feed students, and assist with the closing of our school. COVID19 made it impossible to study the impacts of CICO on behavior because the students were no longer in school at this point. I was not able to see teachers on a consistent basis or follow up with staff following professional development. We were in crisis mode and very worried about feeding students, making sure they had supplies, figuring out how to assist with childcare, and keeping everyone safe. At the outset, the professional development component of the study was intended to parallel the information learned from the book study and presentations shared with the entire staff from teams of teachers. With the pandemic occurring, the book study was completed via Zoom meetings; however, due to school closure, it became impossible to examine how the book study would have impacted CICO with relationships being at the center. The teachers were unable to explore their answers to the reflection questions regarding what they would continue and what they would change in their own practices.

A second limitation emerged because three students were impacted negatively by their classroom teacher taking a leave of absence, thus putting substitute teacher in charge of the 
CICO sheet. This created an issue for those students who could have benefited from being on CICO for the remainder of the quarter. My prediction is that these students would have been more successful working with the original classroom teacher throughout the remainder of the year. Unfortunately, this was not the case and the drop in scored showed this impact, even though the substitute teacher was supported throughout this time.

\section{Recommendations}

The first recommendation based on this study is to continue pairing students with a CICO mentor with whom they have a positive relationship. In addition, the classroom teacher needs to be a part of the relationship-building to enhance and/or repair their connection with the student in conjunction with the CICO mentor. This could take the form of teachers spending time, maybe even as little as 10 minutes extra, with this student on a weekly basis.

Professional development for CICO must be provided for all teachers and staff to increase the fidelity of the intervention. This often occurs at the beginning of the year or the beginning of the intervention; however, fidelity checks should continue to take place with the CICO coach or other stakeholders throughout the process. It would also be beneficial to arrange CICO retraining at different points during the school year to reflect upon and evaluate intervention procedures. For further use of CICO, it is recommended that implementation includes a designated time for CICO to occur. This time should be consistent across all grade levels to make sure that these interactions happen at the same time each day. For example, check-in could take place five minutes after school has started, with check-out happening five minutes prior to school ending. Providing an incentive, such as no bus or dismissal duty, would also help entice more teachers to volunteer to become a CICO mentor. 
Plus, the classroom teacher should receive as much training as the $\mathrm{CICO}$ mentor to ensure the fidelity of the sheets and data. This is an important component and one that was not given enough attention in this study. Regular training for all staff regarding CICO card usage is essential because the data affects the students' evaluations, and staff members must have a consistent approach to the utilization of these cards. When reviewing the cards with the students, the mentors should not only discuss the areas of concern, but also highlight the successful parts of the day. These are all pieces to the puzzle.

In addition to training staff, this study revealed the importance of providing training for substitute teachers who are covering for long-term leaves. Within the study, this became an issue and negatively impacted some students because the intervention was basically dropped due to the presence of a substitute teacher. Unfortunately, the remainder of data was not collected but could have been beneficial to the research to compare the scores given by the regular teacher and the substitute teacher, as well as observe how the students finished in the intervention.

Another recommendation is to incorporate consistent and regular communication with the parents through follow-up by the CICO coach, principal, or classroom teacher, regarding their thoughts on the CICO intervention and feedback about their student's behavior, particularly if it is improving. Quite often, when there is an issue, the classroom teacher is often the first to be contacted by the parent thus the necessity for training teachers alongside the other mentors. School officials should ensure that parents see themselves as part of the team and are able to voice their concerns and celebrate the successes. Support for all is essential.

Professional development within a book study lead to a lot of great opportunities for teachers to collaborate within their grade level, share their learning, and learn from each other. One underutilized support is peer observations, as noted in the rank ordering experience. Each 
time I have walked into classrooms for observations, I have left the classroom learning something. By working together in different settings, such as book studies and presentation, then following up with peer observations, teachers develop some comfort to observe or be observed.

Another recommendation stemming from this study is to develop and utilize an electronic version of the CICO sheet to better communicate with parents regarding their child during the day. Sending an electronic copy to parents each night would eliminate the obstacle that arises when students forget to bring it home or lose it altogether. By delivering it to both the student and the parent electronically, they can discuss the student's day together at home.

One additional recommendation for future research is having a consistent standard for removal from CICO when the intervention is not effective. For instance, after two weeks of not meeting the $80 \%$ goal, a student would stop participating in CICO. Once adjustments are made, whether CICO is individualized or not, it is important to move forward with interventions and then modify or cease the program if the student is not making progress. With relationships being at the forefront of $\mathrm{CICO}$, future research could work to uncover main factor that affect the success rate of CICO, such as the quality of the CICO mentor, the responsiveness of the teacher, or personal situations of the student.

Also, this study implied that when students have been successful and they have met their goals at least 4 out of 5 days for at least a four-week period, the team should consider fading out the support. It would not be recommended to cut off supports suddenly; however, a transition back to independence for the student would be appropriate, especially if there are no office referrals during this time. 


\section{Implications for Teachers}

This study provided an opportunity for teachers to implement CICO and foster relationships with their students. CICO is an intervention that encourages positive feedback at all times of the day. Each student in this study had been impacted negatively by trauma for a variety of reasons; therefore, providing frequent, positive feedback, helped fill a void, assist with overall behavioral issues, and open a pathway for teachers and staff to focus on student growth. The data gathered for the research was also beneficial while reviewing behavioral goals. Seeing the positive results aids teachers in operating under the right mindset as well. Teachers were all able to implement the components with fidelity within this setting, except for the substitute teacher.

During the rank ordering of interventions and supports, many positive comments arose regarding the book study, professional development, and supports that are in place. One of the best takeaways from the rank ordering experience was that Shandy already works diligently to assist students on a regular basis, mostly at the Tier 1 level, some of which may be taken for granted. However, seeing the items ranked in this way paralleled more of a Tier One approach with the highest ranked supports being more teacher driven. On the other hand, the extensive supports, more of a Tier 2 or Tier 3 approach, were ranked lower because teachers attempt other options before they move on to intensive interventions. In theory, these interventions were ranked almost in the same order as typically implemented at the school level.

Also, this study provided staff an opportunity to learn more about best practices via a book study, teacher responses, and presentations. Teachers had individual opportunities to reflect regarding trauma and difficult behaviors on their own. Furthermore, this study and professional development fostered a learning experience among the grade level teams. The final benefit for adult participants was the randomness of the breakout rooms in which they collaborated with 
others to complete the rank ordering of supports and interventions. Discussions were had, decisions were made, and they made the best of a difficult situation, especially with COVID-19.

\section{Recommendations for Future Research}

CICO offers opportunities for teachers and parents to collaborate, increases positive interactions between adults and students within each day, and provides positive feedback regarding targets for individual students. The results of this study add to the literature connected

to positive behavioral interventions and supports within schools. To effectively meet the needs of all students, education requires both academic and behavioral supports that will allow all students to have access and find success within the current curriculum. Parents and guardians are a piece of the puzzle and must be included as often as possible. After completing a quarter of the 2020 school year virtually, it seems reasonable to utilize ZOOM for continued meetings when inperson meetings are unable to happen. This will hopefully increase the amount of parent and other stakeholder participation.

Results from this study can assist parents and other stakeholders to understand that CICO is flexible. CICO can be very efficient and meet the needs of all students on a variety of levels. The goal is to connect interventions and supports to improve both academic and behavioral outcomes for students. Flexibility in goal setting, adjusting approaches when the student struggles, and working together to meet expectations will benefit all students within that classroom. Students need to have buy-in and want to make a change. This change has to come with support from both staff and families.

\section{Conclusion}

The goals of this research were to better understand trauma, examine interventions for students focusing on a Tier 2 intervention, Check In-Check-Out, and develop plan for teachers 
and staff to effectively meet the needs of all students. With Help for Billy, professional development gave insight into how to understand trauma, apply a new thought process, and reflect on practices. This opportunity gave teachers a chance to work together and apply what they learned in the school and their own classrooms. Completing a book study about trauma during a pandemic was ironic at best. However, we were still able to finish this portion of the program with the functionality of Zoom. The purpose was to see how the book study supported teachers within the classroom and to discover if the new approaches and mindset would improve scores with CICO; however, due to COVID-19, this was not entirely possible. CICO can positively impact the classroom environment by primarily focusing on the successes and clearly defined goals as noted in individual cases shared. CICO, a Tier 2 intervention, resulted in improvement in almost all behavior for individual students within classrooms across all grade levels based on their average daily scores while enrolled in CICO. Building strong relationships, as noted in the rank ordering experience, was noted as the first intervention to be put into place, hence revealing that teachers value its importance to success within the classroom.

As a building principal, I will continue to propose a change in practice with de-escalation techniques utilizing a relationship approach, such as CICO with appropriate training and continuous monitoring of results. It was also clear through the extended comments during the breakout sessions that teachers need additional staff as support in the classroom to deal with students who have experienced trauma. Finally, I will prioritize professional development regarding behavior and appropriate approaches for handling trauma for the staff at Shandy to ensure students can reach their maximum potential. 


\section{REFERENCES}

Adelman, H., \& Taylor, L. (2008). School-wide practices approaches to addressing barriers to learning and teaching. Thousand Oaks, CA: Corwin.

Agaibi, C. E., \& Wilson, J. P. (2005). Trauma, PTSD, and resilience: A review of the literature. Trauma, Violence, \& Abuse, 6(3), 195-216.

Alisic, E. (2012). Teachers' perspectives on providing support to children after trauma: A qualitative study. School Psychology Quarterly, 27(1), 51-59.

Alisic, E., Bus, M., Dulack, W., Pennings, L., \& Splinter, J. (2012). Teachers’ experiences supporting children after traumatic exposure. Journal of Traumatic Stress, 25(1), 98-101.

Amankwaa, L. (2016). Creating protocols for trustworthiness in qualitative research. Journal of Cultural Diversity, 23(3), 1-14.

Anderson, K. J., \& Minke, K. M. (2007). Parent involvement in education: Toward an understanding of parents' decision making. The Journal of Education Research, 100(5), $311-323,328$.

Arvidson, J., Kinnenburgh, K., Howard, K., Spinazzola, J., Smothers, H., Evans, M.,...Blaustein, M. (2011). Treatment of complex trauma in young children: Developmental and cultural considerations in application of the ARC Intervention Model. Journal of Child \& Adolescent Trauma, 4, 34-51.

Bandura, A. (1977). Social learning theory. Englewood Cliffs, N.J: Prentice Hall.

Blaustein, M., \& Kinniburgh, K. (2010). Treating traumatic stress in children and adolescents. New York, NY: The Guilford Press. 
Blodgett, C., Harrington, R., Lohan, J., Short. Rl, Turner, N., \& Winikoff, J. (2010). Adverse childhood experience and developmental risk in elementary school children (Unpublished manuscript). Area Health Education Center, Washington State University, Spokane, WA.

Blodgett, C., Lawyer, K., Gates, G., Turner, N., \& Wagner, B. (2012). CLEAR Initiative building staff surveys (Unpublished manuscript). Area Health Education Center, Washington State University, Spokane, WA.

Blodgett, C. \& Turner, N. (2012). WSU-NCTSN, Cat III narrative (Unpublished manuscript). Area Health Education Center, Washington State University, Spokane, WA.

Blodgett, C., Turner, N., \& Harrington, R. (2010). Increasing school success through traumasensitive school practice (Unpublished manuscript). Area Health Education Center, Washington State University, Spokane, WA.

Bloom, S. (1999). Trauma theory abbreviated. The Sanctuary Model. Retrieved from http://www.sanctuaryweb.com

Briere, J., \& Spinazzola J. (2005). Phenomenology and psychological assessment of complex posttraumatic states. Journal of Traumatic Stress, 18(5), 401-412.

Bronfenbrenner, U. (1993). Ecological models of human development. In M. Gauvain \& M. Cole (Eds.). Reading on the development of children ( $2^{\text {nd }}$ ed., pp. 37-43). New York: Freeman.

Brown, B. (2012). Daring greatly: How the courage to be vulnerable transforms the way we live, love, parent, and lead. New York: Gotham Books. 
Brunzell, T., Waters, L., \& Stokes, H. (2015). Teacher with strengths in trauma-affected students: A new approach to healing and growth in the classroom. American Journal of Orthopsychiatry, 85(1), 3-9.

Campbell, A., \& Anderson, C. M. (2008). Enhancing effects of Check-in/check-out with function-based support. Behavioral Disorders, 33, 233-245.

Campbell, A., \& Anderson, C. M. (2011). Check in/check out: A systematic evaluation and component analysis. Journal of Applied Behavior Analysis, 44(2), 315-326. http://doi.org/10.1901/jaba.2011.44-315

Carnegie Project on the Education Doctorate. (2019). Impacting education. Journal for Transforming Professional Practice. Retrieved from https://www.cpedinitiative.org/journal-impacting-education

Carr, E.G., Dunlap, G., Horner, R.H., Koegel, R.L., Turnbull, A.P., Sailor, W., Anderson, A.L., Albin, R.W., Koegel, L.K., \& Fox, L. (2002). Positive behavior support: Evolution of an applied science. Journal of Positive Behavior Interventions, 4, 4-16.

Chapman, J., Ford, J. D., Albert, D., \& Hawke, J. (2001). Traumatic stress: Exposure, identification, and intervention in correctional systems. In J. Moore (Ed.), Management and administration of correctional health care (Vol. 2). Kingston, NJ: Civic Research Institute.

Child and Adolescent Health Measurement Initiative. (2013). Overview of adverse child and family experiences among U.S. children. Retrieved from http://www.childhealthdata.org/docs/dre/aces-data-brief_version-1-0.pdf?Status=Master

Clark, Ron. (2003). The essential 55: An award-winning educator's rules for discovering the successful student in every child. New York: Hyperion. 
Cole, S.F., Greenwald O’Brien, J., Geron Gadd, M., Ristuccia, J., Luray Wallace, D., \& Gregory, M. (2005). Helping traumatized children learn. Retrieved from: http://tlpi.jacksonwhelan.netdna-edn.com/wp-content/uploads/2013/06/HelpingTraumatized-Childrn-Learn.pdf

Cole, S.F., Eisner, A., Gregory, M., Ristuccia, J. (2013). Creating and advocating for traumasensitive schools. Boston: Massachusetts Advocates for Children.

Cook, A., Spinazzola, J., Ford, J., Lanktree, C., Blaustein, M., Cloitre, M., van der Kolk, B. (2005). Complex trauma in children and adolescents. Psychiatric Annals, 35(5), 390398.

Cooper, J.O., Heron, T.E., \& Heward, W.L. (2007). Applied behavior analysis ( $2^{\text {nd }}$ ed.). Upper Saddle River, NJ: Pearson.

Cosner, S., Walker, L., Swanson J., Hebert, M., \& Whalen, S. (2018). Examining the architecture of leadership coaching: Considering developmental affordances from multifarious structuring. Journal of Educational Administration, 56(3), 364-380.

Costello, E. J., \& Angold, A. (2006). Developmental epidemiology. In D. Cicchetti \& D. J. Cohen (Eds.), Developmental psychopathology: Theory and method (pp. 41-75). Hoboken, NJ: John Wiley \& Sons Inc.

Creswell, J. W. (2009). Research design: Qualitative, quantitative, and mixed methods approaches. Los Angeles: Sage.

Creswell, J. W. (2014). Research design: qualitative, quantitative, and mixed methods approaches (4th ed). Thousand Oaks, California: SAGE Publications.

Crone, D. A., Hawken, L. S., \& Horner, R. H., (2010). Responding to problem behavior in schools: The behavior education program (2nd ed.). New York: Guilford Press. 
Crosby, S. D. (2015). An ecological perspective on emerging trauma-informed teaching practices. Children \& Schools, 37(4), 223-230.

Crozier, J., \& Barth, R. (2005). Cognitive functioning and academic functioning in maltreated children. Children in Schools, 27(4), 197-206.

Demaray, M., \& Malecki, C. (2002). The relationship between perceived social support and maladjustment for students at risk. Psychology in the Schools, 39(3), 305-16.

Downey, L. (2007) Calmer Classrooms: A Guide to Working with Traumatized Children. Melbourne, Australia: Child Safety Commissioner.

Driver, R., Aasoko, H., Leach, J., Mortimer, E., Schott, P. (1994). Constructing scientific knowledge in the classroom. Educational Researcher, 23 (7), 5-12.

Dweck, Carol S. 2006. Mindset: the new psychology of success. New York: Random House.

Ennis, R.P., Jolivette, K., Swoszowski, N.C., \& Johnson, M.L. (2012). Secondary prevention efforts at a residential facility for students with emotional and behavioral disorders: Function-based check-in, check-out. Residential Treatment for Children \& Youth, 29, 79102.

Evers, T. (2012). Creating trauma-sensitive schools to improve learning: A response to intervention (RtI) Model. Retrieved from http://www.dpi.wi.gov/sspw/mhtrauma.htl

Fairbanks, S., Sugai, S., Guardino, D., \& Lathrop, M. (2007). Response to intervention: An evaluation of a classroom system of behavior support for second grade students. Exceptional Children, 73, 288-310.

Farmer, E. M. Z., Burns, B. J., Phillips, S. D., Angold, A., \& Costello, E. J. (2003). Pathways into and through mental health services for children and adolescents. Psychiatric Services, 54(1), 60-66. 
Feinstein, S. (2003). School-wide positive behavior supports. The Journal of Correctional Education, 54(4), 163-173.

Filter, K. J., McKenna, M. K., Benedict, E. A., Horner, R. H., Todd, A. W., \& Watson, J. (2007). Check-in/Check-Out: A post-hoc evaluation of an efficient, secondary-level targeted intervention for reducing problem behaviors in schools. Education and Treatment of Children, 30, 69-84.

Forbes, H.T. (2012). Help for Billy: A beyond consequences approach to helping challenging children in the classroom. Boulder, CO: Beyond Consequences Institute.

Franklin, C. G. S., Kim, J. S., Ryan, T. N., Kelly, M. S., \& Montgomery, K. L. (2012). Teacher involvement in school mental health interventions: A systemic review. Children and Youth Services Review, 34(5), 973-982.

Gearity, A. R. (2009). Developmental repair: A training manual. Minneapolis, MN: Washburn Center for Children.

Gresham, F. M. (2009). Evolution of the treatment integrity concept: Current status and future directions. School Psychology Review, 38, 533-540.

Harn, B., Parisi, D., \& Stoolmiller, M. (2013). Balancing fidelity with flexibility and fit: What do we really know about fidelity of implementation in our schools? Exceptional Children, 79(2), 181-193.

Harris, M., \& Fallot, R. (Eds.) (2001). Using trauma theory to design systems. New Directions for Mental Health Services. San Francisco: Jossey-Bass.

Hawken, L. S., \& Horner, R. H. (2003). Evaluation of a targeted intervention within a schoolwide system of behavior support. Journal of Behavioral Education, 12, 225-240. 
Hawken, L. S., MacLeod, K. S. \& Rawlings, L. (2007). Effects of the behavior education program (BEP) on office discipline referrals of elementary school students. Journal of Positive Behavior Interventions, 9, 94-101.

Hawken, L. S., O'Neill, R. E., \& MacLeod, K. S. (2011). An investigation of the impact of function of problem behavior on effectiveness of the behavior education program (BEP). Education and Treatment of Children, 34, 551-574.

Hernandez, F. J. (2005). Equity and access: The promise of virtual schools. In Z. L. Berge \& T. Clark (Eds.), Virtual schools: Planning for success (pp. 20-34). New York: Teachers College Press.

Hodas, G. (2006). Responding to childhood trauma: the promise and practice of traumainformed care. Retrieved from http://www.childrescuebill.org/VictimsOfAbuse/RespondingHodas.pdf

Hodgkinson, H., \& Goldberg, M. F. (2000). An interview with Harold Hodgkinson: Demographics: Ignore them at your peril. The Phi Delta Kappan, 82(4), 304-306.

Horner, R. H., Sugai, G., Todd, A. W., \& Lewis-Palmer, T. (2005). School-wide positive behavior support: An alternative approach to discipline in schools. In L. Bambara \& L. Kern (Eds.), Positive behavior support (pp. 359-390). New York: Guilford Press.

Horner, R. H., Sugai, G., \& Anderson, C. M. (2010). Examining the evidence-base for schoolwide positive behavior support. Focus on Exceptional Children, 42(8), 1-14.

Hupfeld, K. (2010). A review of the literature: Resiliency skills and dropout prevention. Retrieved from https://datacenter.spps.org/uploads/SC_Resiliency_WP_FNL\%5B1\%5D.pdf

Keller, B. (2008). Book Study Helps Teachers Hone Skills. Retrieved from 
Kiser, L. J. (2007). Protecting children from the dangers of urban poverty. Clinical Psychology Review, 27(2), 211-225.

Kracke \& Hahn (2008). The nature and extent of childhood exposure to violence: What we know, why we don't know more, and why it matters. Journal of Emotional Abuse, 8(102).

Ko, S. J., Ford, J. D., Kassam-Adams, N., Berkowitz, S. J., Wilson, C., Wong, M., Brymer, M. J., \& Layne, C.M. (2008). Creating trauma-informed systems: Child welfare, education, first responders, health care, juvenile justice. Professional Psychology: Research and Practice, 39(4), 396-404.

Lane, K., Capizzi, A., Fisher, M., \& Ennis, R. (2012). Secondary prevention efforts at the middle school level: An application of the behavior education program. Education and Treatment of Children, 35, 51-90.

Lewis, T. J., \& Sugai, G. (1999). Effective behavior support: A systems approach to proactive school-wide management. Focus on Exceptional Children, 31(6), 1-23.

Okapala, C. O. (2002). Educational resources, student demographics and achievement scores. Journal of Education Finance, 27(3), 885-908.

McCracken, H. (2004). Extending virtual access: Promoting engagement and retention through integrated support systems. Online Journal of Distance Learning Administration, 7(1). Retrieved from http://www.westga.edu distance/ojdla/spring71/mccracken71.html McIntosh, K., Campbell, A. L., Carter, D. R., \& Dickey, C. R. (2009). Differential effects of a tier two behavior intervention based on function of problem behavior. Journal of Positive Behavior Interventions, 11, 82-93. 
McLaren, L. \& Hawe, P. (2005). Ecological perspectives in health research. Journal of Epidemiology \& Community Health, 59(1), 6-14. Retrieved from http://www.nctsn.org/nccts/nav.do?pid=ctr_tool_searchMeasures_over

McNeal, R. (2001). Differential effects of parental involvement on cognitive and behavioral outcomes. Journal of Socio-Economics, 30(2), 171-179.

Mitchell, B. S., Adamson, R., McKenna, J. (2017). Curbing our enthusiasm: An analysis of the check-in/check-Out literature using the Council for Exceptional Children's EvidenceBased Practice Standards. Behavior Modification, 41, 343-367.

Mong, M.., Johnson, K., \& Mong, K. (2011). Effects of check in/check out on behavioral indices and mathematics generalization. Behavioral Disorders, 36(4), 225-240.

National Scientific Council on the Developing Child. (2010). Persistent fear and anxiety can affect young children's learning and development. Retrieved from http://www.developingchild.net

Oehlberg, B. (2008). Why schools need to be trauma informed. Trauma and loss: Research and interventions, 8(2). Retrieved from http://www.healthiersf.org/RestorativePractices/Resources/documents/RP\%20Communit y\%20Resources\%20and\%20Articles/Trauma\%20Informed\%20Practice/WhySchoolsNee dToBeTraumaInformed(2).pdf

O’Neill, L., Guenette, F., \& Kitchenham, A. (2010). Am I safe here and do you like me? Understanding complex trauma and attachment disruption in the classroom. British Journal of Special Education, 37(4), 190-196. 
Perry, B. D. (2001). The neurodevelopmental impact of violence in childhood. In D. Schetky \& E.P. Benedek (Eds.), Textbook of child and adolescent forensic psychiatry (pp. 221-238). Washington, DC, American Psychiatric Press, Inc.

Polit, D. F. and Beck, C. T. (2014). Essentials of nursing research: Appraising evidence for nursing practice (8th ed.). Philadelphia, PA: Lippincott Williams \& Wilkins.

Pynoos, R. S., Steinberg, A. M., Schreiber, M. D., \& Brymer, M. J. (2006). Children and families: A new framework for preparedness and response to danger, terrorism, and trauma. In L. A. Schein, H. I. Spitz, G. M. Burlingame, P. R. Muskin (Eds.) \& S. Vargo (Collaborator), Psychological effects of catastrophic disasters: Group approaches to treatment (pp. 83-112). Philadelphia, PA: Haworth Press.

Reinke, W. M., Stormont, M., Herman, K. C., Puri, R., \& Goel, N. (2011). Supporting children’s mental health in schools: Teacher perceptions of needs, roles, and barriers. School Psychology Quarterly, 26(1), 1-13.

Repetto, J., Cavanaugh, C., Wayer, N., \& Liu, F. (2010). Virtual high schools: Improving outcomes for students with disabilities. Quarterly Review of Distance Education, 11(2), 91-104.

Rossin, E., \& Hull, R. (2013). Supporting and educating traumatized children: A guide for school-based professionals. New York: Oxford University Press.

Santiago, C. D., Wadsworth, M. E., \& Stump, J. (2011). Socioeconomic status, neighborhood disadvantage, and poverty-related stress: Prospective effects on psychological syndromes among diverse low-income families. Journal of Economic Psychology, 32(2), 218-230.

Scheffler, M. L., \& Aksamit, D. A. (2006). Every child succeeds: Executive report: Nebraska State Improvement Grant: 1999-2006. Lincoln, NE: Nebraska Department of Education. 
Schneider, P. (2014). Sketchnote: Brené Brown on the power of vulnerability [web log post]. Balanced Action: Thoughts on Life and Work. Retrieved from https://balancedaction.me/2014/01/29/sketchnote-brene-brown-on-the-power-ofvulnerability/

Scott, K. (2016). Housing children: South Auckland, The Housing Pathways Longitudinal Study. doi:10.13140/RG.2.2.24769.76645.

Sheridan, S. M., Swanger-Gagne, M., Welch, G. W., Kwon, K., \& Garbacz, S. A. (2009). Fidelity measurement in consultation: Psychometric issues and preliminary examination. School Psychology Review, 38(4), 476-495.

Simonsen, B., Myers, D., \& Briere, D. E. (2011). Comparing a behavioral check-in/check-out (CICO) intervention to standard practice in an urban middle school setting using an experimental group design. Journal of Positive Behavior Interventions, 13(1), 31-48.

Sitler, H. C. (2009). Teaching with awareness: The hidden effects of trauma on learning. The Clearing House: A Journal of Educational Strategies, Issues and Ideas, 82(3), 119-124. doi:10.3200/TCHS.82.3.119-124

Substance Abuse and Mental Health Services Administration. (2014a). SAMHSA's concept of trauma and guidance for a trauma-informed approach. Retrieved from http://store.samhsa.gov/shin/content/SMA14-4884/SMA14-4884.pdf

Substance Abuse and Mental Health Services Administration. (2014b). Trauma-informed care in behavioral health services. Retrieved from http://store.samhsa.gov/shin/content//SMA14-4816/SMA14-4816.pdf 
Sugai, G., \& Simonsen, B. (2012). History, defining features, and misconceptions. OSEP Technical Assistance Center on Positive Behavioral Interventions and Supports. Retrieved from http://www.pbis.org/school/pbis_revisited.aspx

Tishelman, A., Haney, P., O’Brien, J., \& Blaustein, M. (2010). A framework for school based psychological evaluations: Utilizing a "trauma lens". Journal of Child \& Adolescent Trauma, 3(4), 279-302.

Todd, A., Campbell, A., Meyer, G., \& Horner, R. (2008). Evaluation of a targeted group intervention in elementary students: The check-in/check-out program. Journal of Positive Behavior Interventions, 10, 46-55.

van der Kolk, B. (2005). Developmental trauma disorder: Toward a rational diagnosis for children with complex trauma histories. Psychiatric Annals, 35(5), 401-408.

van der Kolk, B., Blaustein, M., Cook, A., \& Spinazzola, J. (Eds.). (2003). Complex trauma in children and adolescents. National Child Traumatic Stress Network. Retrieved from http://www.NCTSNet.org

Waters, L \& Brunzell, T. (2018). Five Ways to Support Students Affected by Trauma. Retrieved from:https://greatergood.berkeley.edu/article/item/five_ways_to_support_students_affect ed_by_trauma.

Walling, S. M., Eriksson, C. B., Putman, K. M., \& Foy, D. W. (2011). Community violence exposure, adverse childhood experiences, and posttraumatic distress among urban development workers. Psychological Trauma: Theory, Research, Practice, and Policy, $3(1), 42-49$. 
Weist, M. D., Goldstein, J., Evans, S. W., Lever, N. A., Axelrod, J., Schreters, R., \& Pruitt, D. (2003). Funding a full continuum of mental health promotion and intervention programs in the schools. Journal of Adolescent Health: Supplement, 32(6), 70-78.

Westling, D. L. (2010). Teachers and challenging behavior: Knowledge, views, and practices. Remedial and Special Education, 31(1), 48-63.

Wisconsin Department of Public Instruction. (2012). Creating trauma-sensitive schools to improve learning. Retrieved from http://www.dp.state.wi.gov/sspw/mhtrauma.html

Wolf, M. M. (1978). Social validity: The case for subjective measurement or how applied behavior analysis is finding its heart. Journal of Applied Behavior Analysis, 11, 203-214.

Ziegler, D. (2011). Optimum learning environments for traumatized children. How abused children learn best in school. Retrieved from http://www.jaspermountain.org

Zins, J. E., \& Elias, M. J. (2006). Social and emotional learning. Retrieved from www.Nasponline.org/educators/elias_/zins.pdf 


\section{APPENDIX A: FIDELITY CHECKLIST FOR CICO}

\section{CICO Fidelity Check-list}

Complete the following checklist to determine if the $\mathrm{CICO}$ intervention is being implemented with fidelity. After completing, brainstorm recommendations/solutions and create a brief action plan to make any needed adjustments.

\begin{tabular}{|l|l|}
\hline Yes / No & Is feedback being given after each subject? \\
\hline Yes / No & Does each subject have a WOW comment? \\
\hline Yes / No & Are white sheets coming back from home with parent/guardian signature? \\
\hline Yes / No & $\begin{array}{l}\text { Does the student have sufficient time each morning to check in with their } \\
\text { regular coach? }\end{array}$ \\
\hline Yes / No & $\begin{array}{l}\text { Does the student have sufficient time each afternoon to check out with their } \\
\text { regular coach? }\end{array}$ \\
\hline Yes / No & $\begin{array}{l}\text { Is the progress monitoring graph being filled out; are the student and coach } \\
\text { discussing daily/weekly progress on a regular basis (every day)? }\end{array}$ \\
\hline Yes / No & Is the Tier 2 team checking in on student progress every 2 weeks? \\
\hline Yes / No & $\begin{array}{l}\text { When eligible, is the student putting up their stars consistently (3 days } 85 \%+\text { in } \\
\text { one week)? }\end{array}$ \\
\hline Yes / No & Is the student bringing their binder to each subject/classroom? \\
\hline Yes / No & $\begin{array}{l}\text { Is staff being mindful of particular/individualized expectations (what the 3Bs } \\
\text { might look like for internalizers vs. externalizers)? }\end{array}$ \\
\hline
\end{tabular}

Brainstorm and action plan for recommendations and/or needed adjustments:

Note. Retrieved from

https://d93pbis.weebly.com/uploads/2/6/8/4/26846539/cico_fidelity_check-list.pdf 


\title{
APPENDIX B: BREAKOUT SESSION FORMS
}

\section{Group 1}

1. Rank order the supports that are utilized to assist with behavior in your classroom (1 being the most effective to 15 being the least effective).

\author{
Routines/Expectations 3 \\ Positive Relationships 1 \\ Silent signals/Proximity 2 \\ Pre-correcting and prompting 6 \\ Second Step/SEL curriculum 14 \\ Quiet Corrections/Respectful Re-directions 5 \\ Restorative Practices 10 \\ Check-in Check-out 9 \\ Breaks in other classrooms 8 \\ Positive Praise 4 \\ Tangible rewards 7 \\ Peer (Teacher to Teacher) observations 15 \\ Book Study 13 \\ Trauma informed/Trauma Certified 12 \\ IFSS through Baby Fold 11
}

2. What other forms of supports do you need in order to assist students with behaviors and responses?

Everyone should be trained in CPI

3. How did or how will the book study assist with professional practice within your classroom? What will you continue or change once you are back in the classroom?

Continue: Having empathy and consistency with the "Billy's". Being able to remain calm.

Change: We would change our response to the "Billy's". Sometimes the response is sarcastic or somewhat harsh. We would try to utilize the staff more instead of trying to handle all problems on our own. 


\section{Group 2}

1. Rank order the supports that are utilized to assist with behavior in your classroom (1 being the most effective to 15 being the least effective).

1-Routines/Expectations

2-Positive Relationships

3-Silent signals/Proximity

4-Pre-correcting and prompting

10-Second Step/SEL curriculum

5-Quiet Corrections/Respectful Re-directions

6-Restorative Practices

9-Check-in Check-out

8-Breaks in other classrooms

11-Positive Praise

12Tangible rewards

14-Peer (Teacher to Teacher) observations

7-Book Study

13-Trauma informed/Trauma Certified

15-IFSS through Baby Fold

2. What other forms of supports do you need in order to assist students with behaviors and responses?

3. How did or how will the book study assist with professional practice within your classroom? What will you continue or change once you are back in the classroom?

Continue: SEL curriculum-need more updated SEL curriculum

Change: Utilize book study approaches (mindset, questioning, understanding brain) in a more proactive way.

Asking supportive questions?

Make changes that are beneficial to all.

Consider tweaking classroom incentives. 


\section{Group 3}

1. Rank order the supports that are utilized to assist with behavior in your classroom (1 being the most effective to 15 being the least effective).

2. Routines/Expectations

1. Positive Relationships

6. Silent signals/Proximity

4. Pre-correcting and prompting

5. Second Step/SEL curriculum

7.Quiet Corrections/Respectful Re-directions

3. Restorative Practices

10. Check-in Check-out

15.Breaks in other classrooms

8. Positive Praise

9. Tangible rewards (if it's done right)

13. Peer (Teacher to Teacher) observations

14. Book Study

12.Trauma informed/Trauma Certified

11.IFSS through Baby Fold

2. What other forms of supports do you need in order to assist students with behaviors and responses?

3. How did or how will the book study assist with professional practice within your classroom? What will you continue or change once you are back in the classroom?

Continue: Help for Billy provided reminders about trauma informed learning that we have had experience with.

Change: IFSS, Trauma certification, book study and peer to peer observations would have been ranked higher but these seem to be something we would do once everything else had been tried. 


\section{Group 4}

1. Rank order the supports that are utilized to assist with behavior in your classroom (1 being the most effective to 15 being the least effective).

2) Routines/Expectations

1) Positive Relationships

3) Silent signals/Proximity

6) Pre-correcting and prompting

7) Second Step/SEL curriculum

4) Quiet Corrections/Respectful Re-directions

12) Restorative Practices

10)Check-in Check-out

8)Breaks in other classrooms

5) Positive Praise

9)Tangible rewards

14) Peer (Teacher to Teacher) observations

15) Book Study

11) Trauma informed/Trauma Certified

13) IFSS through Baby Fold

2. What other forms of supports do you need in order to assist students with behaviors and responses?

Not having problem solving meetings was a struggle (immediately following the release of MTSS guidebook).

Explicit lessons on how to teach students how to regulate themselves - newer, update, brain based SEL curriculum

3. How did or how will the book study assist with professional practice within your classroom? What will you continue or change once you are back in the classroom?

Continue: keep in mind the sources of behavior and the need to continue to maintain compassion and understanding when behavior is an issue (sometimes we are good at this)

Change: Continue: keep in mind the sources of behavior and the need to continue to maintain compassion and understanding when behavior is an issue (need to improve) 


\section{Group 5}

1. Rank order the supports that are utilized to assist with behavior in your classroom (1 being the most effective to 15 being the least effective).

Routines/Expectations--2

Positive Relationships--1

Silent signals/Proximity--6

Pre-correcting and prompting--12

Second Step/SEL curriculum--9--when SEL is part of the whole classroom culture-incorporated everyday in some way, it becomes exponentially more important / effective and reinforces positive relationships. $10 \mathrm{~min}$. Once a week w/o incorporation into classroom culture is not as effective.

Quiet Corrections/Respectful Re-directions--4

Restorative Practices--7

Check-in Check-out--8

Breaks in other classrooms--11

Positive Praise--3

Tangible rewards-10

Peer (Teacher to Teacher) observations--

Book Study--14

Trauma informed/Trauma Certified--5

IFSS through Baby Fold--15

Some of these could have been equal for us or higher if we had could have ranked them that way. For example, we have never referred a family to IFSS, so we don't know how effective that is--though I imagine it could be pretty powerful. The book study, too, incorporated lots of the principles that are listed here, so it would be unfair to think that we are deeming it ineffective at \#14--it's just that it relates too many of the other options. We also personally value peer observations and wish I could participate in more of that.

2. What other forms of supports do you need in order to assist students with behaviors and responses?

Having PAs and other behavioral supports like Mr. Nicolson with students who need extra support is so beneficial. However, I do think there needs to be more discussion / planning between the classroom teacher / specialist and the behavioral support person who might be pushing in. 
2. How did or how will the book study assist with professional practice within your classroom? What will you continue or change once you are back in the classroom?

Continue: Have the frame of mind: How can I help? How can I teach Billy the skills he needs to regulate so that later, he will have the skills he needs to be ready to learn?

Change: Not be afraid to meet Billy where he is vs. Demand that he meet my expectations right away.

\section{Group 6}

1. Rank order the supports that are utilized to assist with behavior in your classroom (1 being the most effective to 15 being the least effective).

4. Routines/Expectations

2. Positive Relationships

6. Silent signals/Proximity

7. Pre-correcting (Pre-setting expectations) and prompting

8.Second Step/SEL curriculum

5. Quiet Corrections/Respectful Re-directions

10. Restorative Practices

11. Check-in Check-out

13. Breaks in other classrooms

3. Positive Praise

12. Tangible rewards

14. Peer (Teacher to Teacher) observations

15. Book Study

1. Trauma informed/Trauma Certified

9. IFSS through Baby Fold

2. What other forms of supports do you need in order to assist students with behaviors and responses?

SEL curriculum is a need not only for Shandybut also the district. We need to work on teaching social skills in the natural environment. Start the day in each classroom with morning meeting, and message from principal

3. How did or how will the book study assist with professional practice within your classroom? What will you continue or change once you are back in the classroom?

Continue: Help for Billy was a way to review all we have learned regarding trauma and brain research. 
Change: understand the sources of behavior and we need to continue to have empathy and compassion and understanding regarding behavior.

\section{Group 7}

1. Rank order the supports that are utilized to assist with behavior in your classroom (1 being the most effective to 15 being the least effective).

4. Routines/Expectations

1. Positive Relationships

7. Silent signals/Proximity

6. Pre-correcting and prompting

9. Second Step/SEL curriculum

2. Quiet Corrections/Respectful Re-directions

8. Restorative Practices

11. Check-in Check-out

10. Breaks in other classrooms

3. Positive Praise

15. Tangible rewards

12. Peer (Teacher to Teacher) observations

13. Book Study

5. Trauma informed/Trauma Certified

14. IFSS through Baby Fold **we don't feel this is least effective, however, all the above items should be attempted prior to IFSS being mentioned or brought up to Natasha; it's also difficult, too, because families have to get on board and agree for these services and supports to take place

2. What other forms of supports do you need in order to assist students with behaviors and responses?

People! It's so extremely difficult to give children the supports and time they need if we are teaching; it's hard to stop teaching to give children the time they need to help them process through situations and their feelings

3. How did or how will the book study assist with professional practice within your classroom? What will you continue or change once you are back in the classroom?

Continue: positive relationships

Change: 


\section{Group 8}

1. Rank order the supports that are utilized to assist with behavior in your classroom (1 being the most effective to 15 being the least effective).

2- Routines/Expectations

1- Positive Relationships

8- Silent signals/Proximity

6- Pre-correcting and prompting

15- Second Step/SEL curriculum

7- Quiet Corrections/Respectful Re-directions

4- Restorative Practices

9- Check-in Check-out

13- Breaks in other classrooms

5- Positive Praise

12- Tangible rewards

11- Peer (Teacher to Teacher) observations

14- Book Study

3- Trauma-informed/Trauma Certified

10- IFSS through Baby Fold

2. What other forms of supports do you need in order to assist students with behaviors and responses?

Shandy would benefit from a different SEL Curriculum

3. How did or how will the book study assist with professional practice within your classroom? What will you continue or change once you are back in the classroom?

Continue:

Routines and expectations, positive relationships, and SEL

Book study was a great reminder-one I will go back to

Change: 


\section{Group 9}

1. Rank order the supports that are utilized to assist with behavior in your classroom (1 being the most effective to 15 being the least effective).

2 Routines/Expectations

1 Positive Relationships

4 Silent signals/Proximity

7 Pre-correcting and prompting

6 Second Step/SEL curriculum

8 Quiet Corrections/Respectful Re-directions

3 Restorative Practices

12 Check-in Check-out

10 Breaks in other classrooms

5 Positive Praise

9 Tangible rewards

14 Peer (Teacher to Teacher) observations

13 Book Study

11 Trauma informed/Trauma Certified

15 IFSS through Baby Fold

2. What other forms of supports do you need in order to assist students with behaviors and responses?

Support with students that are experiencing trauma and showing it by screaming and crying which then becomes trauma for all.

3. How did or how will the book study assist with professional practice within your classroom? What will you continue or change once you are back in the classroom?

Continue: More intensive strategies are rated lower-not because they are ineffective but because we usually try everything prior to these.

Change: 


\section{Group 10}

1. Rank order the supports that are utilized to assist with behavior in your classroom (1 being the most effective to 15 being the least effective).

2 - Routines/Expectations

1 - Positive Relationships

8 - Silent signals/Proximity

5 - Pre-correcting and prompting

6 - Second Step/SEL curriculum

4 - Quiet Corrections/Respectful Re-directions

9- Restorative Practices

11 - Check-in Check-out

12 - Breaks in other classrooms

3 - Positive Praise

10 - Tangible rewards

15 - Peer (Teacher to Teacher) observations

13 - Book Study

7 - Trauma informed/Trauma Certified

14 - IFSS through Baby Fold

2. What other forms of supports do you need in order to assist students with behaviors and responses?

3. How did or how will the book study assist with professional practice within your classroom? What will you continue or change once you are back in the classroom?

Continue: this is difficult to respond to as we are not classroom teachers.

Change: 


\section{Group 11}

1. Rank order the supports that are utilized to assist with behavior in your classroom (1 being the most effective to 15 being the least effective).

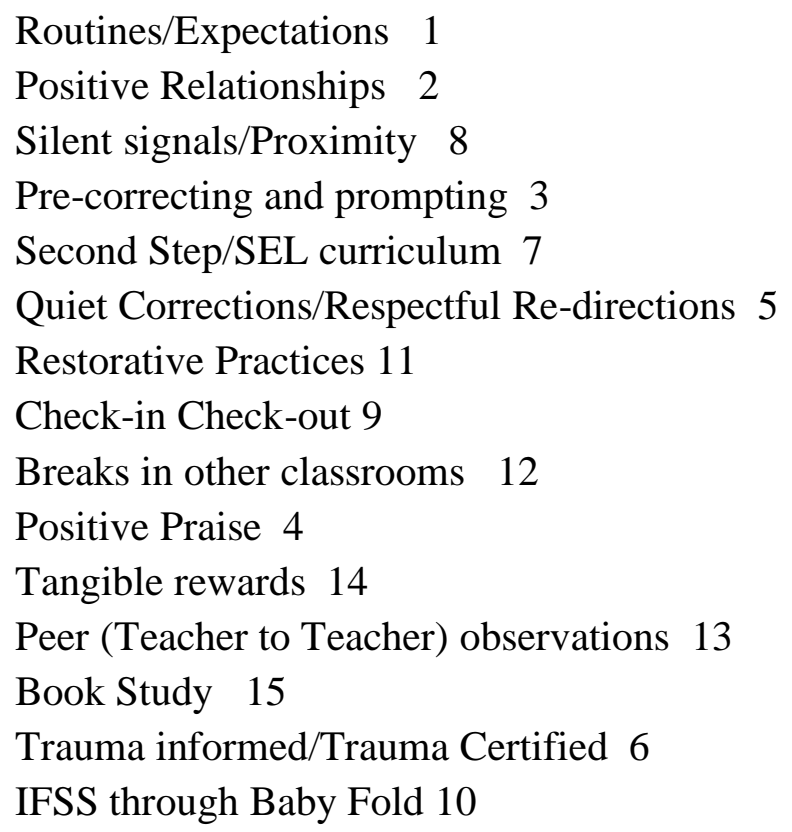

2. What other forms of supports do you need in order to assist students with behaviors and responses?

3. How did or how will the book study assist with professional practice within your classroom? What will you continue or change once you are back in the classroom?

Continue: SEL practices, relationships

-little if no homework, book study was a good reminder

Change: brain research has helped me to understand that the behavior isn't about me...this is a behavior possibly due to trauma. 


\section{Group 12}

1. Rank order the supports that are utilized to assist with behavior in your classroom (1 being the most effective to 15 being the least effective).

1 Routines/Expectations

2 Positive Relationships

6 Silent signals/Proximity

7 Pre-correcting and prompting

11 Second Step/SEL curriculum

8 Quiet Corrections/Respectful Re-directions

9 Restorative Practices

10 Check-in Check-out

4 Breaks in other classrooms

3 Positive Praise

5 Tangible rewards

12 Peer (Teacher to Teacher) observations

13 Book Study

14 Trauma informed/Trauma Certified

15 IFSS through Baby Fold

2. What other forms of supports do you need in order to assist students with behaviors and responses?

Need more support in 4-5 th

Faster response time with problem solving meetings

3. How did or how will the book study assist with professional practice within your classroom? What will you continue or change once you are back in the classroom?

Continue: Book was a good reminder.

Change: Some staff plans to start having classroom pets in 2020. 


\title{
Group 13
}

1. Rank order the supports that are utilized to assist with behavior in your classroom (1 being the most effective to 15 being the least effective).

\author{
Routines/Expectations 2 \\ Positive Relationships 1 \\ Silent signals/Proximity 5 \\ Pre-correcting and prompting 4 \\ Second Step/SEL curriculum 9 \\ Quiet Corrections/Respectful Re-directions 8 \\ Restorative Practices 3 \\ Check-in Check-out 14 \\ Breaks in other classrooms 10 \\ Positive Praise 6 \\ Tangible rewards 7 \\ Peer (Teacher to Teacher) observations 12 \\ Book Study 15 \\ Trauma informed/Trauma Certified 13 \\ IFSS through Baby Fold 11
}

2. What other forms of support do you need in order to assist students with behaviors and responses? Completion of the Tier 1 philosophy/implementation (district-wide)

3. How did or how will the book study assist with professional practice within your classroom? What will you continue or change once you are back in the classroom?

Continue: keeping in mind the sources/causes of behavior, maintaining compassion and understanding

Change: review IEP philosophy (from the classroom teacher's perspective) 